Linköping Studies in Science and Technology.

Dissertations, No.1777

\title{
Inducing large-scale diffusion of innovation An integrated actor- and system-level approach
}

\author{
Ingrid Mignon
}

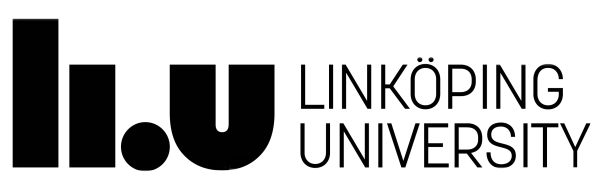

2016

Department of Management and Engineering

Linköping University, SE-581 83, Linköping, Sweden 
(C) Ingrid Mignon, 2016

Inducing large-scale diffusion of innovation. An integrated actor- and system-level approach.

Linköping Studies in Science and Technology, Dissertations, No. 1777

ISBN: 978-91-7685-732-8

ISSN: 0345-7524

Printed by: LiU-Tryck, Linköping

Distributed by:

Linköping University

Department of Management and Engineering

SE-581 83 Linköping, Sweden

Tel: +46 13281000 


\begin{abstract}
In order for the innovation process to be successful, not only do innovations need to be developed and reached the market, but, once they are available for users, they have to spread on a large scale. In the innovation literature, a complete explanation is lacking of why some innovations reach a phase of large-scale diffusion faster than others, including both actor- and system-level components. For instance, what drives and hinders adopters to decide to adopt the innovation on the actor and system levels, and how adopters who participate in the largescale diffusion handle the adoption process and the implementation of the innovation, are questions still unanswered. As a consequence, it remains unclear how the large-scale diffusion process can be facilitated and speeded up.

This thesis addresses these issues by studying the case of renewable electricity (RE) innovations. After decades of technology development and improvements, RE innovations are now mature enough to be bought off-the-shelf by individuals and organizations. Yet, the pace of their large-scale diffusion is still too slow for countries to reach their RE generation targets and to limit global warming.
\end{abstract}

Through qualitative and quantitative methods including 59 semi-structured interviews with adopters, project developers and experts in Sweden, France and Germany as well as a survey sent to the whole population of RE adopters in Sweden, an adopter perspective is taken in to explore the adoption dynamics shaping large-scale diffusion of innovation. More specifically, the thesis identifies the drivers and challenges of adoption during large-scale diffusion and their impact on adoption decisions and strategies. The outcome of this work is presented in a compiling synthesis and six appended papers.

Findings show that adopters are heterogeneous with regard to their characteristics, drivers, challenges and strategies that affect their adoption processes. Depending on their perceptions, some adopters are more influenced by drivers and challenges than and, as a consequence, adopters base their adoption decisions on different motives and follow different strategies to implement the innovation.

The results also suggest that the dynamics occurring during the large-scale diffusion process do not only come from the actor and system levels, but also from parallel systems, which are related to adopters and their social networks and the industries they primarily belong. This makes adopters the central drivers of the innovation diffusion process and this distinguishes the dynamics of large-scale diffusion from the dynamics of innovation development and early diffusion, in which the innovation is the central component.

Based on the findings about the adoption dynamics shaping large-scale diffusion, the thesis raises the need to consider large-scale diffusion as part of a new system, different from the innovation system and that acknowledges the specificities of this process. A tentative model accounting for the central role of adopters and for the interactions between adopters, the diffusion system and parallel systems is introduced.

Finally, the implications of these findings for policy makers and managers are put forward. In particular, there is a need for policies acknowledging adopters' heterogeneity as well as the new challenges of large-scale diffusion. Strategies developed by adopters can be a source of inspiration for policy-makers, who can for instance promote the use of intermediaries, of adopters' task environment and networks, as well as the formation of coalitions among adopters.

Key words: Innovation, large-scale diffusion, adopters, actor, system, drivers, challenges, motives, strategies, policies, renewable electricity, technology, intermediaries. 


\section{POPULÄRVETENSKAPLIG SAMMANFATTNING}

Det utvecklas många innovationer som aldrig når en storskalig spridning, trots att de finns tillgängliga att köpa och kan fylla en viktig funktion för samhället i stort. Ett exempel på sådana innovationer är tekniker för förnybar elproduktion. De har potential att ersätta fossilbränslebaserade teknologier som bidrar till klimatförändringen och finns tillgängliga att köpa för i princip vem som helst, men deras spridning går fortfarande för långsamt för att nå de klimatmål som till exempel EU och dess medlemsländer har satt upp för 2020 och 2050.

Tidigare studier pekar på två olika förklaringar till varför vissa innovationer sprids snabbare eller bättre än andra. Vissa forskare menar att förklaringen ligger på en aktörsnivå, dvs. att spridningen beror på om det finns individer och företag som kan tänka sig köpa tekniken och som har tillräckligt med finansiella resurser och kunskap för att genomföra ett köp. Andra forskare menar att spridningen istället beror på faktorer som ligger på en samhällsnivå, t.ex. om det finns infrastruktur, lagar, eller styrmedel som tillåter att man köper tekniken eller som till och med uppmuntrar det.

Denna avhandling tar hänsyn till båda dessa förklaringsnivåer, med syfte att bättre förstå den process som leder till storskalig spridning av innovationer. Avhandlingen strävar särskilt efter att identifiera de faktorer som på aktörs- och systemnivåerna driver på eller förhindrar nya köpare att genomföra investeringar i förnybar elproduktionsteknik, hur de påverkar inköpsbeslut och investeringsstrategier samt hur den dynamik som formar inköpsprocessen påverkar den teoretiska förståelsen för storskalig spridning av innovationer.

Avhandlingen är baserad på 59 intervjuer med nya köpare, konsulter och olika slags experter i Sverige, Frankrike och Tyskland samt på en enkät till nya köpare av förnybara innovationer i Sverige.

Studierna visar att nya köpare av förnybar elproduktionsteknik skiljer sig åt med avseende på karaktärsdrag (t.ex. bakgrund, storlek, organisationsform), drivkrafter, utmaningar och strategier. Dessutom visar resultaten att det finns skillnader mellan den dynamik som påverkar storskalig spridning och den som påverkar tidigare faser av innovationsprocessen, dvs. innovationsutveckling och tidig spridning. Under den storskaliga spridningsprocessen är nya köpare centrala; det är de som driver processen och de påverkas inte bara av de nätverk, normer och regler som är direkt kopplade till innovationen utan också av nätverk, normer och regler som kommer från andra miljöer, såsom deras industri eller olika sociala grupper de tillhör. Det innebär också att nya utmaningar växer fram som skiljer sig bland köparna beroende på deras specifika kontexter.

Dessa resultat innebär att politiska beslutsfattare måste hantera den storskaliga spridningsprocessen som en unik process. Framförallt måste de ta hänsyn till att nya köpare är och beter sig olika, vilket innebär att styrmedel måste rikta sig mot olika drivkrafter och stödbehov. För att få idéer till sådana anpassade styrmedel kan de politiska beslutsfattarna låta sig inspireras av hur de nya köparna själva hanterar de utmaningar de ställs inför. Bland annat visar avhandlingen att de nya köparna använder sig av sina nätverk för att kunna genomföra sina investeringar, vilket innebär att politiska beslutsfattare kan sprida information och kunskap om innovationer i dessa forum. Det är också vanligt bland nya köparna att anlita konsulter för att få tillgång till kunskap, därför kan nya styrmedel kunna se till att denna kunskap finns tillgängligt för flera potentiella köpare, till exempel genom att sponsra konsulttjänster eller genom att erbjuda dessa tjänster offentligt. 


\section{ACKNOWLEDGEMENTS}

When I was at the point of changing career path and of starting my $\mathrm{PhD}$, I have to admit that there was one thing in particular that made me anxious. How was I going to manage to focus on one project for - what it felt like - the unending period of five year?! Well, looking back at these five years, it is hard to understand that time can fly so fast. Apart for a few endless article revision episodes, I have never felt that research was anything like routine work. Instead, new projects, collaborations and future papers have kept challenging me over and over again.

For creating this exiting and challenging environment, I have Anna Bergek to thank. Anna, you have been a truly fantastic supervisor and I am proud to have been your student. Thank you for agreeing to take me in as your $\mathrm{PhD}$ student in the first place, for supporting my learning in all possible ways, for co-authoring papers with me and for always encouraging me to reach the next level. I hope that we will keep collaborating and I wish you all the best for the future.

I also want to thank Gunnel Sundberg, who also agreed to take me in the research team, who has been a very supportive co-supervisor during the first three years of my $\mathrm{PhD}$ studies and who has contributed to making research fun.

Thank you to Christian Berggren for giving me wise advice whenever I came to you with thoughts about career, research or academia in general.

Thank you to Jenny Palm and Harald Rohracher, who have been involved in helping me to improve my work at the stage of my Licentiate thesis, and to Staffan Jacobsson, who has provided further comments on my $\mathrm{PhD}$ thesis draft and contributed with well-needed motivation talks during the last months of my $\mathrm{PhD}$. I am also grateful to Per-Olof Brehmer, who was the internal reader at the department and provided interesting suggestions.

In many ways, this thesis is a milestone. Not only does it mark the end of my PhD studies and its research outcomes, but it also marks the end of a period in my life. These five last years have combined the best and the worst time in my personal life so far and I am so grateful for the social cocoon that my fantastic colleagues have provided. For being like a life buoy that has helped me to go through storms, I have a few people to thank in particular.

Ksenia and Prae, thank you for being such nice friends. Thank you for the laughs, the fun lunches, the mafia talks, etc. Thank you for always being there when I need you!

Anna, thank you for not only being my supervisor, but also for always being a friend and for those nice early morning coffees at the Moccado coffee shop.

Johanna, I am so grateful for your friendship and for all both the tearful and happy chats that we have had over the last two years.

Mohammad, Filiz, Inessa, Carina, and all other colleagues at PIE, thank you for contributing to making me happy to go to work every morning!

Last, but not least, thank you so much to my husband Bengt for always, always, always, supporting and encouraging me no matter what. Thank you for letting me take big decisions that often affect the both of us. Thank you for loving me, for being my best friend and a great father to Marius. I hope that life has a lot more happiness for us to share.

Ingrid Mignon

Linköping, 2016 

To Astrid, Léa \& Marius 



\section{APPENDED PAPERS}

\section{Paper 1}

Bergek, A., Mignon, I., \& Sundberg, G. (2013). Who invests in renewable electricity production? Empirical evidence and suggestions for further research. Energy Policy, 56, 568581.

\section{Paper 2}

Mignon, I., \& Bergek, A., 2016. Investments in renewable electricity production: The importance of policy revisited. Renewable Energy, 88, 307-316.

\section{Paper 3}

Mignon, I., Bergek, A., 2015. System- and actor-level challenges for the diffusion of renewable electricity technologies: an international comparison. Journal of Cleaner Production, 128, 105-155.

\section{Paper 4}

Mignon, I., Rüdinger, A., 2016. The impact of systemic factors on the deployment of cooperative projects within renewable electricity production - an international comparison. Renewable and Sustainable Energy Reviews, 65, 478-488.

\section{Paper 5}

Mignon, I., 2016. The collaboration process between users and intermediaries during the implementation of innovations. Accepted for publication in Technology Analysis \& Strategic Management, August 2016.

\section{Paper 6}

Bergek, A., Mignon, I., 2016. Motives to adopt renewable energy technologies: evidence from Sweden. Working paper to be submitted to a scientific journal. 


\section{TABLE OF CONTENTS}

1 Introduction

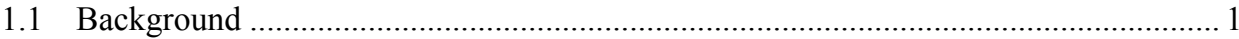

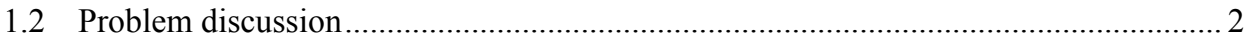

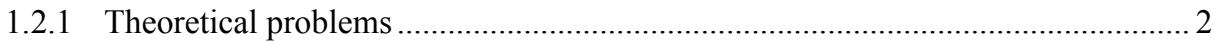

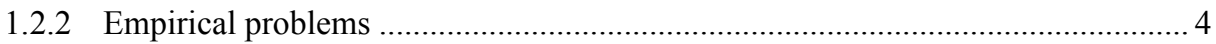

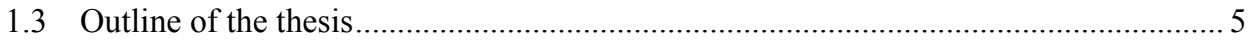

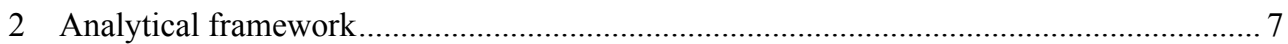

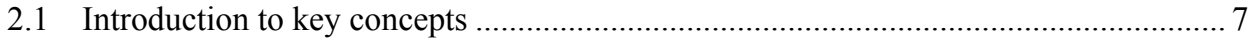

2.1.1 Situating large-scale diffusion within the innovation process ............................. 7

2.1.2 Some innovations are more complex than others ................................................... 8

2.1.3 The importance of individual adoption processes for the understanding of large-

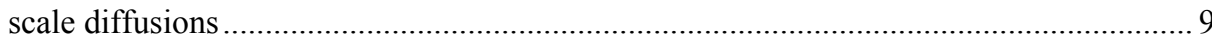

2.2 Adoption drivers during the large-scale diffusion of innovation ............................. 11

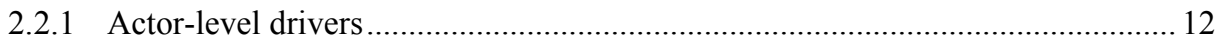

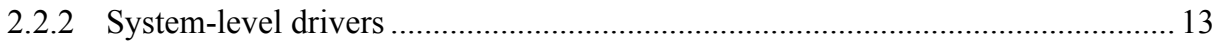

2.3 Adoption challenges during the large-scale diffusion of innovations ........................ 15

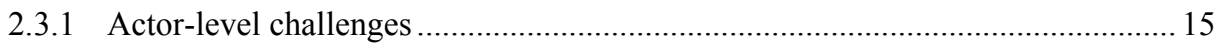

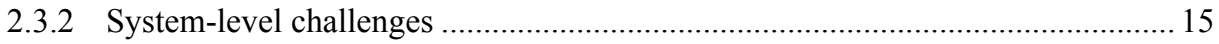

2.4 Adoption strategies and policies during the large-scale diffusion of innovation ......... 17

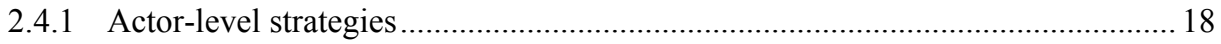

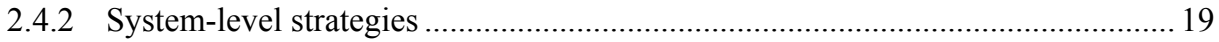

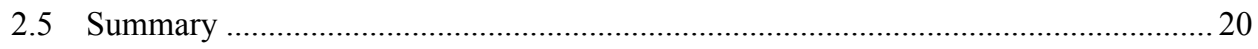

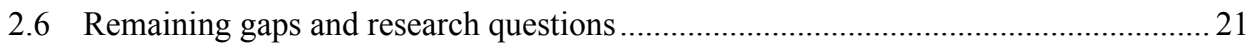

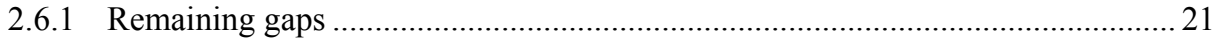

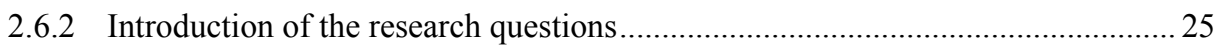

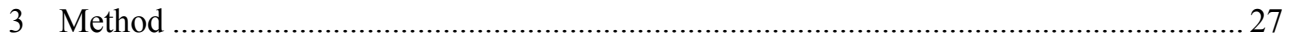

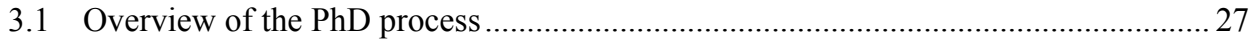

3.1.1 The research project - A starting point in the study of new investors in RE .......27

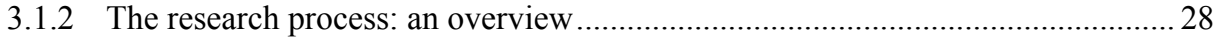




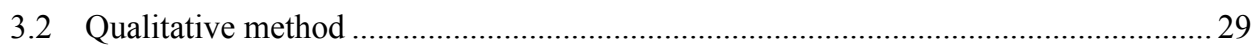

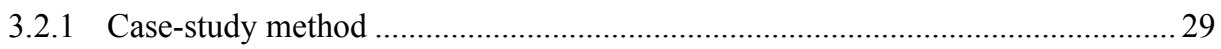

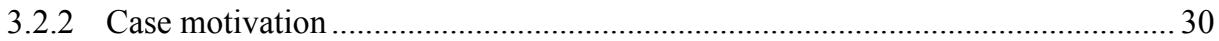

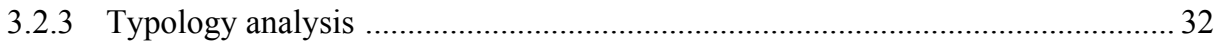

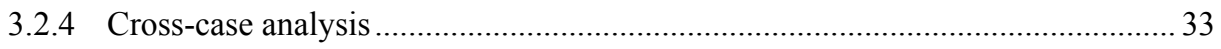

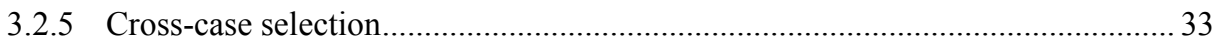

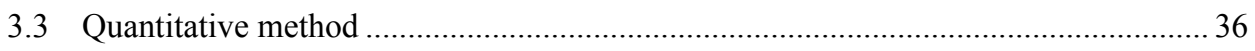

3.3.1 Mixed method through sequential data gathering ............................................ 36

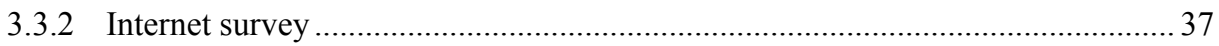

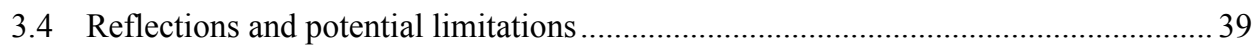

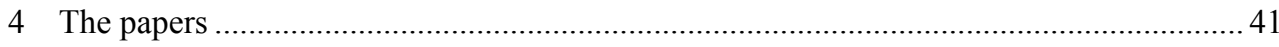

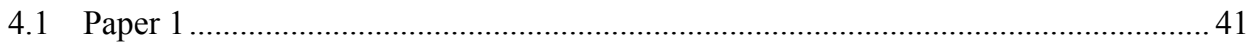

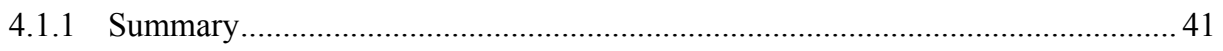

4.1.2 My contribution to the paper and current publication status ............................... 43

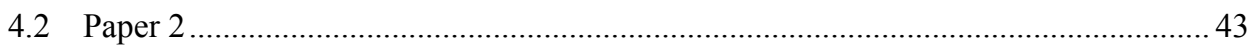

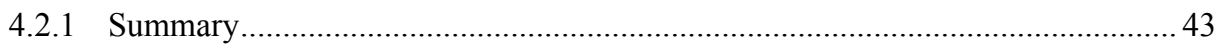

4.2.2 My contribution to the paper and current publication status ................................ 44

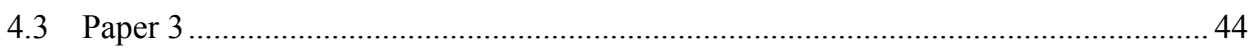

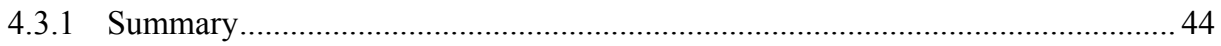

4.3.2 My contribution to the paper and current publication status .............................. 45

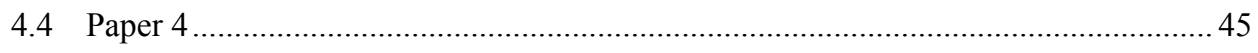

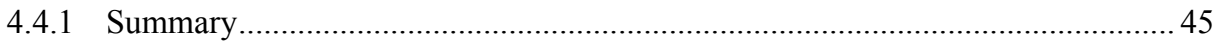

4.4.2 My contribution to the paper and current publication status ............................... 46

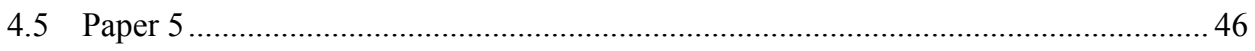

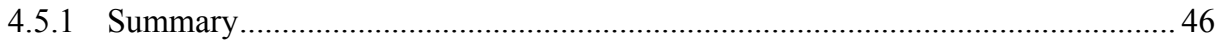

4.5.2 My contribution to the paper and current publication status .............................. 47

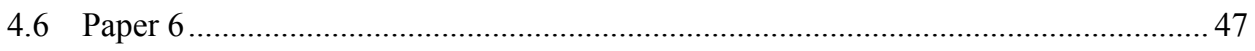

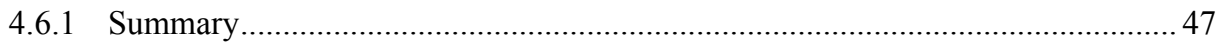

4.6.2 My contribution to the paper and current publication status .............................. 48 


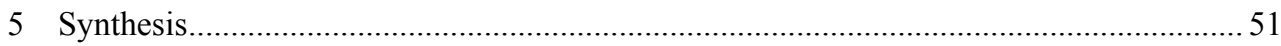

5.1 Heterogeneous adopters drive the large-scale diffusion process............................... 51

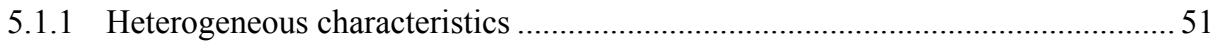

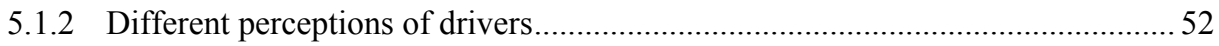

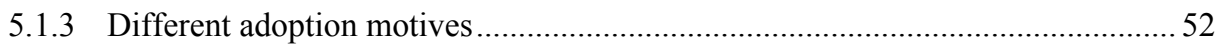

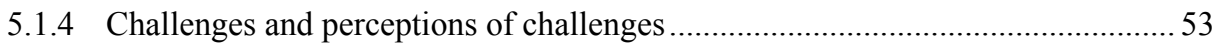

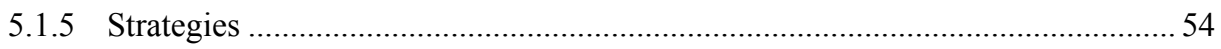

5.2 The emergence of a new diffusion system influenced by parallel systems.................56

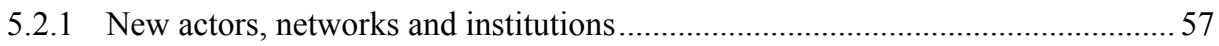

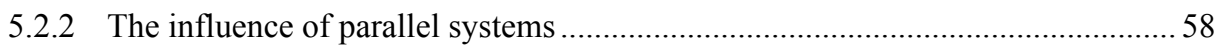

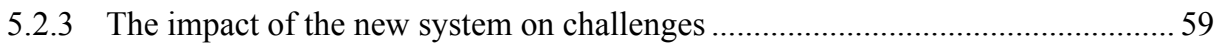

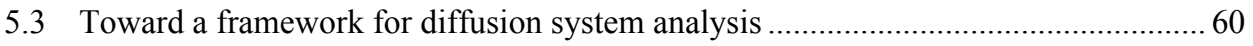

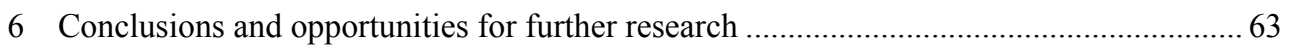

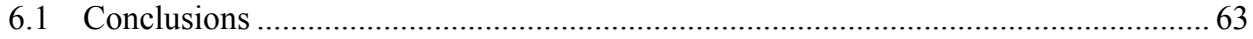

6.2 Contributions and suggestions for further research............................................ 65

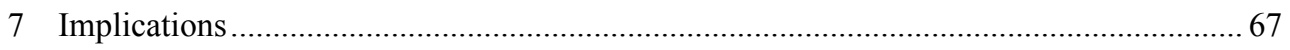

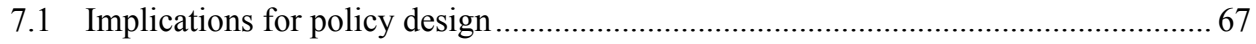

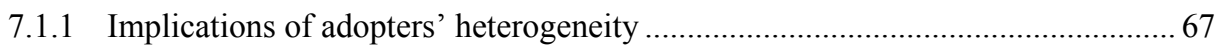

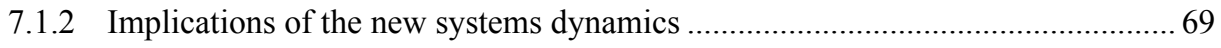

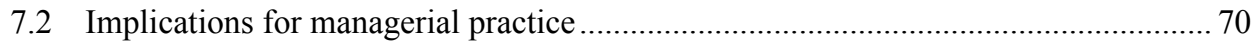

7.2.1 Implications of adopters' heterogeneity …................................................... 70

7.2.2 Implications of the new systems dynamics ................................................ 71

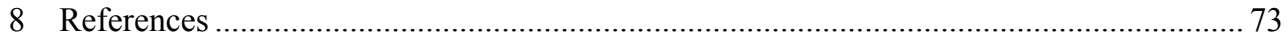




\section{Introduction}

\subsection{Background}

In the innovation literature, the processes of innovation development and early diffusion of innovation have received a lot of attention. These phases indeed involve a number of dynamics among actors, networks, and institutions, which require a number of societal and institutional conditions (e.g. Bergek et al., 2008b; Carlsson and Stankiewicz, 1991; Grübler, 1991).

Although it has not been a particular focus of previous studies, the process of largescale diffusion of innovation is also very complex. Initially, for an innovation to diffuse widely, many adopters must decide to buy and use the innovation. This step requires potential users to understand the innovation's usefulness and relevance compared with alternative technologies. Also, like during the early stages of innovation development and diffusion, societal and institutional conditions must facilitate diffusion of the innovation on a large scale. For example, technology suppliers must be allowed to sell the innovation and potential users must be allowed to buy and use it for its purpose. If some conditions are not fulfilled at this stage, the large-scale diffusion process may never advance, or may occur at a very slow pace.

Innovation scholars have taken different approaches to explain the process of diffusion. Rogers (1962), the initiator of the literature on diffusion of innovation, underlines that the diffusion process is a result of a combination of individual decisions to adopt or reject an innovation. Hence, for an understanding of the diffusion process, it is crucial to understand adopters' innovation-decision processes, including, for instance, what determines adopters' perceptions of innovations, what leads to decisions to adopt or to reject innovations, and how adopters implement their adoption decisions. In contrast, other authors have considered innovation diffusion from a system perspective (e.g. Carlsson and Stankiewicz, 1991; Grübler, 1991). For these authors, the generation, diffusion, and utilization of innovations depend on the creation and development of system components, such as infrastructures, institutions, communication channels, and resources.

Although these approaches increase the understanding of the process of innovation diffusion, they do not explain completely why some innovations reach a phase of large-scale diffusion faster than others, including both actor- and system-level components. For instance, what actor- or system-level factors drive or hinder adoption or how these factors affect the adopters' decisions and strategies, are questions that remain unanswered. As a consequence, it remains unclear how the large-scale diffusion process can be facilitated and speeded up. This uncertainty is problematic because the world currently faces problems that can be solved only through the rapid 
replacement of existing technologies. Hence, the faster these technologies diffuse on a large scale, the greater the chances that the societal consequences of these world problems will be limited.

One such major world problem is climate change. To limit the effects of climate change, a technological transition from fossil-fueled technologies to renewable electricity (RE) innovations is crucial. In contrast with fossil-fueled technologies, which are responsible for high levels of $\mathrm{CO}_{2}$ emissions that cause global warming, $\mathrm{RE}$ innovations generate electricity from renewable sources such as wind, water, sun, and biomass, and emit little or no $\mathrm{CO}_{2}$. After decades of technology development and improvements, RE innovations are now mature enough to be available off-the-shelf for individuals and organizations willing to adopt them. Nevertheless, although studies report yearly worldwide increases in investments in RE innovations (Bloomberg New Energy Finance, 2015), the pace of the large-scale diffusion process of RE innovations is still too slow to limit the increase of the global temperature below $2^{\circ} \mathrm{C}$ per year, above which the consequences of global warming are dangerous for mankind (United Nations Framework Convention on Climate Change, 2009).

In this thesis, the large-scale diffusion process of RE innovations is studied to explore the adoption dynamics shaping large-scale diffusion of innovation by taking an integrated actor- and system-level approach.

\subsection{Problem discussion}

\subsubsection{Theoretical problems}

The large-scale diffusion of innovations is a complex process that, if successful, may occur over a short or long period of time (e.g. David, 1994, 1991; Geels, 2002; Grübler, 1991). Authors of different literature strands have conducted research in order to understand what determines the diffusion process and why some innovations diffuse faster than others. In particular, scholars have taken two main approaches in the innovation literature. The diffusion of innovation approach has studied the process of diffusion based on an actor level of analysis, in which scholars consider adopters and their characteristics central for diffusion (e.g. Bass, 1969; Rogers, 2003, 1962). In contrast, the innovation systems approach has studied the process of innovation development and early diffusion from a system perspective. For these authors, innovation system components and dynamics determine whether innovations are developed, reach the market, and eventually start diffusing within the system (e.g. Carlsson and Stankiewicz, 1991; Jacobsson and Johnson, 2000).

Although both approaches constitute important pillars for understanding the diffusion process, a complete understanding of the process, integrating both actor and system levels of analysis, is missing. This gap in the literature may be due to the fact that both 
approaches have focused on different phenomena, in which one level of analysis or the other has been sufficient. For instance, the diffusion of innovations approach has focused on explaining the diffusion of consumer innovations, such as electronics or appliances, which are available off-the-shelf and which do not require large changes in society or in user habits. In contrast, the focus of innovation systems literature has been on explaining how innovation systems emerge and how innovation system components develop in order for the development and early diffusion of innovations to occur.

At these early stages of diffusion, the system perspective is crucial and an actor perspective is less relevant. Nevertheless, when studying the large-scale diffusion of some innovations, for instance, RE innovations, both levels of analysis are important. The actor level is important to understand why some adopters decide to adopt or reject the innovation or why some adopters implement their adoption decisions later than others. Moreover, the system level is important because, in order to diffuse, innovations such as RE innovations are particularly dependent on system components (Rao and Kishore, 2010).

Looking at one approach at a time also underlines a number of remaining gaps for the study of large-scale diffusion. Although the diffusion of innovation literature presents adopters (i.e. their perceptions, characteristics, and social networks) as determinant of the diffusion process, quantitative methods dominate the empirical studies (Meade and Islam, 2006). Studies focus on testing and modeling factors of adoption (e.g. Lee et al., 2005; Marcati et al., 2008; Masini and Frankl, 2003; Wierenga and Ophuis, 1997), and, as a consequence, an in-depth understanding of adopters' processes for deciding to adopt and for implementing their decisions is missing (Seligman, 2006). The approach also has an innovation bias, because the approach assumes that an innovation is good and that adopters who do not eventually adopt the innovation, despite its obvious usefulness, are irrational (Rogers, 2003). Instead of assuming that adoption is driven by adopters' expectations of the potential economic and/or status gain (or the threat of status loss) (Lyytinen and Damsgaard, 2001; Rogers, 2003), recent studies have questioned these assumptions by highlighting the fact that pure economic rationality has little to do with adoption. Instead, the decision to adopt or to reject is influenced by adopters' own reasoning about the innovation, and other drivers, including interests, identity, and impulses, can lead to the decision to adopt (Seligman, 2006; Selwyn, 2003).

As another consequence of the innovation bias, scholars assume that the failure or delay of an adoption process is mostly the responsibility of the potential adopters; they lack the resources, status, and knowledge needed to adopt or are simply reluctant to make changes (Rogers, 1962). More recently, authors have started to question this assumption by pointing out that adoption is neither uniform nor inevitable and that 
innovation adoption is also influenced by systemic conditions, such as learning, social, or technological conditions (MacVaugh and Schiavone, 2010; Selwyn, 2003). Also, even if adopters choose to adopt, there is no assurance that the implementation process of the adoption will be successful; challenges can occur during the process that may lead adopters to abandon implementation or may result in an implementation that does not allow the innovation to be used to its full potential (e.g. Klein and Sorra, 1996; Voss, 1985). Because empirical, qualitative studies about the adoption process are lacking, an in-depth understanding of the actor- and system-level challenges met by adopters during the decision and implementation processes, which can create obstacles to the diffusion, is also missing.

In the innovation system literature, too, there are gaps remaining for the study of largescale diffusion. Although authors have shed light on the system-level drivers of and challenges to early innovation system growth, such authors' focus has been on the process of innovation development and early diffusion (e.g. Johnson and Jacobsson, 2001; Klein Woolthuis et al., 2005; K. Smith, 2000). Although, to my knowledge, no empirical study has explored whether the system-level drivers and challenges are the same during large-scale diffusion, some authors have started to analyze large-scale diffusion by assuming that those drivers and challenges are similar to those present at the phases of early innovation systems growth (e.g. Negro et al., 2012). This assumption is problematic because if drivers and challenges in fact differ between diffusion phases, then a mismatch may occur between the policies and strategies proposed and the ones actually needed to facilitate and speed up large-scale diffusion.

\subsubsection{Empirical problems}

Many additional investments are necessary for RE innovations to diffuse at the pace needed to limit the irreversible consequences of global warming (International Renewable Energy Agency, 2014; Jacobsson and Bergek, 2011). To reach that level of investment, public investments alone are not sufficient (Wüstenhagen and Menichetti, 2012). Instead, private actors willing to buy and use the RE innovations, thereby increasing production, are needed.

To attract these private actors, a number of policies have been developed, such as the European and national targets for RE production by 2020 (the so-called 202020 targets) as well as regulatory and incentive instruments aimed at either forcing or encouraging investments (e.g. Cansino et al., 2010; European Parliament and Council, 2009; Fouquet, 2013; Jaffe and Stavins, 1995). The problem is that little is known about who these private investors are or what drives them to invest (Agterbosch et al., 2004; Wüstenhagen and Menichetti, 2012). Empirically, it is clear that since the liberalization of the European energy market, a variety of actors have joined the RE production by investing in RE innovations. Among these actors are incumbent actors 
who have been active in the electricity sector for decades and who have either increased their RE production by making additional investments in RE technologies or diversified their types of production by adding RE to the fossil-based electricity that they produce. There are also new types of RE producers, who may come from different sectors and who have recently joined RE production by adopting the RE innovations despite little or no experience in the electricity sector (e.g. Agterbosch et al., 2004; Langniss, 1996).

Despite recent market developments regarding the variety of RE producers, current policies are still assume that the investors in RE technologies are incumbent actors, or at least that adopters have characteristics and investment behaviors similar to those that incumbent actors are assumed to have (Dinica, 2006). In particular, scholars assume that RE investors have access to resources such as knowledge and capital, and that their investment strategies are economically rational. Therefore, scholars also assume that economic policies are the best instruments to encourage additional investments and to attract additional investors.

Very few empirical studies have been conducted on RE producers, including both incumbent actors and new types of adopters. Yet, recent studies have suggested that there are different types of behaviors and strategies when investing in RE innovations (Masini and Menichetti, 2013, 2012). In particular, scholars have suggested that RE investors act under bounded rationality and that they may therefore not behave as policy-makers expect them to (Wüstenhagen and Menichetti, 2012). There is a clear need for further exploration of these suggestions. A better understanding of the new types of actors, who adopt a technology despite little or no previous experience in electricity production, would be particularly interesting, because these actors represent a new source of investments greatly needed to speed up the large-scale diffusion of RE innovations (Agterbosch et al., 2004; Enzensberger et al., 2003; Yildiz, 2014).

Through the study of these adopters, scholars can develop a better of understanding of the drivers, challenges and strategies of the adoption process. Such study may provide a better ground for the evaluation of current policies and the development of new policies and strategies, which may eventually facilitate and speed up diffusion. In that regard, the empirical study of the large-scale diffusion of RE innovations from an RE adopter perspective is a relevant way to explore the adoption dynamics shaping the large-scale diffusion of innovation.

\subsection{Outline of the thesis}

This thesis proceeds as follows. Chapter 2 introduces the main theoretical concepts used throughout the thesis, reviews the previous literature on innovation diffusion, and, based on a synthesis of the remaining theoretical gaps, introduces the research questions. 
Chapter 3 presents the methods used to gather and analyze the data included in the six appended papers and reflects on the methodological limitations of the thesis.

Chapter 4 summarizes each appended paper, the current publication status of each paper, and the contributions made by the authors.

Chapter 5 develops the answers to the research questions, by synthesizing the findings of the appended papers and by analyzing these findings further to conceptualize the large-scale diffusion of innovation.

Chapter 6 concludes the thesis by summing up the answers to the research questions and providing potential directions for further research.

Finally, Chapter 7 presents the policy and managerial implications of the findings. 


\section{Analytical framework}

This chapter introduces the key concepts of the thesis and presents the current understanding about adoption drivers, challenges and strategies during large-scale diffusion. More specifically, the chapter focuses on three main theoretical approaches, which have devoted particular interest to the innovation diffusion process: the diffusion of innovation literature, the innovation systems literature and the energy policy literature. At the end of the chapter, the main points of divergence and convergence of the approaches are highlighted and three main gaps are then presented, which serve as a background for the purpose of the thesis and the research questions.

\subsection{Introduction to key concepts}

\subsubsection{Situating large-scale diffusion within the innovation process}

For technological transitions to take place, not only must innovations be developed and penetrate the market, but once on the market, they also have to get bought and used (Grübler, 1996). This process is far from simple, and thousands of innovations are developed that never reach the market. To understand the dynamics that lie behind technological transitions, the innovation literature has focused on understanding the transition process from one technology to another, with an emphasis on the phases of innovation development and early innovation diffusion on the market, as well as on the reconfiguration process from one sociotechnical system to another (e.g. Carlsson and Stankiewicz, 1991; Geels, 2002; Hekkert et al., 2007; Jacobsson and Bergek, 2004; Utterback and Abernathy, 1975).

To understand the innovation process as a whole, one must consider dynamics, phases, and potential challenges beyond those that occur during innovation development and early diffusion of innovations (Grübler, 1996). In particular, after an innovation has reached the market, additional efforts are necessary for the innovation to get diffused on a larger scale. Eventually, the diffusion often reaches a point of saturation, when the rate of diffusion decreases and stabilizes. Each of these phases deserves specific attention because after an innovation has reached one phase, nothing guarantees that it will automatically reach the next one. ${ }^{1}$ Moreover, each phase goes through a process on its own and is influenced by different dynamics, such as different determinants of diffusion or different relationships to other diffusion processes (Grübler, 1991). In other words, to understand the entire diffusion process, it is important to understand not only the dynamics of the early-diffusion process but also the dynamics occurring

\footnotetext{
${ }^{1}$ Although scholars often described it as a linear process, the innovation process is in fact iterative in nature (Garcia and Calantone, 2002; Kline and Rosenberg, 1986). Even though the process often starts with an invention and ends with saturation, innovations may fail at reaching the product development
} 
when an innovation has penetrated the market and is diffusing on a large scale. This thesis focuses on the process behind large-scale diffusion, i.e. how an innovation becomes largely adopted and eventually becomes a dominant technology in the sociotechnical system.

\subsubsection{Some innovations are more complex than others}

The diffusion process varies from one innovation to another. For instance, during the diffusion of the automobile in the United States during the twentieth century, the process of early diffusion went rather fast, i.e. with an adoption rate of about $30 \%$ per year over 20 years, and was followed by a stable rate of $5 \%$ growth during the largescale diffusion phase (Grübler, 1991). In comparison, the diffusion of steamboats in the United Kingdom took much longer; although the first experiments were reported in the late eighteenth and early nineteenth centuries in the United Kingdom, France, and America, it took over 50 years (i.e. until the mid-1850s) for the steamboat to become the standard technology for passenger transport on oceans (Geels, 2002). The case of the steamboat contrasts with the diffusion of the iPhone, for which the transition from market introduction to large scale diffusion took only a few years and for which the growth rate is still increasing due to incremental improvements of the original design (Aldhaban, 2012).

One explanation for the differences among diffusion processes is that the nature of some innovations makes them more or less complex to diffuse (Rogers, 2003). There are several perspectives on what is meant by innovation complexity in this context. For some authors, complexity is related to the degree of customization of the innovation (Acha et al., 2004; Hobday, 1998). Although some innovations, such as commodity goods, can be mass produced, other innovations, i.e. complex products and systems (CoPS) such as bridges, high speed trains, or nuclear power plants, require very high customization and engineering competencies (Hobday, 1998). In contrast, other authors consider complexity in relation to the efforts needed by adopters to understand the innovation and to implement it (Nord and Tucker, 1987; Rogers, 2003). Some innovations are more knowledge-based and have a higher technological level than others, which make them more difficult to understand (e.g. Aiman-Smith and Green, 2002). In this context, adopters' perceptions and backgrounds also play a role, because scholars assume that the more an adopter knows about an innovation, the easier it will be to understand and implement it (e.g. Linton, 2002), and the less complex it will be perceived (Tornatzky and Klein, 1982). Finally, some authors argue that innovation complexity is related to the degree of system-embeddedness of innovations (e.g. David, 1994, 1991; Grübler, 1991). Indeed, innovations are more or less dependent on the sociotechnical systems to which they belong, and their use requires more or less societal changes, for instance, with regard to user habits or to system infrastructures making their use possible. For example, although most 
consumer innovations, such as computers, refrigerators, and mobile phones, are quite easy to start using without changing other day-to-day practices, innovations with much higher levels of system-embeddedness require long-term changes, investments, and persuasion in order for legitimization to grow, infrastructures to be built, and user practices to transform (Hughes, 1987; Lyytinen and Damsgaard, 2001).

This thesis focuses on one specific type of innovation: RE technologies. Although these technologies are not as complex to develop and implement as CoPS and, instead, have a manufacturing process that is rather standardized, they can be considered highly system-embedded. They depend both on existing infrastructures (e.g. the existing electricity grid) and on the development of infrastructures adapted to their use (e.g. smart grids). Moreover, their use is contingent on rules and regulations, e.g. deregulation of the electricity market, building permits, and regulations regarding the direct consumption of electricity produced. As highly system-embedded, most RE technologies are complex to diffuse, not only because they can be perceived as highly technological by adopters with little or no previous experience of such innovations, but also because a complex institutional process needs to be followed in order to gain the authorization for the technology to be implemented. ${ }^{2}$

\subsubsection{The importance of individual adoption processes for the understanding of} large-scale diffusion

As presented above, the diffusion of certain innovations is dependent on the sociotechnical system in which the innovation is used. In the innovation systems literature, scholars have paid particular attention to the processes of innovation development and early diffusion of highly system-embedded innovations such as RE innovations (e.g. Jacobsson and Bergek, 2011, 2004). However, whether an innovation diffuses or not, or whether this process is fast or slow, is not only a system-level phenomenon. Indeed, no matter how well adapted the system is or how fast its transformation occurs, the diffusion of an innovation is the result of a combination of individual adoption decisions (Rogers, 2003). In other words, although the conditions may exist for potential adopters to decide to adopt, it is still up to the individual adopter to decide to adopt now, later, or never (MacVaugh and Schiavone, 2010).

To understand why some innovations diffuse faster than others, there are three aspects of the adoption process that seem particularly relevant from an adopter perspective:

\footnotetext{
${ }^{2}$ Some RE technologies are more complex to diffuse than others. For instance, adopting small solar power technology does not require very high technological knowledge, because it can be bought in stores as standard packages and its implementation is rather simple because it does not require building permits and can easily be connected to the electricity grid. In contrast, the adoption of wind power technology involves a number of technological and financing choices, which can be considered very complex for inexperienced adopters, and the implementation of such technology requires a rather high level of customization, either through complex building permit processes or through the involvement of several infrastructure and technology suppliers.
} 
the drivers of adoption decisions (e.g. why adopters choose to adopt the innovation and what influences the decision to adopt early or late), the challenges of adoption implementation (e.g. what kind of challenges adopters face during the implementation of the innovation and what obstacles create additional implementation difficulties for adopters), and strategies and policies that influence and facilitate adoption (e.g. how adopters handle the challenges that they face and how policies can facilitate the adoption and implementation processes). These three aspects of the adoption process are particularly complex with highly system-embedded innovations such as RE innovations. For instance with regard to drivers of adoption, while the potential gains of RE innovations for society are often put forward, the potential individual gains for adopters are less clear. In the policy arena, policy-makers sometimes assume that institutional pressures, such as financial incentives, can trigger an adoption decision by creating a potential economic gain. Nevertheless, the fact that despite these incentives, the RE innovation diffusion still moves slowly suggests that there may be drivers other than economic gain to consider.

With regard to challenges, previous studies have stressed that the adoption process involves a number of steps and that each of these steps may not necessarily lead to the next one or to a successful innovation adoption (Schiavone and MacVaugh, 2009). Instead, some adopters may face difficulties (e.g. lack of resources, lack of information) during the implementation of the adoption decision, which may result in an unsuccessful adoption (e.g. if the innovation is not used to its full potential (Klein and Knight, 2005)) or in an unsuccessful confirmation phase (e.g. if the adopter is dissatisfied about the innovation-decision) (Rogers, 2003). The implementation of highly system-embedded innovations is also particularly complex because, in addition to the problems originating on the actor level, obstacles can emerge from the system on which these innovations are dependent (e.g. Johnson and Jacobsson, 2001). To understand what blocks or slows down diffusion, therefore, it is crucial to take an adopter perspective, in order to grasp the extent of both adopter- and system-level obstacles.

Finally, the literature has focused mostly on system-level strategies to influence and realize adoption, such as policies. Authors have proposed economic policies in order to encourage investment in RE technologies or to penalize the use of fossil-fueled technologies (e.g. Jacobsson et al., 2009; Pettersson and Söderholm, 2009). Authors have also suggested strategies aimed at lowering systemic challenges (e.g. Bergek et al., 2014, 2008b). Nevertheless, the fact that adopters, despite a variety of both systemand actor-level problems, still manage to implement their adoption decisions suggests that they also develop individual strategies. Here again, in order to suggest long-term, efficient policies to speed up diffusion, taking an adopter perspective can shed light on new types of actor-level strategies as well as provide deeper insight into the real impact that system-level policies have on facilitating the adoption process needed to 
reach large-scale diffusion.

This thesis studies adopters and their contexts with an explorative approach. Rogers' (2003) definition of adopter considers as adopters those for whom an innovation is new; if the technology is not new to an individual or organization, the technology is not an innovation and the buyer is not an adopter. Depending on the individual adopter (e.g. depending on the need or on how reluctant to change s/he is), adoption may occur earlier or later, after the penetration of the innovation on the market. This explains why authors in the diffusion of innovation literature emphasize the need to consider the adoption process in order to understand and predict the rate of diffusion of innovations (e.g. Wejnert, 2002). Depending on the theoretical approach, this thesis uses different denominations for adopters, e.g. investors, producers, or users. Despite different terminologies, these actors have in common that they buy a RE technology with the purpose of producing electricity, no matter whether they participated in the construction of the RE plant or whether they bought a turn-key or second-hand plant. Hence, individuals or organizations that implement an innovation, e.g. installation or construction, with the purpose only of selling it once ready for operation are not considered adopters. Likewise, financial investors who limit their contributions to financial input (e.g. pension funds or shareholders) and project developers who limit their contribution to coordinating the implementation of RE plants in order to sell the plants to potential producers are not considered adopters.

The following sections of this chapter review the literature contributing to these three important aspects of diffusion (i.e. drivers, challenges, and strategies/policies). More specifically, this chapter presents the actor- and system-level approaches suggested by different strands of literature, in particular the diffusion of innovation literature, the innovation systems literature, and the energy policy literature, in order to give an overview of the present understanding of the aspects that can drive or block adoption, as well as the current strategies used to realize and facilitate adoption. After the review, this chapter presents existing overlaps between approaches and remaining gaps as well as the research questions of the thesis.

\subsection{Adoption drivers during the large-scale diffusion of innovation}

The first step in understanding how to reach large-scale diffusion is to understand what drives adopters to make their decisions to adopt. In the literature, authors have pointed to a number of drivers emerging either from the actor-level of adopters, e.g. what leads individuals or organizations to decide to adopt an innovation, or from the system-level, e.g. incentives targeting adopters coming from the sociotechnical system in which the innovation is embedded. 


\subsubsection{Actor-level drivers}

In the diffusion of innovation literature, there are two main drivers to adoption: individual characteristics of adopters and the dynamics of adopters' social networks. With regard to individual characteristics, Rogers (2003) underlines that adopters' interests and personality traits directly affect the timing of their adoption. For Rogers, all prospective adopters of an innovation can be divided into different groups depending on their characteristics. Adopters who are interested in new ideas and have leadership traits are more likely to be innovators, i.e. they adopt the innovation earlier than the rest of the potential adopters. In contrast, potential adopters who are reluctant to change and skeptical about new ideas are more likely to be laggards, i.e. they are among the last ones to adopt the innovation, at a time when the diffusion is already slowing down.

Another driver related to adopters' individual characteristics is the individual perceptions of the innovation (Frambach and Schillewaert, 2002; Rogers, 2003). For instance, if adopters perceive that the innovation has a relative advantage compared with the technology or practice it aims to replace or the innovation with which it competes, adopters will be motivated to adopt the innovation as soon as possible (Rogers, 2003). In particular, the literature underlines the relative advantage of an innovation in terms of economic gain as a main driver (e.g. Eastin, 2002; Frambach and Schillewaert, 2002; Katz and Shapiro, 1986; Knowler and Bradshaw, 2007). Adopters' characteristics also influence such perceptions. For instance, whether adopters have previous knowledge of or experience with a similar innovation contributes to the development of their perceptions about the innovation (Seligman, 2006).

With regard to adopter network dynamics, the diffusion of innovation literature defines diffusion as a social process, in which information about the innovation circulates in communication channels and results in adoption and implementation (Rogers, 1962). Inspired by the institutional theory literature (e.g. DiMaggio and Powell, 1983), diffusion of innovation scholars argue that adopters belong to networks, which act as drivers of the adoption process. This driving process can occur in different ways for different groups of adopters. For instance, some adopters (i.e. the adopters Rogers (1962) categorized as innovators) may be driven to adopt by the potential legitimacy that the adoption decision may give them within their networks or because they want to influence the rest of their networks (Abrahamson and Fombrun, 1992; Burkhardt and Brass, 1990; Zimmerman and Zeitz, 2002). In other cases, adopters may be (consciously or unconsciously) pressured to adopt due to the fact that all other members of their networks are also adopting (e.g. Abrahamson, 1991; Teo et al., 2003). This influence is actually so strong that it can affect adopters' rationality and lead to adoption of inferior innovations (Tingling and Parent, 2002). Finally, 
through the diffusion of an innovation in social or business network, the perception of the innovation can become more positive, and the perceived risks associated with the innovation can decrease (Scherer and Cho, 2003; Wejnert, 2002).

In contrast to consumer innovations, social dynamics and individual characteristics are not enough to explain the diffusion of highly system-embedded innovations (Grübler, 1996; MacVaugh and Schiavone, 2010; Rao and Kishore, 2010)(Grübler, 1996)(Grübler, 1996). In particular, authors in the innovation systems and energy policy literature have pointed out the need to also consider system-level drivers (e.g. Johnson and Jacobsson, 2001; Rao and Kishore, 2010).

\subsubsection{System-level drivers}

In contrast to the diffusion of innovation literature, from the innovation systems perspective, an innovation system emerges and grows due to dynamics occurring at the system level of the innovation (e.g. Bergek et al., 2008b; Carlsson and Stankiewicz, 1991; Hekkert et al., 2007; Jacobsson and Johnson, 2000). Although the authors in this strand of the literature do not primarily aim to explain the diffusion of innovations as such, their perspective remains important because the more the innovation system grows, the more established the innovation will become and the more easily the diffusion will occur.

The innovation systems literature shares with the diffusion of innovation literature the understanding that networks are important. However, while the diffusion of innovation literature emphasizes the importance of actors' social networks, the innovation systems literature system-level networks are the crucial ones for the growth of innovation systems. These networks often emerge on the supply side of the innovation (e.g. around technology developers and suppliers) and promote the innovation development and early diffusion by spreading information about the innovation, identifying the innovation as a new solution, and influencing system actors' perceptions of the innovation (Jacobsson and Johnson, 2000; Johnson and Jacobsson, 2001). Networks can also induce the growth of the system by stabilizing it, for instance by developing and deploying resources for their members (Musiolik et al., 2012). In that sense, networks can contribute to key innovation processes, such as influencing the direction of the search, providing knowledge development and diffusion, and encouraging legitimation and resource mobilization, which are crucial drivers of the formation and growth of new innovation systems (Bergek et al., 2008b; Johnson and Jacobsson, 2001).

Institutions are also essential drivers of industry development and innovation diffusion (Carlsson and Stankiewicz, 1991; Johnson and Jacobsson, 2001; Nelson and Nelson, 2002). These institutions may be soft, such as cultures or norms and values present within the system, or hard, such as regulatory or incentive policies. Soft institutions 
are created and controlled by social systems and can also lead the diffusion of an innovation, for instance if the norms and values within a system are positive about an innovation or negative about the incumbent technology (van Lente, 1993).

Hard institutions are instruments used by policy makers to artificially create drivers in order to solve a system problem (e.g. regulations aimed at reducing $\mathrm{CO} 2$ emissions or tax incentives aimed at encouraging organizations to reduce their electricity consumption), to create new industries (e.g. supporting grants or tax reductions for companies willing to develop new products or services), or to induce the diffusion of innovations (e.g. investment subsidies to encourage actors to buy an innovation, measures affecting relative prices such as guaranteed purchase prices for products produced from a certain technology) (Bergek et al., 2014).

In addition to market dynamics, scholars of energy policy also consider hard institutions one of the major drivers of diffusion (e.g. Ackermann et al., 2001; Jaffe et al., 2002; Jaffe and Stavins, 1995). These authors in fact assume that companies will rationally be driven to invest in innovations if the proper policies exist (e.g. Muñoz et al., 2009; Pettersson and Söderholm, 2009; Söderholm et al., 2007). If economic incentives are high enough, the profitability of the innovations will be high enough to motivate the investment and the risks related to investing in the innovation will be decreased (Dinica, 2006). Likewise, if the cost of punitive regulations is high enough, the balance between the cost of investing and the cost of not investing will drive organizations to invest in the innovation (e.g. Ambec et al., 2013; Beise and Rennings, 2005; Langniss and Wiser, 2003).

Despite the power of system-level networks and institutions, system actors can still affect the system (Carlsson and Stankiewicz, 1991). Actors can act as "prime movers" or "system builders" by raising awareness about the innovation, by undertaking investments, by providing legitimacy, by exercising political leverage in favor of the innovation, and by diffusing the innovation (Hellsmark, 2010; Hughes, 1982; Jacobsson and Johnson, 2000). These actors are present in the system as supporters, developers, banks, lobbies promoting alternative technologies, or actors bridging other actors with each other, and some actors may combine one or several of these roles while adopting the innovation. The dynamics created by these actors can influence the political system to take actions to stimulate system change, and some of the uncertainties about the innovation can be resolved (which creates additional dynamics motivating other actors to invest in the innovation or to support the innovation system) (Brown et al., 2013; Jacobsson and Bergek, 2011; Jacobsson and Johnson, 2000). 
2.3 Adoption challenges during the large-scale diffusion of innovation

\subsubsection{Actor-level challenges}

In the diffusion of innovation literature, the challenges identified by scholars were originally related to the actor level of adoption. More specifically, scholars mainly used variables related to the internal context of the adopter to predict diffusion (Havens, 1975; Rogers, 1962). These variables included organizational characteristics (e.g. size, structure), organizational capabilities (e.g. knowledge, experience, ability to learn, or financial resources), organizational networks, and the compatibility of the technology with the organizational structure and other technologies used within the organization (Kennedy, 1983; Rogers, 1962). According to this model, if the adoption process fails, the failure is either the result of the potential adopter's lack of critical capabilities or characteristics needed for a successful adoption, or the consequence of the potential adopters' irrationality or reluctance to change (Abrahamson, 1991; Rogers, 2003).

In the innovation systems literature, authors also underline the challenge of deficiencies in capabilities. These deficiencies include the lack of resources, knowledge, experience, or adaptability to change that are required at the actor level for a technological transition to occur (Klein Woolthuis et al., 2005). In contrast with the diffusion of innovation literature, in which the actors affected by capacity challenges are mainly adopters, the innovation systems literature stresses that capacity challenges can also affect technology suppliers, policymakers, NGOs, users, and consumers (Negro et al., 2012).

\subsubsection{System-level challenges}

Despite the strong focus on adopters' responsibility for problems that occur during the adoption process, more recent diffusion of innovation research has started to point out that system-level conditions are also important for the diffusion of innovation (Lyytinen and Damsgaard, 2001; MacVaugh and Schiavone, 2010; Selwyn, 2003). Hence, institutional, social, and infrastructural conditions must be fulfilled for a successful adoption (1996, 1991; MacVaugh and Schiavone, 2010; Schiavone and MacVaugh, 2009; Wejnert, 2002). The innovation systems literature shares this perspective. Indeed, the innovation systems literature stresses that there are infrastructure obstacles, institutional obstacles, network obstacles, market obstacles, and capability obstacles, all of which can create problems for market penetration and the early diffusion of innovations (Johnson and Jacobsson, 2001; Klein Woolthuis et al., 2005; Negro et al., 2012; K. Smith, 2000)

Both approaches recognize obstacles related to hard and soft institutions. Problems with hard institutions occur when the framework of laws, regulations, and standards 
prevents innovation development from occurring. Examples of hard institutional problems with an impact on innovation development and early diffusion include a lack of stability of political systems, regulations limiting the opportunities to develop or adopt innovations, and a lack of policies supporting the development of new technologies or their penetration into the market (Klein Woolthuis et al., 2005; Negro et al., 2012; Wejnert, 2002).

Obstacles related to soft institutions (also referred to as social conditions in the diffusion of innovation literature) occur when the culture, norms, or values of a system (or within communities of potential adopters) hinder an innovation from emerging and diffusing (Klein Woolthuis et al., 2005; Wejnert, 2002). These problems may hinder market penetration and early diffusion of innovations because they directly affect the selection process within the system as well as the process of identifying and exploiting new opportunities (Johnson and Jacobsson, 2001; Klein Woolthuis et al., 2005). Soft institution problems can occur, for instance, because the risk aversion to new technologies is high or because actors supporting the innovation lack political leverage to influence policies (Johnson and Jacobsson, 2001; Klein Woolthuis et al., 2005). Likewise, if within a group, an innovation is perceived as unfitting with the group's values or habits, group members will be reluctant to adopt (Schiavone and MacVaugh, 2009).

Both diffusion of innovation and innovation systems approaches underline the importance of infrastructural conditions and the problems associated with such conditions. Infrastructural conditions are the physical and organizational structures upon which the innovation depends to be used successfully within the system (Grübler, 1996; Klein Woolthuis et al., 2005; Negro et al., 2012). If infrastructures are missing or if they exist but are incompatible with the innovation, it is almost impossible for the innovation to be adopted (MacVaugh and Schiavone, 2010). Likewise, if the communication channels (e.g. the media, access to internet, proximity to adopter networks or to innovation suppliers) are weak, it is difficult for potential adopters to get information about the innovation or its implementation (Wejnert, 2002). Infrastructures also represent very large investments, which are impossible to afford for individual adopters and which may be hard to motivate due to the lock-in risks that they represent or due to the fact that the system is already locked in by investments in infrastructures made for the incumbent technology (Klein Woolthuis et al., 2005).

In addition to the hard and soft institutional obstacles and the infrastructural obstacles, network problems can occur if networks are either too strong or too weak (Carlsson and Jacobsson, 1997). If interactions and synergy effects are too strong within a network, the internal orientation of the network may become so strong that it can lead to myopia (i.e. alternative thinking, new opportunity identifications, or new 
collaborations become impossible) or to the emergence of dominant actors upon which the rest of the network is dependent (Klein Woolthuis et al., 2005). In contrast, as the diffusion of innovation literature has stressed, if networks are too weak, access to information, knowledge, experience, and know-how is hindered. This lack of access may affect diffusion, for instance, by preventing the coalition between system actors or by limiting the development of a shared vision of future technology development or use (Carlsson and Jacobsson, 1997).

Finally, the innovation systems literature stresses the presence of market obstacles, which refer to the current structure of the market and the criteria used to select innovations (Negro et al., 2012). Market obstacles may occur, for instance, if there are a few dominant incumbents in the market who want to protect their current market positions by hindering potential competitors or competing technologies (Johnson and Jacobsson, 2001). Likewise, if the competition with alternative innovations or incumbent technologies is high, it may be harder to motivate the development of new technologies and it may be more difficult for innovations to be selected on the market (Andersson and Jacobsson, 2000). Energy policy literature also focuses on market obstacles when explaining why diffusion does not occur or occurs slowly (e.g. Brown, 2001). However, in this literature, the understanding of these obstacles is much more economically grounded into the neoclassical "market failure" approach, in contrast with the rather institutional understanding of market obstacles or system weaknesses in the innovation systems approach. According to energy policy authors, the main reason that the new technologies do not diffuse (or at least, not fast enough) is that electricity consumers are not ready to pay a higher price for the RE produced and that potential investors prefer less costly technologies than RE innovations (Menanteau et al., 2003). The main obstacles to investments are therefore either the cost of RE innovations (in comparison with incumbent technologies) or the risks related to investing. Among the challenges related to cost, the literature considers engineering costs (i.e. costs of capital, operation, and fuels), costs of institutional procedures (e.g. permit applications), and costs of resources (e.g. production sites) (Berry, 2009; Dinica, 2011; Söderholm et al., 2007). Among the challenges related to risk, risks associated with policy uncertainty, prices, lack of consumer demand, and technology are predominant in the literature (Barradale, 2010; Bhattacharya and Kojima, 2012).

\subsection{Adoption strategies and policies during the large-scale diffusion of innovation}

To lower or eliminate the challenges to adoption and to large-scale diffusion, a number of strategies can be used. These strategies are either actor-level strategies, i.e. strategies developed by adopters, or system-level strategies, e.g. policies developed to 
support innovation diffusion or activities organized at the system level by different actors to support adoption.

\subsubsection{Actor-level strategies}

In order to handle actor- and system-level weaknesses, the diffusion of innovation literature considers a number of adopter strategies. In particular, networks can be of great help for adopters who want to motivate others to adopt, or for adopters who want to learn or get support during implementation (Rogers, 2003). As underlined in Section 2.2, networks can act as drivers to innovation adoption by legitimizing and spreading information about the innovation. Actors who have adopted or who want to adopt an innovation and who want to increase its legitimacy (for instance, in order to increase their status within their networks) can therefore create diffusion networks (e.g. Lesnick, 2000).

Adopters who want to learn more about the innovation and its implementation can also use networks. Through observations and interactions with adopters within their networks, actors can share their perceptions and get access to the information needed for the adoption decision and its implementation (e.g. Conley and Udry, 2001; Munshi, 2004). This strategy, however, is not risk free, because strictly relying on others may in fact lead to dissatisfaction or unsuccessful implementation (Ellison and Fudenberg, 1993).

Another strategy is for adopters to increase their knowledge and expertise by learning on their own. In the context of a firm, this strategy may mean investing in R\&D or competence development (Woiceshyn and Daellenbach, 2005). This way, an actor can improve both its adoption-decision process (e.g. by choosing to adopt the technology that is best adapted to its needs, rather than the technology adopted by a majority of its networks or by the strong network leaders) and its implementation of the adoption decision (e.g. by implementing the adoption decision in a way that will bring out the best possible outcome for the innovation), which may result in a better decisionmaking and improved implementation. The energy policy literature also shares the understanding that to speed up the diffusion of RE innovations, investors should develop new strategies for developing their investments (Awerbuch, 2006, 2003, 2000). For instance, investors should consider developing portfolios of energy projects (e.g. including both RE and incumbent technologies) to balance the costs and risks or take a broader approach when calculating their investments, e.g. by considering other costs than those usually taken or by considering not only costs but also potential investment revenues. 


\subsubsection{System-level strategies}

Authors have suggested a large variety of system-level strategies to either stimulate the adoption or to lower the system-level challenges presented in Section 2.3.2.

Starting with infrastructure challenges, previous literature stresses that policies have a great role to play to support the development and attribution of human, financial, knowledge, and physical infrastructure needed for the growth of the innovation system (Karltorp, 2014; K. Smith, 2000). Policies can for instance increase the share of direct public funding in these resources or develop regulations or incentives to encourage private investments, for instance, by getting public banks to provide loans or by acting as guarantors by issuing specific bonds targeted at investments in resource mobilization (Jacobsson and Karltorp, 2012; K. Smith, 2000). More specifically, policies supporting research and education in the innovation can lower obstacles associated with a lack of knowledge infrastructure, e.g. by providing funding for research institutes, universities, or training institutes (Bergek et al., 2010; Jacobsson and Karltorp, 2012)

Although soft institutions take time to affect, given their social nature, the policy formation process directly affects them. For instance, the development of long-term political visions or the identification and involvement of different types of political networks and advocacy coalitions can increase the legitimacy of an innovation (Bergek et al., 2008c; A. Smith, 2000). The funding of demonstration plants aimed at creating awareness and interest in the innovation can also affect a perceived lack of legitimacy (e.g. Budde et al., 2012). The diffusion of innovation literature, in which networks are crucial, suggests that policymakers can identify and use opinion leaders to spread information about an innovation and to change the perceptions and behaviors of network actors and potential adopters toward the innovation to increase its legitimacy (Rogers, 2003; Valente and Davis, 1999). Moreover, policymakers, innovation developers and adopters can artificially create diffusion networks in which information can be spread, learning can take place, and legitimacy can increase (Rogers, 2003). Following the same argument, the innovation systems literature highlights the possibility of developing R\&D labs, in which actors (e.g. innovation developers and supporters) can interact (Bergek et al., 2008a).

Policies can also affect market obstacles, e.g. by the creation of economic incentives aimed at encouraging diffusion or by the creation of economic penalties or regulations that may lower the interest in the incumbent technology (Bergek et al. 2010). Policies can also support the innovation by protecting its developers or its early supporters through the creation of protected market spaces that may act as nursing markets at first, and then as bridging markets until the innovation reaches large-scale diffusion (Andersson and Jacobsson, 2000). For instance, public subsidies can created protected market spaces (Bergek et al., 2008a), to compensate for the potential profit disparities 
between RE technologies and incumbent technologies (e.g. by increasing the cost of producing fossil-fueled electricity (e.g. Boyd et al., 1995; Nordhaus, 2007), by increasing the potential revenues of RE production and/or by lowering the costs associated with RE technologies (e.g. Butler and Neuhoff, 2008; Menanteau et al., 2003), or by combining both types of policies (e.g. del Río González, 2007)).

Change agents can affect obstacles related to lack of capabilities on a system level (Rogers, 2003). Change agents can be teachers, consultants, and public or private organizations that support adopters in their adoption processes. Change agents can, for instance, help adopters understand their capacity needs or diagnose problems, establish information exchange relationships (between the change agents and adopters or between adopters and other actors), and affect behaviors to pursue the adoption implementation (Fullan, 1993; Howells, 2006; Leeuwis and Aarts, 2011; Rogers, 2003). Additionally, policymakers can intervene by providing government subsidies, research institute funding, or loans aimed at deducing the individual risks taken by investors (Bergek et al., 2010).

\subsection{Summary}

To sum up, the three theoretical approaches reviewed above present a number of drivers, challenges, strategies, and policies, which provide an interesting combination of actor- and system-level perspectives on the large-scale diffusion of innovation. As Table 1 illustrates, the three approaches share some common dimensions. Most notably, the diffusion of innovation and the innovation systems approaches share the understanding that networks and soft institutions are key drivers and, on the contrary, malfunctioning or lacking networks and soft institutions and infrastructures represent key issues for innovation diffusion. Likewise, in both energy policy and innovation systems approaches, hard institutions and policies may represent key challenges and are also key mechanisms to facilitate innovation development and early diffusion.

As Table 1 also indicates, although these three approaches have different loci of attention, i.e. either the actor or the system level, for some aspects, they each acknowledge the other level of analysis. For instance, although the diffusion of innovation literature focuses on the actor perspective, it acknowledges the importance of systemic conditions for adoption. Likewise, although the innovation systems literature focuses on the understanding of system dynamics, the approach still considers actors key components of the system. Finally, although the energy policy literature considers issues and policies situated at the level of the energy system, it also emphasizes that strategies situated at the actor level are needed. This indicates that in fact both levels matter for a full understanding of diffusion. Yet, as I will develop in the next section, it may be problematic that none of the approaches considers both levels of analysis together. 
Table 1. Overview of the actor- and system-level drivers, challenges, policies, and strategies ${ }^{3}$

\begin{tabular}{|c|c|c|}
\hline & Actor level & System level \\
\hline Drivers & $\begin{array}{l}\text { Adopters' interests and personality } \\
\text { traits (DOI) } \\
\text { Adopters' individual perceptions of } \\
\text { potential gains and risks associated } \\
\text { with adopting the innovation (DOI, } \\
\text { EP) } \\
\text { - } \\
\text { Adopters' social networks (DOI) }\end{array}$ & $\begin{array}{ll}\text { - } & \text { System networks (DOI, IS) } \\
\text { Hard \& soft institutions (DOI, EP, } \\
\text { IS) } \\
\text { - } \\
\text { Supporting actors, e.g. system } \\
\text { builders and prime movers (DOI, IS) }\end{array}$ \\
\hline Challenges & $\begin{array}{ll}\text { - } & \text { Obstacles due to adopters' } \\
\text { organizational characteristics (DOI) } \\
\text { - Lack of capabilities (DOI, IS) }\end{array}$ & 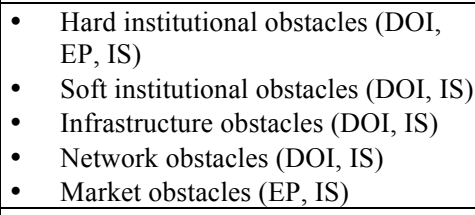 \\
\hline Strategies \& Policies & $\begin{array}{ll}\text { - } & \text { Use of networks (DOI) } \\
\text { - } & \text { Capability development (DOI) } \\
\text { the adoption process/investment } \\
\text { process (DOI, EP) }\end{array}$ & 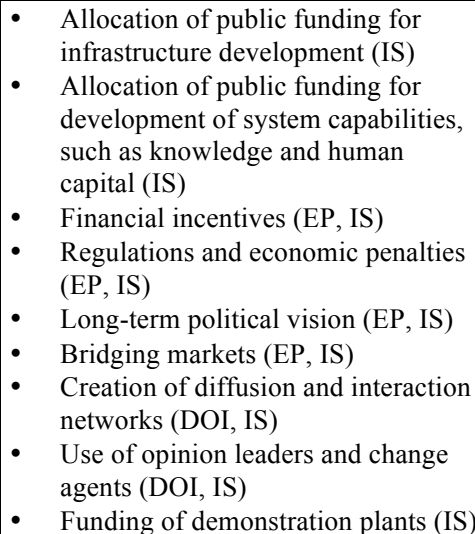 \\
\hline
\end{tabular}

\subsection{Remaining gaps and research questions}

\subsubsection{Remaining gaps}

Although the literature provides interesting insights into the adoption process contributing to large-scale diffusion of highly system-embedded innovations, a number of gaps remain, which this thesis addresses. First, at the actor level of analysis, there are a number of assumptions made about adopters that should be questioned. Second, at the system level of analysis, in current frameworks, there is a lack of focus on the large-scale diffusion phase and its specificities. Finally, in current approaches, there is a lack of integration of the actor and system levels of analysis.

\footnotetext{
${ }^{3}$ Abbreviations used in the table stand for "diffusion of innovation literature" (DOI), "energy policy literature" (EP) and "innovation system literature" (IS).
} 
- Questionable assumptions of adopters and their behaviors

As the above review underlines, the current literature, particularly diffusion of innovation and energy policy literature, makes a number of assumptions about adopters with regard to who they are, what their characteristics, motives, and challenges are, and what strategies they choose for implementing their adoption decisions.

The energy policy literature widely assumes that actors buying and using an innovation belong to an homogeneous group of utilities or energy companies that have access to physical and economic resources and are knowledgeable and experienced in energy-related business activities (e.g. Bhattacharya and Kojima, 2012; Faúndez, 2008; Muñoz et al., 2009; Pettersson and Söderholm, 2009; Söderholm and Klaassen, 2007). In contrast, the diffusion of innovation literature acknowledges that adopters differ from one another depending on the timing of their adoption decisions. Scholars assume that adopters who decide to adopt early are knowledgeable and risk-taking and have high status within their social networks and access to economic resources, and that adopters who adopt at the later stages of diffusion are instead reluctant to change and, because of a lack of resources and social status, cannot take any risk related to the decision to adopt (Rogers, 1962).

In addition, both energy policy and diffusion of innovation approaches assume that adopters are mainly driven to decide to adopt based on economic motives. More specifically, the diffusion of innovation literature assumes that adopters adopt because the innovation has the potential to bring a profit or because it is cheaper than the incumbent technology, because it has the potential to fill a need in the market or to be more efficient than the incumbent technology, or simply because of its potential status gain or the threat of the status loss (for instance, in the eyes of competitors or customers) (e.g. Abrahamson, 1991; Burkhardt and Brass, 1990; Frambach and Schillewaert, 2002; Zimmerman and Zeitz, 2002). Likewise, in the energy policy literature, actors who buy and use RE innovations aim to maximize the profits generated from electricity generation and from economic policies (e.g. Fleten et al., 2007; Kahn, 1996; Kangas et al., 2011).

Finally, both approaches share the assumption that adopters act rationally. In the diffusion of innovation literature, an innovation is regarded as positive and the ground assumption is that it will be adopted eventually (Rogers, 2003). As a consequence, adopters who, despite an understanding of the potential of an innovation and the knowledge and resources to adopt it, still decide not to adopt are considered irrational (MacVaugh and Schiavone, 2010; Selwyn, 2003). In the energy policy literature, it is assumed that because actors who invest in RE innovations are driven by economic motives, they will made all implementation choices according to profit-maximization logic (MacVaugh and Schiavone, 2010; Selwyn, 2003). 
Yet, there are reasons to believe that these assumptions may be wrong. Indeed, these assumptions have mostly been developed without a real understanding of the adoption process from an adopter perceptive or without supporting empirical studies. In the diffusion of innovation literature, Rogers (2003) recognizes that too little attention has been paid to understanding adopters' motives or to taking adopters' contexts as a starting point. Other authors stress the need to use a process-oriented approach to understand the process of adoption from an adopter perspective, e.g. how adopters' mental processes unfold, what influences these processes, and how these processes can be affected or manipulated (Eugene Pereira, 2002; Langley and Truax, 1994; Seligman, 2006). In fact, recent diffusion of innovation literature has highlighted the fact that adopters develop their own patterns of sensemaking when adopting an innovation (MacVaugh and Schiavone, 2010; Seligman, 2006; Selwyn, 2003). For these scholars, rationality has little to do with adoption, because actors who decide to adopt or to reject the innovation in fact develop their own (logical) reasoning to motivate their decisions. Instead of rationality, habits, impulses, identity, concerns, interests, and social components can be at the origin of such decisions (Seligman, 2006; Selwyn, 2003).

In the energy policy literature, too, authors have called for additional studies taking an investor perspective on the investment process of RE innovations (e.g. Dinica, 2006). In particular, authors have started to suggest that investors may in fact not be driven by economic motives; they may be under the influence of bounded rationality and have motives other than economic ones (Masini and Menichetti, 2013, 2012; Wüstenhagen and Menichetti, 2012). Investors may, for instance, be driven by environmental motives, i.e. they invest as a way to contribute to a cleaner energy system, or by symbolic motives, i.e. they invest in order to improve their images or statuses (e.g. Caird et al., 2008; Dóci et al., 2015; Palm and Tengvard, 2011).

- Lack of focus on the large-scale diffusion phase and its potential specificities

In recent years, some authors have started to use the innovation systems framework to study problems that slow down large-scale diffusion (Negro et al., 2012). This use is, on the one hand, understandable, because the innovation systems literature is one of the best developed when it comes to understanding dynamics of diffusion. On the other hand, the focus of the innovation systems literature has been to understand how innovations emerge and grow, as well as to identify and propose solutions to minimize problems occurring at the formation phase of innovation systems, i.e. creation of the market and early diffusion of the innovation. Considering the case of RE innovations, one may question whether the dynamics occurring during innovation development and early diffusion are actually the same as the ones occurring during large-scale diffusion. For instance, at the large-scale diffusion stage, new actors are emerging in the market, policies are being adjusted, and technology prices are going down. As RE innovations 
mature, there may be an increase in research taking the findings of previous innovation systems studies as a starting point, and it is therefore important to evaluate whether these findings are still accurate for later stages of diffusion. For instance, it is becoming difficult to argue for the same extent of nursing market places or public funding allocation for resource mobilization at a time when investors compete with one another to implement the innovation or to invest in the infrastructure (Batlle et al., 2012; Yildiz, 2014).

\section{- Lack of combined actor and system levels of analysis}

As mentioned above, although different approaches acknowledge the importance of both actor and system levels of analysis, approaches usually take either an actor- or a system-level perspective on diffusion. As such, a combined actor and system approach is missing, which may have consequences for the understanding of large-scale diffusion of innovation. Indeed, by focusing on consumer innovations, the diffusion of innovation literature leaves aside the dynamics coming from the system, which may be relevant, for instance, for the study of the large-scale diffusion of highly systemembedded innovations (Grübler, 1991; Lyytinen and Damsgaard, 2001; Meade and Islam, 2006; Rao and Kishore, 2010). The lack system-level approach has led recent conceptual diffusion of innovation research to stress that system-level conditions, such as learning conditions or social conditions, may also explain why some people decide to reject an innovation (Schiavone and MacVaugh, 2009; Selwyn, 2003).

In contrast, the innovation systems literature focuses on the understanding the dynamics created on the system level. As such, although this strand of the literature assumes that systems are composed of interactions among actors, networks, and institutions (Jacobsson and Johnson, 2000), the main aim is to understand how innovation systems emerge and develop (or not), not to understand the dynamics through which individual actors become part of the system or how they behave within that system. Yet, according to Markard and Truffer (2008), to understand the development and dynamics of innovations systems, it is crucial to understand the structural variety of these systems, i.e. understand the diversity of actor groups (e.g. manufacturers, suppliers, service providers, associations, policy markets) and their characteristics (e.g. what group(s) they belong to, what size profiles they have, what systemic roles they play, what strategies they have, and/or what motives they have). Understanding the structural variety of systems is particularly important at a stage of large-scale diffusion, when new actors, for instance, adopters, have emerged and may influence the process much more than they previously have.

As indicated above, an integrated actor- and system-level approach is needed for a full understanding of large-scale diffusion of innovation (in particular, highly systemembedded innovations such as RE innovation). Without such understanding, it may be 
hard to find the most adapted solutions to challenges. In the current stage of research, as Table 1 illustrates, solutions to obstacles diverge; while the innovation systems and energy policy approaches suggest a rather extensive use of public funding and other hard institutions (e.g. Bergek et al., 2010; del Río González, 2007; Jacobsson and Karltorp, 2012), the diffusion of innovation approach focuses on making best use of adopters' context, for instance, through the use of networks to get advice (e.g. Conley and Udry, 2001; Munshi, 2004). With a full understanding obtained through an integrated actor- and system-level approach, new strategies and policies may be developed. Indeed, there are areas in which translating actor-level strategies to systemlevel policies (and the other way around) may be possible but has not yet been exploited. For instance, how can actor strategies aimed at increasing the quality of the adoption process be translated into policies inducing large-scale diffusion? Likewise, are there policies targeting problems that actors are better at solving on their own?

\subsubsection{Introduction of the research questions}

Given the literature and the remaining gaps, it is clear that there is a need for a better understanding of the adoption process during the large-scale diffusion of highly system-embedded innovations. This thesis therefore explores the adoption dynamics shaping large-scale diffusion of innovation by taking an integrated actor- and systemlevel approach. More specifically, through the identification of actor- and system-level drivers and challenges of adoption during large-scale diffusion of innovation and their impact on adoption decisions and strategies during that process, the thesis intents to contribute to theory by conceptualizing large-scale diffusion of innovation, and to suggest new policies and managerial strategies to induce that process.

Against this background, the research questions of this thesis are as follows:

(1) What are the actor- and system-level drivers and challenges of adoption during large-scale diffusion of innovation?

(2) How do the actor- and system-level drivers and challenges affect adoption decisions and strategies during large-scale diffusion of innovation?

(3) How can large-scale diffusion of innovation be conceptualized, based on an improved understanding of the adoption dynamics shaping that process?

Research questions 1 and 2 are answered in Paper 1-6, as well as in Sections 5.1 and 5.2. Research question 3 is an attempt at conceptualizing the outcomes of the studies conducted in the appended papers and is answered in Sections 5.2 and 5.3. 


\section{Method}

This chapter puts the process of this $\mathrm{PhD}$ thesis in a larger research context and gives an overview of the methods used in the appended studies. At the end of the chapter, a short reflection discusses the strengths and weaknesses of the choices made during the $\mathrm{PhD}$ process.

\subsection{Overview of the $\mathrm{PhD}$ process}

3.1.1 The research project - A starting point in the study of new investors in RE This $\mathrm{PhD}$ project has been realized within the frame of the research project "New investors in renewable electricity production: motives, criteria, policy implications," financed with the support of the Swedish Energy Agency's Energy System Research program.

The starting point of the project was empirical. The two main project applicants, Anna Bergek and Gunnel Sundberg, had noticed that there was a mismatch between the energy policy literature, which traditionally described or indirectly assumed that RE investors are utilities or large energy companies, and the empirical reality, in which $\mathrm{RE}$ adopters are both utility-type actors as well as new actors from different sectors and industries. Based on this mismatch, the project aimed to develop a scientific basis for the development and implementation of energy policies aimed at new types of investors in RE production. The project included five sub-aims: (1) to identify and categorize the actors who had invested in RE production in Sweden since the creation of the Tradable Green Certificate (TGC) system in May 2003, (2) to characterize the identified categories with regard to these actors' motives for investing in RE production, the criteria considered in the investment process, and their interests in contributing to the development of the technology (and potentially to establish a difference in comparison with traditional actors such as utilities), (3) to compare the categories and characteristics of these actors with those present in the United Kingdom, and (4) to identify the consequences of these findings for the development and implementation of policies aimed at encouraging investments in RE production and the development of RE technologies.

This project ran from November 2010 to December 2014 and I started my PhD project in August 2011. At that time, the frame of the project was already settled but I was nevertheless allowed to put my own touch on the design of the project, based on my interests. For instance, we modified the second sub-aim to include general adoption strategies, rather than only pure economic investment strategies, and the international comparison was made with France and Germany, rather than with the United Kingdom. 
The project has been the guiding thread of my work from my first day as a $\mathrm{PhD}$ candidate and has had a clear impact on the empirical studies that I have done, on the aims of the papers, and on the overall implications of this thesis.

\subsubsection{The research process: an overview}

As Table 2 illustrates, the studies included in this thesis and the research design associated with them follow three main phases: an exploratory phase, in which the research topic was refined and the research questions developed in order to be relevant to the research topic; a theory-building phase, in which the variation between cases was identified and propositions formulated; and a testing phase, in which propositions were tested.

The choice of research methods was therefore associated with the purpose of the different phases of the research, starting with qualitative methods for the exploration and in-depth understanding of the phenomenon and continuing with quantitative methods for generalization and for increasing the validity of the research.

During the exploratory phase, which resulted in Paper 1, qualitative methods were used in order to better understand the main actor group in focus in the research. The case of Sweden was the basis for the empirical study. Typology analysis and exploratory interviews were conducted with a small sample of RE adopters. In the second step of the research, i.e. the theory-building phase, which resulted in Papers 25 , additional semi-structured interviews with $\mathrm{RE}$ adopters were added to the explorative ones, and additional cases of countries (France and Germany) were added to the case of Sweden. At this step, cross-case analyses of RE adopters and of countries were performed, which allowed for patterns to appear. Based on these patterns, propositions were developed and tested in the last step of the research, i.e. the testing phase, which resulted in Paper 6, in which a survey was conducted on the total population of RE adopters in Sweden. 
Table 2: Overview of the methods used in the articles

\begin{tabular}{|c|c|c|c|}
\hline Papers & Purpose of the study & Data source & $\begin{array}{l}\text { Method used to gather and } \\
\text { analyze data }\end{array}$ \\
\hline Paper 1 & $\begin{array}{l}\text { (1) To empirically identify } \\
\text { different categories of RE } \\
\text { investors. } \\
\text { (2) To provide a multi- } \\
\text { dimensional framework for } \\
\text { understanding different } \\
\text { categories of RE investors in } \\
\text { terms of the characteristics and } \\
\text { factors that influence their } \\
\text { investment behavior. }\end{array}$ & $\begin{array}{l}\text { Swedish databases of } \\
\text { individuals and } \\
\text { organizations supported } \\
\text { within the frame of the TGC } \\
\text { system (July 2012) and } \\
\text { within the frame of } \\
\text { investment support for solar } \\
\text { plants (August 2011) }\end{array}$ & $\begin{array}{l}\text { Qualitative method based on } \\
\text { typology analysis }\end{array}$ \\
\hline Paper 2 & $\begin{array}{l}\text { To identify how emerging } \\
\text { investors' investment decisions } \\
\text { are influenced by various formal } \\
\text { and informal institutional } \\
\text { demands. }\end{array}$ & Interviews & $\begin{array}{l}\text { Multiple-case analysis of } 35 \mathrm{RE} \\
\text { adopters in Sweden }\end{array}$ \\
\hline Paper 3 & $\begin{array}{l}\text { To identify the main challenges } \\
\text { faced by adopters of RE } \\
\text { technologies under different } \\
\text { institutional frameworks as well } \\
\text { as adopters' strategies for } \\
\text { overcoming those challenges. }\end{array}$ & Interviews & $\begin{array}{l}\text { Cross-country analysis of France } \\
\text { and Sweden. } \\
\text { Multiple-case analysis of } 28 \mathrm{RE} \\
\text { adopters in Sweden (14) and } \\
\text { France (14) }\end{array}$ \\
\hline Paper 4 & $\begin{array}{l}\text { To understand the factors that } \\
\text { affect the deployment of } \\
\text { projects driven by RE } \\
\text { cooperatives. }\end{array}$ & $\begin{array}{l}\text { Interviews with RE } \\
\text { cooperative experts, } \\
\text { literature review }\end{array}$ & $\begin{array}{l}\text { Multiple-case analysis of the } \\
\text { institutional contexts for the } \\
\text { deployment of RE cooperatives } \\
\text { in France, Germany, and Sweden }\end{array}$ \\
\hline Paper 5 & $\begin{array}{l}\text { To explore how intermediaries } \\
\text { and adopters collaborate during } \\
\text { the implementation of an } \\
\text { innovation. }\end{array}$ & Interviews & $\begin{array}{l}\text { Multiple-case analysis of six } \\
\text { collaboration cases during the } \\
\text { implementation of wind power } \\
\text { projects }\end{array}$ \\
\hline Paper 6 & $\begin{array}{l}\text { To understand the motives of } \\
\text { RE adopters in Sweden. }\end{array}$ & Interviews, Internet survey & $\begin{array}{l}\text { Sequential mixed methods, } \\
\text { including multiple-case analysis } \\
\text { and survey analysis }\end{array}$ \\
\hline
\end{tabular}

In the following sections, I describe in detail these methods and their motivation.

\subsection{Qualitative method}

\subsubsection{Case-study method}

The starting point of the overall research project was explorative; there was very little previous literature on RE adopters and, as such, it was necessary to start the research by getting an in-depth understanding of these actors and their behaviors. Hence, the case-study method was relevant. This method is a research strategy that focuses on one context in order to explore a phenomenon in its real-world setting. Through interviews, observations, archives, and field studies (or a combination of these data collection methods), the researcher can gather rich data for conducting in-depth 
analyses, which have the power to broaden the understanding of the human condition (Weick, 2007; Yin, 1981). A researcher can use the case-study method to provide description, to test, or to generate theory (Eisenhardt, 1989; Eisenhardt and Graebner, 2007).

One considerable advantage of case-study method is that it allows a researcher to focus on studying a phenomenon in one context at the time, instead of having to struggle with large data sets, which make the complexity of the phenomenon difficult to understand (Stake, 2006). One potential drawback of case-study research is that it relies on a very limited sample (i.e. sometimes one or two cases), which may make it be difficult to convince the reader of the importance of the phenomenon and of the validity of the example.

\subsubsection{Case motivation}

- Sweden - The main case

For case-study research to be relevant and the limited study sample be justifiable, it is crucial for the researcher to choose a case that is both unique, in the sense that it allows one to gain insights into a phenomenon that other cases would not provide, and relevant for theory building, in the sense that it has to inspire new ideas, for instance by contradicting previous theories or assumptions, or by shedding a whole new idea about a process or an organization (Siggelkow, 2007).

In this thesis, the cases have been chosen precisely for their uniqueness and their relevance. The first step was to choose a main case. Sweden was chosen for three main reasons. First, as described in Section 3.1.1, Sweden was chosen as the main case given the empirical observation of an interesting phenomenon, i.e. the emergence of new types of actors within RE production, such as farmers, diversifying companies, and private individuals, with no earlier experience in the energy sector. This phenomenon had not received much attention in the energy policy literature and therefore constituted a potential theoretical gap.

Second, the case of Sweden is unique because of the particularities of its institutional framework for RE production. Indeed, since 1996, the electricity production market in Sweden has been liberalized, which makes it possible for new types of actors to enter RE electricity production. Moreover, in 2003, Sweden implemented a TGC system, which aims to encourage new investments in RE technologies by allocating certificates to all RE producers for each MWh produced and sent to the grid. ${ }^{4}$ In parallel, there is a

\footnotetext{
${ }^{4}$ The RE technologies included in the TGC system are, with some restrictions, wind power, solar power, wave power, geothermal power, biomass-based power, peat in combined heat and power plants, and hydropower (Bergek and Jacobsson, 2010). Currently, there are no wave or geothermal power plants in the system.
} 
quota obligation for electricity consumers and suppliers, which creates a demand for the certificates sold by RE producers. The fact that this policy instrument is market based, instead of technology specific, has led Sweden to receive considerable attention in the literature (e.g. Bergek and Jacobsson, 2010; Jacobsson et al., 2009; Meyer, 2007), and the opportunity to understand the impact of this support system on the studied phenomenon increases the relevance of the case.

Finally, the case of Sweden is also unique due to the availability of data that it offers. Indeed, the TGC system includes almost all RE producers in Sweden. The list of RE producers is publicly available, ${ }^{5}$ which implies that reliable data on the RE adopter group was readily available for the first exploratory step of the research.

- Comparative country cases ${ }^{6}$

After the main case had been chosen, the second step of the case selection was to select additional cases to be used as comparisons with the main case. These comparisons have focused on some specific components of the large-scale diffusion of $\mathrm{RE}$ innovations, such as the actor- and system-level challenges of adoption or the system-level challenges affecting the deployment of RE cooperatives. Hence, although it does not provide enough elements to perform a cross-country comparison of largescale diffusion of RE innovations, it contributes instead by broadening the understanding of the phenomenon to additional contexts, and therefore increases the generalizability of the results.

France was first chosen as a contrasting case. Both countries have deregulated electricity markets, incentive instruments for the diffusion of RE technologies, and, within the frame of the strategy for competitive, sustainable, and secure energy (European Commission, 2010), and ambitious targets for RE production by 2020 . Nevertheless, France presents a number of contrasting characteristics. Indeed, the diffusion of RE technologies runs at different speeds in the two countries; i.e. the proportion of electricity generated from renewable sources (in relation with the percentage of national gross electricity consumption) reached $61.8 \%$ in Sweden in 2013, while the same year it was only $16.9 \%$ in France. Likewise, although new types of actors have multiplied in Sweden, types of actors are still very limited in France (Poize and Rüdinger, 2014). Finally, although both countries have implemented incentive policies for the diffusion of RE technologies, Sweden has a market-based instrument (i.e. the TGC system) and France has a technology-specific instrument (i.e.

\footnotetext{
${ }^{5}$ The names of private persons are, however, anonymized in accordance with the Private Protection Law (1998:204).

${ }^{6}$ This section is based on the method description included in appended Paper 3 by Mignon and Bergek (2016) and appended Paper 4 by Mignon and Rüdinger (2016).
} 
a feed-in tariff (FIT) system, guaranteeing a certain price for the electricity produced and sold, which is different for different RE technologies.

Finally, in addition to the cases of Sweden and France, the case of Germany was selected to provide an additional setting aimed at understanding the impact of institutional framework and context on the studied phenomenon, as well as to increase the validity of the two first cases. Germany, like Sweden and France, falls under the European framework for the promotion of the use of energy from renewable sources (European Parliament and Council, 2009). Germany also has ambitious targets and incentive policies to increase the diffusion of RE technologies. Like France, Germany has implemented a FIT system. Compared with both France and Sweden, the diffusion rate of RE technologies has been very high over the last 20 years in Germany, which makes it a leading country in the energy transition (Rode, 2014). Also, unlike France and similar to Sweden, the majority of investments in RE production in Germany are made by new types of actors, such as private persons, cooperatives, and small diversifying companies (Morris and Pehnt, 2015).

\subsubsection{Typology analysis ${ }^{7}$}

Paper 1 used the case of Sweden with a specific goal; as presented in Table 2, the purpose of this paper was to empirically identify the different categories of RE investors in Sweden in order, in a second step, to provide a multi-dimensional framework for understanding different categories of RE investors in terms of the characteristics and factors that influence their investment behavior.

To reach this goals, information about the whole population of RE adopters in Sweden was therefore needed, in order to sort the population into different categories based on contrasting characteristics. For that reason, a typology analysis method was used.

The method consists of dividing the overall dataset into categories based on predetermined typologies, which are generated from theory, common sense, or research goals (Hatch, 2002). Through this categorization process, it becomes possible, to a certain extent, to understand and explain a complex reality (Kluge, 2000).

In this research, the typology analysis was done based on the public database gathering all RE producers who were part of the TGC system in 2012, as well as a public database gathering all applicants who had been granted an investment subsidy for solar power in 2011. Categories of RE actors were predefined based on empirical observations and were adjusted during the categorization process, e.g. when some data

\footnotetext{
${ }^{7}$ This section is based on the method description included in appended Paper 1 by Bergek et al. (2013).
} 
did not match the predefined categories and the need for a new category was clear, or when several categories could be merged into one.

This typology analysis was the first exploratory step into the research on RE adopters. This analysis made it possible to grasp the importance of RE adopters in Sweden and to motivate the further research in that direction; it also provided a framework for the selection of individual cases of RE adopters. Paper 1 contains more information about the typology and about the categorization process.

\subsubsection{Cross-case analysis}

The cross-case analysis method was used during the theory-building phase of the project, in Papers 2 to 5 (see Table 2). During this phase of the research, the aim was develop an understanding of the similarities and differences among RE adopters and to increase the understanding of the differences or similarities among the countries. For this investigation, cross-case analysis was particularly appropriate because it broadens the phenomenon by allowing intuitive theories and patterns to emerge. Once developed, these theories and patterns are constantly tested, validated, and adjusted, which makes them particularly truthful about the reality by the end of the process (Eisenhardt, 1989; Eisenhardt and Graebner, 2007).

\subsubsection{Cross-case selection}

Cross-case analysis requires replication of cases through incremental and iterative case selection and data gathering. In other words, cases are selected and added to other cases because they provide contrasting or confirming patterns.

In contrast with methods that rely on statistical sampling, in which researchers aim to gather a representative sample from the population in order to ensure the generalizability of their studies, the multiple-case study method relies on theoretical sampling, which means that cases are selected to ensure variation among cases, with the aim of covering all patterns among, for instance, individuals or firms' behaviors. In other words, the goal is not to explain how common a pattern is, but rather to show what variation of patterns exists. (Eisenhardt, 1989)

To select cases for Papers 2, 3, 5, and 6, the principle of iterative variation was followed. A few explorative interview were first conducted in Sweden, with RE adopters with contrasting characteristics in terms of size, main activity, and the RE technology that they adopted. This process confirmed a clear variation in motives, driving forces, access to knowledge and resources, networks, challenges, and strategies. To investigate this variation further and to identify potential patterns among $\mathrm{RE}$ adopters and country cases, additional cases were therefore chosen, both in Sweden and in France. Table 3 provides a complete overview of the interviews 
conducted. The method section of each paper contains more information about the interviews included in each paper.

For the study of RE cooperatives in France, Germany, and Sweden in Paper 4, the goal was to gather more information about the country cases in order to identify the systemic challenges and to understand their impact on one specific type of RE adopter, the RE cooperatives. The level of analysis was therefore the national system level, rather than the RE adopter level. Interviews were therefore conducted with both RE cooperative leaders and with experts in RE cooperative organizations in the three countries. The choice of interviewees was led by the competence in answering questions, which were relevant for the national system level of analysis, rather than to reach variation or to validate patterns. The method section of Paper 4 contains more information about the interview process and the interviewees.

Paper 5 used the multiple-case method to study the collaboration process between RE adopters and the consultants that supported them in the implementation of their adoption decisions. Instead of focusing on reaching variation among adopters, the cases were selected in this paper to reach a variation among collaborations. The method section of Paper 5 contains more information about the cases, the interview process, and the RE adopters and consultants included in the study.

The RE adopters, consultants, and experts included in the cases combine several roles in overall RE production. For instance, many consultants also produce RE, which makes them both RE adopters and consultants. Some of these actors were interviewed in their RE adopter role in Paper 2 and in their consultant role in Paper 4. Likewise, some of the experts in RE cooperatives that were interviewed in Paper 3 were also interviewed for the RE adopter role in Papers 2 and 3. I am, however, confidant that this overlap has not affected the data in any way. Indeed, the data collection occurred on different occasions and the questions asked were different for the different studies. When defining the goal of each interview, I was clear about the role in which I was interested. Of course, interviewees may have been tempted to answer in ways that legitimized their other roles; for instance, they may have tried to emphasize the problems resulting from lack of financial support when I interviewed them in their roles as RE cooperative experts, with the hope that it would serve them in their roles as $\mathrm{RE}$ adopters. There is always a risk with the collection of narrative data that cannot be controlled with official numbers or with interviews that hold no risk in distorting the truth. Nevertheless, the triangulation process (e.g. in Paper 5, in which both intermediaries and RE adopters were asked to describe the process) and the multiple cases at my disposal to compare the patterns of answers confirm the quality of the interview data. 
Table 3. Overview of the interviews conducted for the cross-case analyses

\begin{tabular}{|c|c|c|c|c|}
\hline & Interviewee type & Main activity & $\begin{array}{c}\text { Type of RE } \\
\text { innovation adopted }\end{array}$ & $\begin{array}{c}\text { Country } \\
\text { case }\end{array}$ \\
\hline 1 & RE adopter & Baking company & Wind power & Sweden \\
\hline 2 & RE adopter & Independent power producer (IPP) & Wind power & Sweden \\
\hline 3 & RE adopter & International test center & Solar power & Sweden \\
\hline 4 & RE adopter & Pulp and paper company & Biomass & Sweden \\
\hline 5 & RE adopter & Farmer & Wind power & Sweden \\
\hline 6 & RE adopter & RE cooperative & Wind power & Sweden \\
\hline 7 & RE adopter & Public waste management company & Biomass & Sweden \\
\hline 8 & RE adopter & IPP & Wind power & Sweden \\
\hline 9 & RE adopter & IPP & Wind power & Sweden \\
\hline 10 & RE adopter & Pulp and paper company & Biomass & Sweden \\
\hline 11 & RE adopter & Grain mill company & Hydropower & Sweden \\
\hline 12 & RE adopter & Municipality & Wind power & Sweden \\
\hline 13 & RE adopter & Farmer & Wind power & Sweden \\
\hline 14 & RE adopter & Wind power project developer & Wind power & Sweden \\
\hline 15 & RE adopter & Public waste management company & Biomass & Sweden \\
\hline 16 & RE adopter & Farmer & Biomass & Sweden \\
\hline 17 & RE adopter & Children wear designer and manufacturer & Wind power & Sweden \\
\hline 18 & RE adopter & Public housing company, landlord & Solar power & Sweden \\
\hline 19 & RE adopter & Fur manufacturer & Wind power & Sweden \\
\hline 20 & RE adopter & IPP & Wind power & Sweden \\
\hline 21 & RE adopter & Wind power project developer & Wind power & Sweden \\
\hline 22 & RE adopter & Pulp and paper company & Wind power & Sweden \\
\hline 23 & RE adopter & Pulp and paper company & Biomass & Sweden \\
\hline 24 & RE adopter & Wind power project developer & Wind power & Sweden \\
\hline 25 & RE adopter & Infrastructure development company & Wind power & Sweden \\
\hline 26 & RE adopter & IPP & Hydropower & Sweden \\
\hline 27 & RE adopter & Furniture retailing company & Wind power & Sweden \\
\hline 28 & RE adopter & Public waste management company & Biomass & Sweden \\
\hline 29 & RE adopter & RE cooperative & Wind power & Sweden \\
\hline 30 & RE adopter & Municipality & Wind power & Sweden \\
\hline 31 & RE adopter & Tenant association & Solar power & Sweden \\
\hline 32 & RE adopter & Farmer & Biomass & Sweden \\
\hline 33 & RE adopter & Farmer & Wind power & Sweden \\
\hline 34 & RE adopter & Building owner, landlord & Wind power & Sweden \\
\hline 35 & RE adopter & IPP & Wind power & Sweden \\
\hline 36 & RE adopter & Grocery store & Solar power & Sweden \\
\hline 37 & RE adopter & IPP & Solar power & France \\
\hline 38 & RE adopter & Organic store & Solar power & France \\
\hline 39 & RE adopter & Gardening retailing store & Solar power & France \\
\hline 40 & RE adopter & Grocery store & Solar power & France \\
\hline 41 & RE adopter & Farmer & Solar power & France \\
\hline 42 & RE adopter & RE cooperative & Solar power & France \\
\hline 43 & RE adopter & RE cooperative & Wind power & France \\
\hline 44 & RE adopter & IPP & Biomass & France \\
\hline 45 & RE adopter & IPP & Solar power & France \\
\hline
\end{tabular}




\begin{tabular}{|l|l|l|l|l|}
\hline 46 & RE adopter & Farmer & Biomass & France \\
\hline 47 & RE adopter & Municipality & Solar power & France \\
\hline 48 & RE adopter & Municipality & Wind power & France \\
\hline 49 & RE adopter & Municipality & Wind power & France \\
\hline 50 & RE adopter & Municipality & Wind power & France \\
\hline 51 & RE adopter & IPP & Solar power & France \\
\hline 52 & RE cooperative expert & Project developer, researcher & & Sweden \\
\hline 53 & RE cooperative expert & Researcher, RE community member & & Germany \\
\hline 54 & RE cooperative expert & Researcher & & Germany \\
\hline 55 & RE cooperative expert & Regional energy agency & & France \\
\hline 56 & RE cooperative expert & Utility & & France \\
\hline 57 & Intermediary & Project developer & & Sweden \\
\hline 58 & Intermediary & Project developer & & Sweden \\
\hline 59 & Intermediary & Project developer & & Sweden \\
\hline
\end{tabular}

\subsection{Quantitative method}

\subsubsection{Mixed method through sequential data gathering}

After the exploratory and theory-building phases of the research were completed, the testing phase was performed. Data was collected through an Internet survey sent to the total population of RE adopters in Sweden during the spring of 2014 (i.e. from February 2014 to April 2014) and that survey data was analyzed sequentially, together with qualitative data, i.e. semi-structured interviews with 36 adopters. This process resulted in Paper 6, which explored both the motives of RE adoption and the relative importance of each motive tested on the total population of RE adopters in Sweden.

The advantage of the mixed method strategy is that it increases the reliability and generalization of both the qualitative and quantitative methods included in the study (Creswell, 2013). If, through a triangulation of methods, i.e. the use of two or more methods that complement or balance each other in order to study the same phenomenon, the results obtained through the different methods verify each other, then the validity of the results is strengthened. Moreover, mixed methods can be used to develop each method, meaning that the results from one method can be used to develop or inform the other method. Finally, through mixed methods, the breadth and the range of inquiry can be expanded, for instance, by enlarging the scope of the study from one case study to a study sample representing a whole company or country (Greene et al., 1989).

The purpose of the sequential design was to use the strengths of qualitative methods for exploration in the first sequence of the study and to complement the study in the second sequence by testing the hypotheses on the total population of RE adopters in Sweden. Through this strategy, the validity of the results was enhanced (through triangulation), the reliability of the research was improved (through the use of complementary methods), and the generalization of the results was increased (through 
the expansion of the study scope). Paper 6 provides more information about the tests and tools used for the quantitative.

\subsubsection{Internet survey ${ }^{8}$}

The main strength of the survey method is that it allows the researcher to get many answers to predefined questions in a short amount of time and with limited resources (De Leeuw et al., 2008). The most acknowledged weaknesses are coverage error, which occurs when the design of the survey implies that some members of the studied population have zero possibility of being included in the survey; sampling error, which occurs when only a sample of all potential respondents in the population is included in the survey; nonresponse error, which happens when some of the sampled respondents do not respond, leading to a mismatch between the actual respondents of the study and the respondent group relevant for the study; and measurement error, which occurs when a respondent's answer is erroneous (De Leeuw et al., 2008). The challenge of the survey method is therefore to minimize these four issues.

In the survey study conducted in this research, different strategies were used to minimize the four issues described above. First, with regard to coverage error and sampling error, the strategy was to include the total population of RE adopters in Sweden (i.e. $2157 \mathrm{RE}$ adopters in the database). The contact information of all RE adopters (i.e. their postal or email addresses) who were part of the TGC system was obtained from the Swedish Energy Agency, i.e. the administration in charge of administrating the TGC system in Sweden. As mentioned in Section 3.2.3, it is important to note that it is not compulsory to join the TGC and some RE adopters may have chosen not to do it, in which case they were not included in the survey population. Moreover, the database does not include RE adopters, who are not connected to the grid or whose production does not reach $1 \mathrm{MWh}$ per year, which excludes a large part of the population that has adopted solar power technology. Finally, because the focus of the research was the new types of actors in RE production, utility-types actors were excluded from the respondent groups. Nevertheless, the quality of the data can be considered strong because it was possible to access the large majority of the RE adopter group in Sweden (i.e. no sampling strategy was needed) and respondents represented all main RE technologies (i.e. hydropower, wind power, solar power, and biomass-based power) and all previously identified RE-adopter categories (i.e. those categories developed in Paper 1).

Although the survey was conducted on the Internet, the link to the survey was sent by normal mail to RE adopters that had not indicated any email address in their TGC applications, in order to avoid excluding one specific group (i.e. those who wanted to

\footnotetext{
${ }^{8}$ This section is based on the method description included in appended Paper 6 by Bergek and Mignon (2016).
} 
protect their privacy) from the respondent group. Moreover, to avoid excluding RE adopters who did not have access to the Internet, the mail advertised possibility of receiving a paper version of the survey or filling it in by phone with the help of a researcher. Twenty-six people received help on the phone or filled in the paper version of the survey.

The survey was sent to $2157 \mathrm{RE}$ adopters. To formulate questions matching RE adopters' contexts and to limit the risk of misunderstanding leading to measurement error, four different versions of the survey were designed: one version for public organizations (including municipalities and other types of public organizations), one version for private persons, one version for companies (including private and public companies, project developers, diversifying companies, farmers, and companies specialized in RE generation), and one version for associations (including cooperatives and other types of associations). These multiple versions also allowed the researcher to track the number of surveys gathered in the different categories.

To increase the response rate, two reminders were sent to respondents that had not yet answered, either by email for those that had indicated an email address in the TGC database, or by normal mail for the other ones. In total, after cleaning the data from empty questionnaires or questionnaires that were left unfinished after fewer than 10 questions, 602 answers were gathered, which corresponds to a response rate of approximately $28 \%$, which is within the average for Internet surveys (Deutskens et al., 2006; Kaplowitz et al., 2004; e.g. Kwak and Radler, 2002).

As Table 4 illustrates, the respondent share of sole traders is overrepresented, while the respondent share of companies (i.e. independent power producers and diversified companies) is underrepresented. This uneven representation is a common problem in survey research (Baruch and Holtom, 2008). Nevertheless, the overall study of descriptive statistics of sole traders and companies' answers indicated that there was no clear pattern of answers among companies or sole traders. The over- or underrepresentation of one respondent group therefore did not affect the results of the overall respondent group. Moreover, the survey was conducted within the frame of a mixed-method study. The qualitative interviews included in this study (which also showed the lack of answer patterns depending on whether respondents were sole traders or companies) therefore decreased the impact of non-response and over- or underrepresentation among respondents. 
Table 4. Representativeness of the Internet survey respondents

\begin{tabular}{|c|c|c|c|}
\hline RE adopter categories & $\begin{array}{c}\text { Number of survey } \\
\text { answers }\end{array}$ & Percent & $\begin{array}{c}\text { Compared with the } \\
\text { whole population of } \\
\text { RE adopters (based on } \\
\text { number of plants in the } \\
\text { TGC database in 2012) }\end{array}$ \\
\hline Associations & 29 & $4.8 \%$ & $7 \%$ \\
\hline Municipalities & 9 & $1.5 \%$ & $4 \%$ \\
\hline Sole traders & 321 & $53.3 \%$ & $13 \%$ \\
\hline Independent Power Producers & 134 & $22.3 \%$ & $47 \%$ \\
\hline Diversified companies & 109 & $18.1 \%$ & $29 \%$ \\
\hline Total & 602 & $100 \%$ & $100 \%$ \\
\hline
\end{tabular}

Because all questions were not applicable for all respondents, some of the questions were excluded from the surveys designed for some of the respondent groups. Hence, 39 questions were included for associations and companies, 37 questions for municipalities and 36 questions for sole traders. Surveys were divided into four main sections to facilitate respondents' understanding and therefore minimize measurement error: (A) questions regarding the RE plant owner, (B) questions regarding the RE production, (C) questions regarding the investment process for the first developed RE plant, and (D) questions regarding the support system. The questions treated the main research areas, which had previously been studied qualitatively, namely, the motives for RE adoption, the implementation of the RE adoption decision through the development of the project, the impact of policies on RE adoption decisions, and future plans for RE production.

\subsection{Reflections and potential limitations}

This $\mathrm{PhD}$ thesis includes six papers, in which studies have been conducted following a variety of methods, as Table 2 illustrates. Overall, the large amount of data and the variety of research methods, combined with the fact that results all point in the same direction, create a good basis for the reliability, validity, and generalizability of the results. Nevertheless, this research journey has had its ups and downs.

First, during the exploratory phase of this research project, I had to familiarize myself with the study context and with a variety of industries in which various RE adopters had their main activities. This phase was a learning process, which was at some points rather challenging given my non-technical background and my rather new role as a $\mathrm{PhD}$ student. However, the active participation of one of my supervisors during these first interviews minimized the negative effect of my lack of experience.

Second, the data collection process was remarkably smooth: it was not difficult to schedule interviews and to get interviewees to share their experiences and thoughts. The process was similarly uncomplicated in all countries I studied and among all 
categories of RE adopters. This ease of data collection resulted in a lot of useful data and is, I think, one of the main strengths of this thesis. Nevertheless, I discovered that having a large amount of rich data is both a blessing and a curse. Indeed, I often struggled to identify the most important and illustrative data to include in the articles. This struggle is consistent with Eisenhardt's (1989) reflection on the fact that a large amount of data creates the difficulties of both omitting unnecessary details and highlighting the simplicity of an overall perspective. To cope with this problem and keep articles short enough for scientific journals' formats, I included quote tables and wrote case descriptions with a mind to including only key information. A consequence of this approach, however, is that I exploited only a small portion of the (qualitative and quantitative) data collected over the last four years of this research project.

Third, during the research process, I had to familiarize myself with the quantitative method and survey design. I received significant support in this difficult process both in the form of individual advice from Karl Wahlin and courses in quantitative methods. Despite the difficulties, I was always convinced that the quantitative method was an important strategy to increase the validity and reliability of results. Although the response rate of the survey was average, I was positively surprised at the enthusiastic responses from some of the respondents. Likewise, the process of testing the survey results with results from qualitative studies was very gratifying, because the two sets of results often matched beyond better than I expected.

Finally, the research presented in this thesis has methodological limitations, which represent opportunities for further research. For instance, considerable focus is on Sweden and its institutional framework, such as the TGC system and Swedish norms and values. Even if none of the studies focusing on Sweden claimed that the institutional context and its specificities should be generalized to other settings, focusing from the start on one particular setting may have influenced the understanding of the issues studied in the research. Indeed, the comparative studies of France and Germany were included precisely to avoid such lack of breath and generalization power. Nevertheless, it may be argued that these three countries are not comparable with developing countries or countries with different sets of norms and values such as China or the United States. Additional comparisons with other countries and institutional settings should therefore be pursued in future research. One strategy would be to enlarge the survey population to include RE adopters in additional countries. 


\section{The papers}

This chapter summarizes each of the six appended papers and defines my contribution in their writing process. This constitutes the basis for the synthesis presented in the next chapter. Table 5 presents the current status of the papers and the research questions posed in the thesis, which they address.

Table 5. Publication status and research questions addressed in the papers

\begin{tabular}{|l|l|l|}
\hline \multicolumn{1}{|c|}{ Papers } & \multicolumn{1}{|c|}{ Status } & \multicolumn{1}{|c|}{$\begin{array}{c}\text { Research question(s) } \\
\text { addressed }\end{array}$} \\
\hline $\begin{array}{l}\text { Paper 1 - Who invests in renewable } \\
\text { electricity production? Empirical evidence } \\
\text { and suggestions for further research }\end{array}$ & $\begin{array}{l}\text { Published in Energy Policy, January } \\
2013\end{array}$ & RQ1 \\
\hline $\begin{array}{l}\text { Paper 2 - Investments in renewable electricity } \\
\text { production: the importance of policy revisited }\end{array}$ & $\begin{array}{l}\text { Published in Renewable Energy, } \\
\text { April 2016 }\end{array}$ & RQ1, RQ2 \\
\hline $\begin{array}{l}\text { Paper 3 - System- and actor-level challenges } \\
\text { for diffusion of renewable electricity } \\
\text { technologies: an international comparison }\end{array}$ & $\begin{array}{l}\text { Published in Journal of Cleaner } \\
\text { Production, August 2016 }\end{array}$ & RQ1, RQ2 \\
\hline $\begin{array}{l}\text { Paper 4 - The impact of systemic factors on } \\
\text { the deployment of cooperative projects within } \\
\text { renewable electricity production - an } \\
\text { international comparison }\end{array}$ & $\begin{array}{l}\text { Published in Renewable and } \\
\text { Sustainable Energy Reviews, } \\
\text { November 2016 }\end{array}$ & RQ1, RQ2 \\
\hline $\begin{array}{l}\text { Paper 5 - Intermediary-user collaboration } \\
\text { during the innovation implementation process }\end{array}$ & $\begin{array}{l}\text { Accepted for publication in } \\
\text { Technology Analysis and Strategic } \\
\text { Management, August 2016 }\end{array}$ & RQ2 \\
\hline $\begin{array}{l}\text { Paper 6 - Motives to invest in renewable } \\
\text { electricity production: evidence from Sweden }\end{array}$ & $\begin{array}{l}\text { Working paper to be submitted to a } \\
\text { scientific journal }\end{array}$ & RQ1 \\
\hline
\end{tabular}

\subsection{Paper 1}

\subsubsection{Summary}

Paper 1 takes a closer look at the composition of the actor group that invests in RE technologies in Sweden. Motivated by recent literature underlining the differences among RE investors with regard to motives and investment strategies, we question the existing assumptions in the energy policy literature, which assumes that RE investors are incumbent actors in the energy sector, with access to knowledge and to resources, and are driven exclusively by profit-maximization motives.

The results invalidate these assumptions and instead show a heterogeneous group of investors invests in RE technologies. As Figure 1 illustrates, when considering the overall RE production in Sweden in terms of capacity installed, it appears that although incumbent actors in the energy sector do invest in RE technologies, the majority of investments are in fact made by actors who come from other sectors, who have limited access to resources and knowledge, and who adopt the technologies for the first time. 


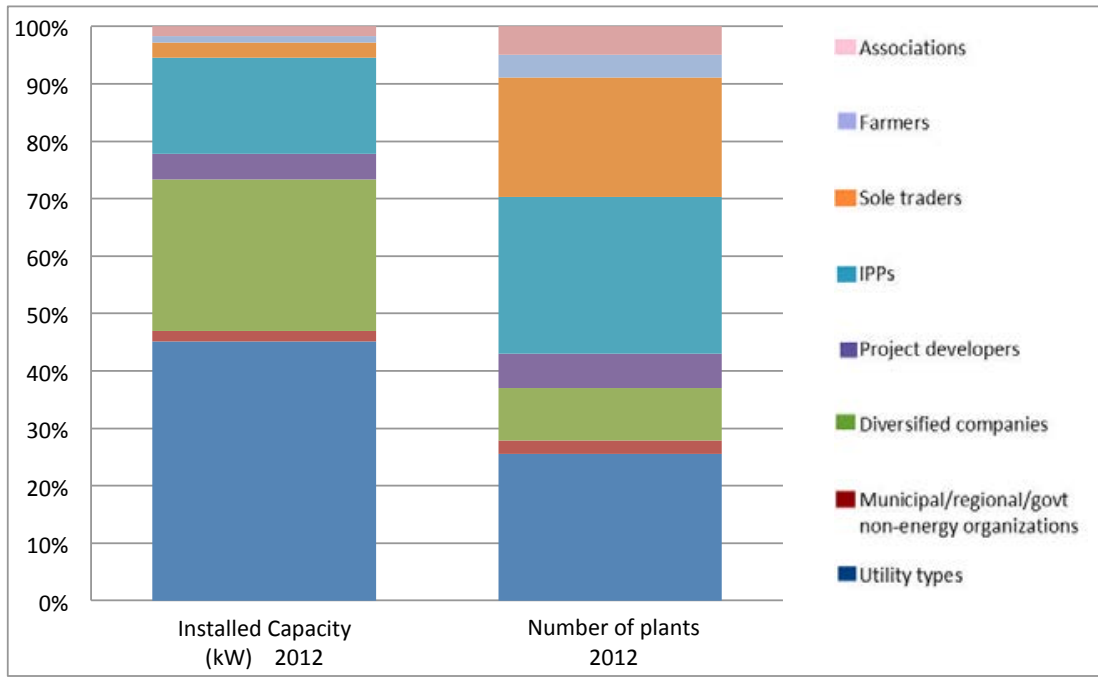

Figure 1. Investor categories, shares of total number of plants and total installed capacity (July 2012) ${ }^{9}$

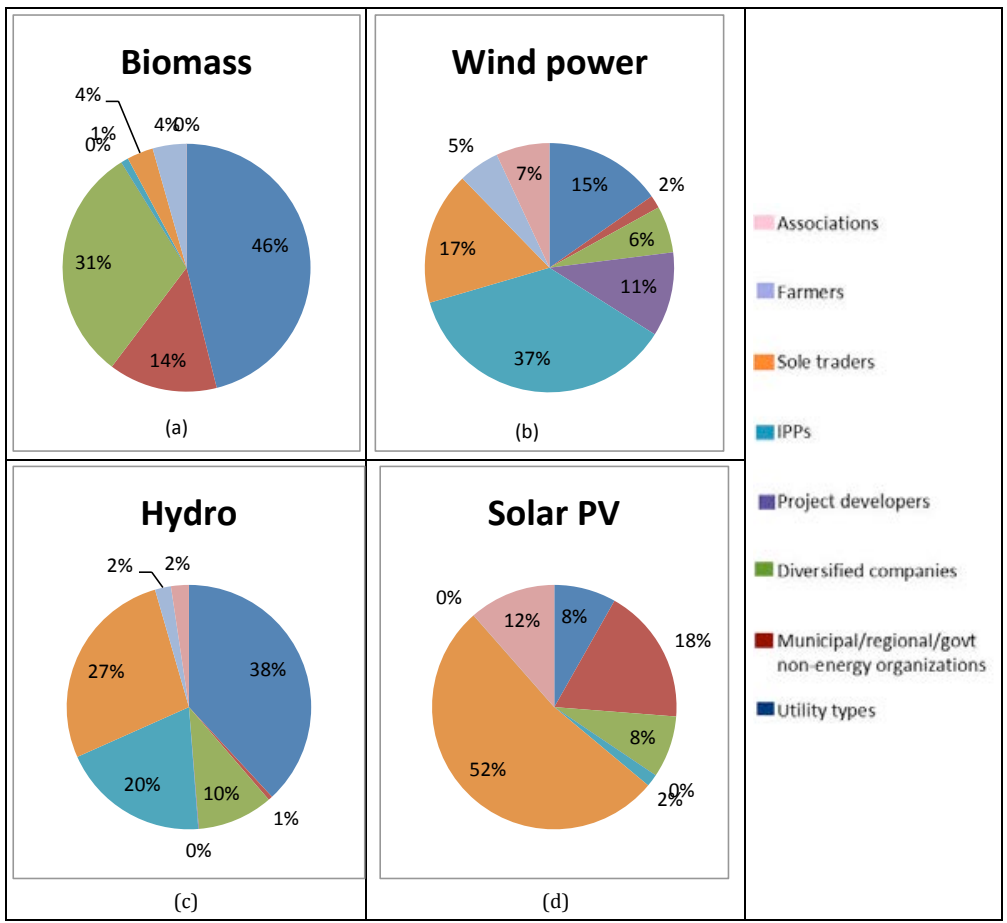

Figure 2. Investor categories for different renewables, shares of total number of plants (July 2012)

${ }^{9}$ Figures 1 and 2 are taken directly from Paper 1 by Bergek et al. (2013). 
Results also show that a variety of investors exist and that their formation varies among the different types of renewable sources. As Figure 2 illustrates, investors include associations, farmers, sole traders, IPPs, project developers, diversified companies, municipal non-energy companies, and utility-type investors. Although utility-type investors own much of the capacity installed in biomass and hydropower, other new types of actors own the majority of the plants in all RE sources. Moreover, in wind and solar power, the key players are not utility-type actors but instead other new actors such as sole traders and IPPs.

This is a new phenomenon that has not been studied previously, and which deserves additional attention in order to understand what motivates and drives these actors to adopt the technology, and indirectly, to participate to the diffusion of these innovations.

For further studies of the phenomenon, the paper introduces a multi-dimensional framework, which not only considers the standard economic dimension predominant in the contemporary energy literature, but also the entrepreneurship, innovationadoption, and institutional dimensions. The framework emphasizes the influence of four main investor-related factors on the investment process, which should be studied in future research and considered in energy policy design: motives, background, resources, and personal characteristics.

\subsubsection{My contribution to the paper and current publication status}

I wrote this paper first during my $\mathrm{PhD}$ studies. It is the result of intensive discussions with both co-authors, Anna Bergek and Gunnel Sundberg. During the data analysis process and the initiation of the analytical framework, I participated actively in the typology analysis of the data included in the paper and in the development of the multi-dimensional framework for further studies on new investors in RE technologies, i.e. the RE adopters on which this thesis focuses. I participated in the writing of different versions of the whole paper and I took the lead in the writing of the framework for future research. After some major revisions by Anna and I, and with the crucial input of Gunnel, Energy Policy published the paper in January 2013.

\subsection{Paper 2}

\subsubsection{Summary}

Paper 2 goes deeper into understanding why RE adopters decide to adopt and implement their adoption decisions the way they do. Instead of considering that only incentive and regulatory policies explain the adoption decision, and therefore assuming that adopters respond rationally to energy policy demands, Paper 2 takes the 
institutional theory as a starting point to consider additional formal and informal institutional demands, which may influence emerging RE investors.

Results show that in addition to formal institutional demands, task environments and various informal demands that originated from collective and internal contexts influenced the RE adopters included in the study. The results also confirm the results from Paper 1 by highlighting that RE adopters are heterogeneous, in the sense that they are affected by different institutional demands, and in the way they respond to the same demands; while some RE adopters perceived a specific demand as imposing, others regarded it as inducing.

Hence, policies should be designed that understand the heterogeneity of RE investors. Moreover, the influence of informal demands suggests that new policies could explore new ways to reach different types of RE adopters; for instance, networks could be used as channels to trigger adoption decisions.

\subsubsection{My contribution to the paper and current publication status}

Anna Bergek and I co-authored this paper. We based this paper on the framework developed in Paper 1, which suggested that RE adopters should be studied from an institutional perspective. I collected most of the empirical data and I wrote the methodological and empirical parts of the paper. After intensive discussions, Anna took the lead in writing the theoretical framework, while I took the lead in writing the analysis and conclusion parts of the paper. After minor revisions, Renewable Energy published the paper in April 2016.

\subsection{Paper 3}

\subsubsection{Summary}

Paper 3 explores the challenges that RE adopters face in various institutional settings, in order to understand what kind of institutional frameworks and governance tools are needed to achieve effective large-scale diffusion when technologies are commercially available and new demand-side actors become involved.

Based on a comparative study of RE adopters in France and Sweden, Paper 3 found that RE adopters face system-level challenges, such as market-structure obstacles and lack of institutional routines, as well as actor-level challenges, such as lack of resources and behavioral characteristics. Although scholars have previously considered these obstacles blocking mechanisms, the results indicate that barriers are better thought of as challenges that can be overcome. Indeed, even if challenges can sometimes be blocking and thus prevent the implementation of the adoption decision, challenges can also be restraining and result in slowing down the implementation or decreasing the quality of the implementation. 
Paper 3 shows that policymakers must consider not only system-level diffusion challenges, but also understand actor-level contexts, including the behaviors of adopters who contribute to large-scale diffusion. By doing so, new policies may be used to facilitate the adoption of new adopters, for instance, by encouraging the use of networks or by supplying specific information to potential adopters who lack it.

\subsubsection{My contribution to the paper and current publication status}

I am the first author of this paper, which I co-authored with Anna Bergek. I initiated the process of this article after collecting data in Sweden and France. I took the lead in the redaction of the methodological part of the paper, as well as the results, analysis, and conclusion. Anna took the lead in the introduction and theoretical framework. We discussed, gave input, and revised all the parts of the paper before and during the review process of the publication. The Journal of Cleaner Production published Paper 3 in its special issue "New approaches for transitions to low fossil carbon societies: promoting opportunities for effective development, diffusion and implementation of technologies, policies and strategies" in June 2016.

\subsection{Paper 4}

\subsubsection{Summary}

Paper 4 focuses on a specific type of RE adopters, i.e. the cooperative organizations created with the aim to initiate, develop, and operate RE projects (also called RE cooperatives). These organizations have received particular attention in recent literature on sustainable transition. On the one hand, writers praise RE cooperatives for their roles in the transition to a sustainable energy system (e.g. they contribute to raising equity for RE projects, they increase the local acceptance of such projects, and they give citizens the opportunity to actively participate in the energy system transition), but on the other hand, the disparities among countries suggest that some contexts are better than others for their deployment.

Against this background, the goal of the paper is to systematically identify the systemic factors that affect the deployment of RE cooperative projects, by comparing the market structures, infrastructures, institutions, interactions, and capabilities available in France, Germany, and Sweden.

Results show that although RE cooperative projects share some obstacles with most new entrants of RE (e.g. issues related to market dynamics and the dominance of incumbent actors or issues related to energy policies), RE cooperatives are particularly exposed to a lack of financial infrastructure, a lack of knowledge, and problems related to a lack of regulatory frameworks facilitating their deployment. It also appears that 
systemic factors are complementary and dependent upon each other: lowering one barrier lowers other barriers and some obstacles strengthen other obstacles.

Drawing on the comparison among Germany, France, and Sweden, we highlight some examples that could be used in the coordination and alignment of systemic conditions for the deployment of RE cooperative projects. For instance, the participative financial model in Sweden could be a first step toward RE cooperative deployment in France, and the routinized support offered to RE cooperatives and the political leverage created through strong RE cooperative networks in Germany are examples of good practices that could be used in other countries.

\subsubsection{My contribution to the paper and current publication status}

I am the first author of this paper co-authored with Andreas Rüdinger, research fellow at the Institute for Sustainable Development and International Relation. I initiated this collaboration during my visiting research period in France in the fall of 2013. I wrote the introduction, theoretical framework, and methodology, and Andreas gave comments and suggestions. In the empirical section, I wrote the sections about Sweden, Andreas wrote the sections about Germany, and we both contributed to the sections about France. I wrote the analysis, which is based on intensive discussions between Andreas and me. Andreas took the lead on the conclusion, upon which I commented and which I partly revised. Anna Bergek also commented on the paper several times. I presented the paper at the International Sustainability Conference in Brighton in August 2015. We submitted it to Renewable and Sustainable Energy Reviews in September 2015. After going through the review process, the paper was accepted for publication in July 2016 and will be published in the November 2016 issue.

\subsection{Paper 5}

\subsubsection{Summary}

Paper 5 focuses on the collaboration process between the new users of a technology and intermediary organizations (such as consultants) that occurs during the implementation of innovation. Paper 5 explores the perspectives of both users and intermediaries in order to understand the characteristics of intermediary-user collaboration and the impact of such collaborations on the outcome of innovation implementation.

The results of a multi-case analysis of six implementation processes show that collaborations are characterized in different ways of matching users' needs and demands with intermediaries' services, different formal and informal governance mechanisms, and different implementation outcomes. Further, the results show that in 
the cases included in the study, the matching process between users and intermediaries was rather easy, because users could choose the service packages they wanted to purchase from intermediaries. Nevertheless, it was users' strategies, rather than their capabilities, that determined the type of services users purchased. Moreover, although all collaborations were formally designed according to formal consultancy contracts, informal governance differed among collaborations. In some collaborations, users were the leaders of the implementation process, whereas in others, users delegated the responsibility for the implementation to the intermediaries.

When a user led the implementation, some knowledge transfer occurred between the intermediary and the user, who eventually gathered enough knowledge to handle critical parts of its next implementation without the help of an intermediary. Implementations entirely delegated to intermediaries, however, had different implementation outcomes. Some users were satisfied and even decided to pursue additional implementation, whereas others' satisfaction was limited.

Results suggest that for a successful intermediary-user collaboration to occur, the implementation process requires a high degree of transparency, especially if the intermediary has responsibility for the entire implementation process. Additionally, findings suggest that in comparison with collaborations that occur during early innovation development phases, collaboration processes between intermediaries and users are easier when the technology is already developed and can be implemented.

Among the managerial implications of the paper, Paper 5 stresses that users can handle a complex implementation process even without complete knowledge of the process, through the collaboration with intermediaries. Nevertheless, the paper also insists that for collaborations to be successful, both users and intermediaries must have some level of control over the implementation process.

\subsubsection{My contribution to the paper and current publication status}

I am the single author of Paper 5. I presented earlier versions of the paper at the ETH PhD Academy on Sustainability and Technology in Zurich in June 2013 and at the $13^{\text {th }}$ Colloquium of the European Group for Organizational Studies in July 2013 in Montréal. The paper was accepted for publication in Technology Analysis and Strategic Management in August 2016.

\subsection{Paper 6}

\subsubsection{Summary}

Paper 6 complements and expands upon the available empirical evidence regarding motives to adopt RE innovation by identifying motives for RE adoption in Sweden and investigating the relative importance of different $\mathrm{RE}$ adoption motives among $\mathrm{RE}$ 
technologies (i.e. biomass, small-scale hydropower, wind power, and solar power) and among RE adopter categories (i.e. associations, municipalities, individuals, IPPs, and diversified companies).

Paper 6 uses sequential mixed methods, including semi-structured interviews with 36 adopters and a survey sent to the total population of RE adopters in Sweden. The results confirm that there are many different types of motives to adopt RE innovation and that adopters combine several motives to adopt. Among the main motives are economic and non-economic instrumental motives, environmental motives, and symbolic motives.

In Sweden, the most important adoption motives are that RE innovations are good for the environment, that the adopter is interested in the technology or has access to a base resource, and that RE production is a good way to make money. These motives contrast, to some extent, with previous literature, in which the adopter's interest in the technology was not so important and economic motives were usually not associated with the exploitation of an existing base resource.

There are no clear patterns among motives, types of RE technology, and adopter categories. This lack of pattern underlines adopters' heterogeneity with regard to motives for adoption. Moreover, the results of the survey analysis show interesting differences between RE technologies and adopter categories, which were until now unknown and which deserve further attention in future research. Among these differences, more wind and small-scale hydro power adopters than solar power adopters have motives related to making money or to a renovation need. Solar power adopters instead have greater motives related to reducing energy costs. Also, IPPs attach greater importance to making money and less importance to other motives than individuals and diversified companies.

The paper underlines the importance of policy instruments that have received limited attention in previous energy policy literature and which could be of great relevance for adopters with particular motives. For instance, the importance of the motive related to paying fewer taxes or reducing energy costs makes it clear that policies such as tax exemptions would be attractive to some adopters. Likewise, regulations allowing the net debit of the balance between consumed and produced electricity may be good incentives for actors considering adopting RE technology because of the potential of such incentives to reduce energy costs.

\subsubsection{My contribution to the paper and current publication status}

I co-authored this paper with Anna Bergek, who is the main author. The paper was developed into two phases. In the first phase, Anna and I developed the ideas behind the research questions, analyzed the data, and discussed the main conclusions. I gathered most of the qualitative data and wrote the methodology and findings sections. 
Anna wrote the theoretical section and we wrote the analysis and conclusion sections together. At that stage, in July 2012, I presented the paper at the $14^{\text {th }}$ Conference of the International Joseph A. Schumpeter Society in Brisbane. In the second phase, survey data was added. I collected the survey data and, together with Anna, we analyzed the quantitative data and compared the qualitative and quantitative results. Anna took the responsibility for revising the paper in the second phase. This paper still has the status of a working paper, but the goal is to submit it to an academic journal by the end of 2016. 


\section{Synthesis}

Chapter 5 develops the answers to the research questions, by synthesizing the findings of the appended papers and by analyzing these findings further to conceptualize the large-scale diffusion of innovation.

Research questions 1 and 2 are answered in Sections 5.1 and 5.2. Research question 3 is an attempt at conceptualizing the outcomes of the studies conducted in the appended papers and is answered in Sections 5.2 and 5.3.

\subsection{Heterogeneous adopters drive the large-scale diffusion process}

The first major finding of this thesis is that the adopters who contribute to the largescale diffusion of highly system-embedded innovations by buying and using the technology are a heterogeneous group. The diffusion of innovation literature had already noticed this heterogeneity with regard to adopters' different timing of adoption (Bass, 1969; Rogers, 1962). Yet the results of this thesis go beyond that by showing that adopters differ from one another in terms of drivers, challenges, and strategies (see Table 6).

\subsubsection{Heterogeneous characteristics}

In contrast with the energy policy literature, which has assumed that RE production and its potential expansion is in the hands of incumbent actors, the first finding of this thesis is that during large-scale diffusion and in particular with respect to RE innovations, adopters present heterogeneous characteristics. This finding is consistent with the diffusion of innovation literature, which argues that basically anyone can be an adopter at the stage of large-scale diffusion.

Paper 1 found that in addition to incumbent actors, who have been active in the energy sector for decades and who are familiar with both incumbent technologies (i.e. largescale hydropower, fossil fuels, and nuclear technologies) and RE technologies, there is a large number of new adopters. These adopters come from other industries (e.g. pulp and paper, housing, and agriculture), have different sizes (e.g. some are one-person businesses while some are multinational companies with thousands of employees), and take diverse organizational forms (e.g. cooperatives, sole traders, public organizations, and limited companies).

These adopters not only contribute to the diffusion of RE innovations by performing additional investments needed to reach a large scale, but they in fact actively drive the large-scale diffusion process. Indeed, as Paper 1 illustrated, when summing up adopters' share of innovation ownership (i.e. in terms of capacity installed and number of plants), it appears that adopters own the majority of RE production capacity. 


\subsubsection{Different perceptions of drivers}

In contrast with the energy policy literature, which has assumed the superiority of economic incentives (e.g. Fouquet, 2013), but in agreement with the recent studies that have suggested that RE adoption can be driven by factors other than economic rationality (Masini and Menichetti, 2013, 2012; Wüstenhagen and Menichetti, 2012), the findings showed that different internal and external institutional demands drive adopters to adopt.

Even if adopters differ from one another with regard to the characteristics described above, they share the fact that they found adopting the innovation attractive. Yet what makes adoption attractive differs from one adopter to another. As Paper 2 showed, some adopters are driven by formal demands, such as incentive policies and regulations, while some are driven by informal demands, such as collective norms emerging from their social networks or internal values and norms emerging from their cognitive frameworks. Additionally, some adopters are driven by pressures from their task environments, such as new formal or informal industry requirements (e.g. if their competitors have earlier decided to adopt) or pressures expressed by customers (e.g. an increased demand for "greener" products).

Adopters do not perceive the same signals, even when they are targeted by similar institutional demands. For instance, even when adopters share a task environment, some adopters may be driven to adopt because they feel the pressure created by their competitors or customers, while others may be driven by economic incentives. In fact, even when reacting to the same signal, for instance, governmental policy instruments, some adopters perceive the signal as inducing and consider the innovation an opportunity, while others perceive the signal as imposing and consider themselves forced to adopt.

\subsubsection{Different adoption motives}

In contrast with the energy literature, which has mostly assumed that the main motive for adoption is the potential economic gain, the findings showed that adopters have different motives for adopting. As Paper 6 showed, in addition to instrumental economic motives, adopters can also have instrumental motives that are noneconomic, as well as environmental and symbolic motives. Interestingly, among adopters with instrumental motives (i.e. adopting is a way to achieve something), the purpose of the adoption is not related only to financial gain (i.e. saving costs or generating rents). Indeed, the prospect of gaining independence or experimenting with the technology is at least as important for adopters' decisions to adopt. In line with the diffusion of innovation literature, which has underlined the impact of legitimization on adopters' decisions to adopt, symbolic motives are related to the opportunity to gain 
recognition in adopters' communities, including their social networks and their task environments.

Also, adopters often combine several motives at once. They usually have one primary motive and several secondary motives. For instance, one adopter may have as a primary motive of adoption an interest in the technology (i.e. non-economic instrumental motive), which may be reinforced by secondary motives such as the potential financial gain (i.e. economic instrumental motive) and the potential status gain (i.e. symbolic motive). Similarly, another adopter may adopt with the primary motive of improving the adopter's image (i.e. symbolic motive), and with the secondary motives of profit (i.e. economic instrumental motive) and the positive impact of the innovation on the environment (i.e. environmental motives), which reinforce the decision to adopt.

Although adopters with instrumental and symbolic motives are directly interested in achieving an individual goal and at directly collecting the fruits of the adoption, adopters with environmental motives have goals that go beyond the actor level. Indeed, their motive is to directly contribute to the system level, for instance, by contributing to the large-scale diffusion of innovation or, in the case of RE innovations, to contribute to a cleaner energy system.

\subsubsection{Challenges and perceptions of challenges}

In line with the diffusion of innovation and innovation systems literatures, which have proposed differences in capabilities and in organizational characteristics to explain or predict diffusion, the results show that different adopters are faced with different challenges. As Paper 3 illustrated, when adopters lack resources, such as knowledge and experience, financial resources, physical resources, or social capital, they often face challenges.

Additionally, adopters' organizational forms have an impact on adoption challenges. For instance, as Paper 4 illustrates, RE cooperatives suffer from system-level challenges or from other challenges related to their task environments. Paper 4 shows that RE cooperatives in France, despite a high commitment of members, are often more vulnerable to system-level challenges such as instability of the political framework or a lack of institutional transparency. RE cooperatives in France also have specific system-level challenges affecting them, for instance, a lack of regulative framework allowing them to raise external capital and to share profits among members.

Surprisingly, in contrast with the previous literature that considers access to resources as a shield against some challenges, the results of Paper 3 underline that access to resources, such as natural resources (e.g. land), may in fact lead to challenges during 
implementation. For instance, several adopters designed their adoptions around the resource to which they had access instead of considering other alternative resources. Likewise, as Paper 5 illustrates, some adopters with access to financial resources may be tempted to outsource much of the adoption process instead of completing the tasks themselves, which may lead to negative consequences. The next section further develops adopters' strategies and the consequences on the adoption process.

In contrast with the previous literature, which often considers adoption obstacles as preventing adoption, results of the studies show that challenges may be either blocking or restraining. Indeed, as Papers 3 and 4 illustrate, some challenges on the system level may reinforce each other to the point that they become blocking, while other challenges, due to the positive externalities of some system strengths (e.g. the impact of strong cooperative networks in Germany) may be only restraining. On the actor level, too, challenges may be blocking or restraining. Interestingly, the impact of challenges is not determined by adopters' organizational forms or capabilities, but instead by adopters' perceptions of challenges. Indeed, as Paper 3 illustrates, some adopters may perceive a lack of infrastructure as blocking whereas others in the same institutional system may consider that same lack of infrastructure as restraining. For instance, a lack of profitability of the adoption resulting from lower electricity prices may be a deal breaker for adopters with economic instrumental motives, whereas adopters with non-economic instrumental motives, environmental motives, or symbolic motives may not be affected at all. In contrast, whether the innovation is well accepted or not in society or in the local area may have only a restraining effect on an adopter with instrument economic motives, whereas the same situation may be a blocking challenge for an adopter with symbolic motive wanting to improve its image.

\subsubsection{Strategies}

In contrast with the energy policy literature, which has until now assumed that adoption followed traditional economic models of full rationality, the results of the studies show that adopters in fact develop a variety of adoption strategies, which may be considered more or less rational from a pure economic standpoint. Among the adoption strategies presented in the studies (e.g. the use of consultants, the development of capabilities, and the use of networks), several strategies are consistent with the inducing mechanisms suggested in the innovation systems literature for the development and early diffusion of innovation.

To cope with adoption challenges, one common strategy among adopters has been to turn to their networks. As Paper 3 illustrates, some adopters partnered with other adopters who could complement the lack of resources. Likewise, as Paper 4 illustrates, adopters in some cases gathered into cooperatives in order to pool financial capital, knowledge and experience, and political leverage. In the case of Germany, strong 
networks within the task environment of the cooperatives also helped adopters benefit from additional support and resources (e.g. from cooperative banks or from federal cooperative networks).

Another interesting adoption strategy is the use of intermediaries, such as consultants and project developers. As Papers 3 and 5 describe, adopters in some cases got help from or delegated the whole implementation process to such professionals. Although the three theoretical approached reviewed in Chapter 2 have not put specific attention on this strategy, other literature streams, such as the open innovation and innovation implementation literatures have previously underlined the potential benefit of using intermediaries in the innovation process (e.g. Chesbrough, 2003; Gassmann et al., 2011; Hargadon, 1998; Howells, 2006). Through intermediaries, as Paper 5 explains, adopters accessed knowledge and experience as well as to RE networks (e.g. suppliers, technology maintenance providers). Through this strategy, some adopters managed to develop knowledge about the implementation process, which they used in their next implementation process.

In many cases, adopters developed innovative solutions individually designed for their adoption processes. For instance, some adopters built the technology from scratch (e.g. instead of buying a RE plant from one of the main available technology manufacturers), some developed local investment clubs to be able to collect capital from multiple adopters, and some created local funds in order to gain legitimacy with the local inhabitants of the area where the technology was to be implemented. These examples illustrate how the perceptions of challenges described above have an impact on strategies; some adopters kept looking for solutions (i.e. challenges were perceived as restraining), while others gave up (i.e. challenges were perceived as blocking).

Interestingly, there is a clear link among characteristics, demands, and strategies. The results of Paper 2 suggest that adopters' institutional demands may explain strategy choices. For instance, adopters who identify themselves with strong environmental values may be prepared to wait 15 years and to spend a lot of money to reach the completion of the adoption. In contrast, adopters induced to adopt driven by economic incentive policies may be reluctant to complete the adoption if those policies become unstable during the adoption process.

Most of all, when analyzing the results of Papers 3 and 6 together, a link appears between motives and strategies. Indeed, adopters with a specific adoption motive seem to choose a specific strategy. Cases in Paper 6 underline that if adopters have economic instrumental motives, they design the adoption in order to maximize the potential gain (or saving). For instance, as mentioned in the previous section and developed in Paper 3, in many cases, adopters with motives related to the exploitation of a base resource designed the adoption around that resource, instead of considering other (potentially better) alternatives. Also, many adopters with non-economic 
instrumental, environmental, and symbolic motives chose strategies that are not rational from a traditional economic point of view. For instance, as Paper 3 illustrates, many adopters with a motive related to a technology interest chose to adopt a less mature technology or an experimental implementation process. Likewise, adopters with environmental or symbolic motives were ready to take a loss on their investments because adoption was part of their marketing strategies and because they were aware of the positive influence that adopting would have on their images.

Through these diverse and innovative strategies of adoption, many adopters successfully completed their adoption processes. Nevertheless, as Paper 5 suggests, a complete adoption does not mean that adopters are satisfied. For instance, delegating the whole implementation of the innovation to consultants is not risk free, because adopters may suffer from a loss of control over the process. Likewise, as Paper 3 illustrates, some of the strategies lead to very long and expensive adoption processes, even if adopters manage to complete those processes.

Moreover, it may be questioned whether all adoptions are positive for the large-scale diffusion of innovations. The results of the studies indicate that successful adoptions do not in fact always lead the large-scale diffusion process forward most efficiently. For instance, money spent on a very expensive adoption processes may be better used elsewhere in the system (for instance, on adopting alternative RE technologies or on the implementation of the innovation in alternative places). Likewise, persevering in very long adoption processes may be part of the reason that the large-scale diffusion moves slowly. In some cases, it may be more efficient for an adopter to adopt the innovation through several small and uncomplicated projects (e.g. the implementation of small-scale solar plants) than through one large, complex, and controversial project (e.g. the implementation of a large off-shore wind park).

\subsection{The emergence of a new diffusion system influenced by parallel systems}

The second major finding of this thesis is that at the stage of large-scale diffusion, new actors, networks, and institutions interact within a system, which can be considered an extension of the innovation system emerging in early innovation phases. ${ }^{10}$ Similar to the innovation system of innovation development and early diffusion (Bergek et al., 2015), this "diffusion system" is not only influenced by components within the system, but also by components from parallel systems, such as the sector in which the innovation is to be implemented (e.g. the energy sector), adopters' task environments (e.g. the industry where they primarily belong professionally), and adopters'

\footnotetext{
${ }^{10}$ This idea is not new, although scholars have not developed it. Indeed, Malerba (2002) has suggested that because of the different processes that occur at different stages of innovation, it might be analytically useful to study separately the innovation system, the production system, and the distribution-market system.
} 
communities (e.g. their neighbors, friends, and family members). As a consequence, new dynamics emerge at different levels of the system and between systems; these dynamics are important to consider for the understanding of the large-scale diffusion process.

\subsubsection{New actors, networks and institutions}

The dynamics of the large-scale diffusion process make clear that new actors, networks, and institutions add to those present during the phases of innovation development and early diffusion. These new system components drive the large-scale diffusion process forward by creating formal and informal institutional demands affecting the decision to adopt, by adopting the innovation and supporting the adoption process. In the early phases, the main actors are often innovation developers or technology suppliers that have strong links to the innovation and its development, but during the large-scale diffusion process, the main actors are instead adopters and other actors with strong links to the adoption process (e.g. intermediaries). As Paper 1 illustrates, these adopters do not have strong links with the technology specifically. Instead, they are active in other sectors or industries, or recently joined the electricity production market to focus exclusively on producing renewable electricity (i.e. IPPs). These actors rarely participate in the development of the innovation, although, as developed in Section 5.1.5, they can choose to develop individual technical solutions as their adoption strategies. They cannot be considered prime movers, either, because they adopt the technology at a time when it can be considered rather mature and is available off-the-shelf. Instead, these actors drive the large-scale diffusion process by investing in innovations that are developed and sold by other actors.

In addition to networks of engineers, suppliers, or technology supporters, which are already present during innovation development and early diffusion phases, new networks with strong links to adopters also appear at the phase of large-scale diffusion. These networks come from adopters' social communities or from their task environments. As developed in Section 5.1.2, the new networks influence the adoption decision, for instance, by creating collective pressures (e.g. recommendations or opinions from friends) or by developing formal demands (e.g. industry strategies or standards). As developed in Section 5.1.5, these networks also play a major role in supporting adopters during the adoption process, by acting as information channels, and by contributing with complementary resources, such as knowledge and experience.

Finally, during the large-scale diffusion process, new institutions add to the institutions present during early innovation phases. Paper 2 highlights that in addition to the hard institutions supporting the innovation that are often developed at the early diffusion phases (e.g. feed-in tariffs or green certificates), at the large-scale diffusion phase, new 
hard institutions play a role, for instance regulations or policies coming from industries (e.g. corporate or industry policies - such as sustainable strategies, or regulations targeting adopters' main activity - such as regulations aimed at energy-intensive industries). Moreover, as Papers 2 and 6 illustrate, new soft institutions appear, which lead adopters to adopt in order to fulfill legitimization needs or intrinsic wishes. Here again, these soft institutions can be collective institutional demands appearing from adopters' social or industry networks, or emerge from adopters' cognitive frameworks in the form of specific identity traits or values. In many cases, soft institutions lead adopters to develop specific motives of adoption.

\subsubsection{The influence of parallel systems}

Even though drivers, challenges, strategies, and policies emerging from the actor and system levels are important for the analysis of large-scale diffusion of innovations, it is also crucial to consider the drivers, challenges, strategies, and policies of parallel systems (see Figure 1). Even though scholars have stressed that during the phase of innovation development and early diffusion, contextual influences matter (Bergek et al., 2015), when large-scale diffusion is concerned, these parallel systems are linked to adopters rather than supply-side companies. Parallel systems are, for instance, related to adopters' main activity, their organizational forms, their local communities, and the communities formed through their hobbies or specific interests. Each of these parallel systems has its own standards, strategies, culture, norms, and values that influence adopters and their behaviors. Examples of such parallel systems include the agricultural sector, the pulp and paper industry, cooperative organizational networks, and local communities.

Adopters are often part of several systems at the same time. As such, they receive influences from different actors, networks, and institutions. For instance, if an adopter's main business is farming and the adopter lives in an area where many other farmers have adopted wind power technology, it is possible that the adopter will be influenced by collective institutional demands from neighbors and colleagues, that the adopter will have norms and values associated with farming, and that the adopter will have to follow standards, strategies, and regulations from a farming trade association and the electricity sector.

As Paper 4 illustrates, these parallel systems may have a number of strengths and weaknesses that impact the adoption process. For instance, going back to the example of the farmer-adopter, in addition to being influenced by different systems, the farmer will also have access to social networks with knowledge and experience about the innovation, and he may be able to receive economic incentives targeted at farmers who make environmentally friendly investments and to get a loan from the farming trade association. Meanwhile, he may also have to struggle with challenges related to 
different parallel systems. For instance, it may be a bad year for harvest; his bank, which lacks experience with investments in RE innovations, may not be willing to give him good interest rates for the loan needed for the adoption; his family may discourage him from investing in anything given the current bad economy; and the government might want to make changes in the economic incentives for RE innovations.

\subsubsection{The impact of the new system on challenges}

As a result of the appearance of the new system components described in Section 5.2.1 and of the influence of parallel systems described in Section 5.2.2, new challenges appear.

At the phase of large-scale diffusion, the system has reached a level of maturity, which may have lowered some of the previous system challenges. To start with, the technology has reached a higher level of maturity, which often has led to fewer technological risks (and improved legitimacy), to some standardization of the manufacturing process, and to lower acquisition costs. Also, infrastructures, which had to be developed at the phases of innovation development and early diffusion, have reached a sufficient level for the innovation to be used on a large scale. ${ }^{11}$

Likewise, as Papers 4 and 5 illustrate, when a system becomes more mature, actors get organized. For instance, over time, RE cooperatives in Germany have developed routines (e.g. checklists, forums, etc.) to support new adopters and have gained political leverage, which has increased the legitimacy of RE cooperatives. Also, some kind of division of labor occurs in the system; instead of each adopter having to go through a capability development process in order to join the system, professional services become available, e.g. from intermediaries, who act as providers of knowledge and expertise.

As the innovation matures and becomes available for large-scale diffusion, new challenges also appear, which are primarily situated at the actor level of adoption (rather than at the system level). As Paper 3 describes, adopters' challenges related to resources, i.e. knowledge and experience, social capital (e.g. political or market contacts), physical assets (e.g. land, organic matter), and/or financial resources are important. Likewise, as developed in Section 5.2.2, challenges from parallel systems affect the diffusion system; e.g. a lack of legitimacy or norms and values negatively affects the diffusion. Finally, adopters' strategies sometimes create new challenges. Indeed, as developed in Section 5.1.5, adopters' norms, values, and motives lead them

\footnotetext{
${ }^{11}$ This description is not applicable to all RE technologies. For instance, in Sweden, although onshore wind power, solar power, and hydropower infrastructures have had time to develop, other technologies, such as biomass power and off-shore wind power, still face a lack of infrastructure, making their diffusion possible on a large scale (Jacobsson and Karltorp, 2013, 2012).
} 
in some cases to pursue adoption implementation strategies that are complicated and time-consuming. These strategies clearly affect the large-scale diffusion because they result in longer adoption processes and may, from a system perceptive, decrease the quality of the adoption, for instance, if the implementation leads to an inefficient use of resources.

\subsection{Toward a framework for diffusion system analysis}

There are thus a number of drivers and challenges that influence the large-scale diffusion of innovation (see Table 6 and Figure 3). These drivers and challenges are directly caused by adopters' characteristics, by the diffusion system, and by parallel systems, to which adopters belong. Depending on their perceptions, some adopters are particularly influenced by drivers and challenges, while others are not, or are only influenced to a limited extent.

Moreover, the results suggest that the origin of the dynamics that occur during the large-scale diffusion process is even more complex than expected. Indeed, during the large-scale diffusion process, dynamics emerge not only from actor level and the level of the system where the large-scale diffusion takes place, but also from parallel systems, which are related to adopters, their contexts, and the industries to which they primarily belong (see Table 6 and Figure 3).

Although Table 6 presents the list of drivers, challenges, strategies and policies occurring during large-scale diffusion, it does not pay tribute to the dynamic character of these elements. Instead, Figure 3 constitutes a tentative model conceptualizing large-scale diffusion of innovation, which attempts to illustrate how the dynamics that emerge from the actor level and from both the diffusion system and parallel systems shape one another.

First, drivers such as policies and regulations that emerge from the diffusion system may lead to new policies or collective pressures within parallel systems, which may lead adopters to develop a certain motive of adoption. For instance, the creation of subsidies for solar power plants on the diffusion system level may lead to an increased awareness of RE investments within the housing industry, which may lead some housing companies to adopt based on an economic instrumental motive.

Conversely, the perception of a challenge at the level of actors may spread to a parallel system (e.g. an industry network) where this perception may generalize and ultimately affect the diffusion system. For instance, if several farmers encounter problems in the collaboration with intermediaries during the implementation of their innovation, these experiences might spread to other people or farmers within their networks and may even result in a lack of legitimacy of intermediaries within the whole diffusion system. 
Table 6. Drivers, challenges, strategies, and policies that occur during large-scale diffusion of innovation

\begin{tabular}{|c|c|c|c|}
\hline & \multirow{2}{*}{ Actor level } & \multicolumn{2}{|c|}{ System level } \\
\hline & & Diffusion system & Parallel systems \\
\hline Drivers & $\begin{array}{l}\text { - Heterogeneous } \\
\text { characteristics (e.g. industry } \\
\text { origin, size, organizational } \\
\text { form, access to resources, } \\
\text { networks such as family } \\
\text { and friends). } \\
\text { - Cognitive frameworks (i.e. } \\
\text { internal values and norms } \\
\text { related to the cognitive } \\
\text { identity or culture of } \\
\text { adopters). } \\
\text { - Different perceptions of } \\
\text { formal and informal } \\
\text { demands. } \\
\text { - Different motives (i.e. } \\
\text { economic instrumental, } \\
\text { non-economic instrumental, } \\
\text { environmental, and } \\
\text { symbolic motives). }\end{array}$ & $\begin{array}{l}\text { Formal and informal demands } \\
\text { (i.e. hard institutions, such as } \\
\text { RE policy instruments, and soft } \\
\text { institutions, such as norms and } \\
\text { values related to RE } \\
\text { technologies and to RE } \\
\text { adopters). }\end{array}$ & $\begin{array}{l}\text { Formal demands } \\
\text { emerging from the task } \\
\text { environment (e.g. } \\
\text { industry standards, } \\
\text { corporate strategies, } \\
\text { specifically targeted } \\
\text { regulations). } \\
\text { - Informal demands } \\
\text { emerging from the task } \\
\text { environment (industry } \\
\text { culture, norms, and } \\
\text { values). } \\
\text { Collective demands } \\
\text { emerging from } \\
\text { adopters' social } \\
\text { networks (e.g. norms, } \\
\text { values, and opinions). }\end{array}$ \\
\hline Challenges & $\begin{array}{l}\text { - Challenges linked to } \\
\text { adopter characteristics (e.g. } \\
\text { lack of or access to } \\
\text { resources). } \\
\text { - Different perceptions of } \\
\text { challenges (i.e. restraining } \\
\text { or blocking). }\end{array}$ & $\begin{array}{l}\text { - Challenges related to the further } \\
\text { development and adaption of } \\
\text { the innovation system } \\
\text { components (e.g. infrastructure, } \\
\text { interactions, RE policy } \\
\text { framework). } \\
\text { - Challenges related to the } \\
\text { development of the diffusion } \\
\text { system components (e.g. lack } \\
\text { of actor-specific institutional } \\
\text { frameworks, lack of adapted } \\
\text { support). }\end{array}$ & $\begin{array}{l}\text { - Challenges specific to } \\
\text { adopters' parallel } \\
\text { networks (e.g. lack of } \\
\text { legitimacy or legal } \\
\text { status of cooperative). }\end{array}$ \\
\hline $\begin{array}{l}\text { Strategies } \\
\text { and } \\
\text { policies }\end{array}$ & $\begin{array}{l}\text { - Use of networks } \\
\text { - Use of intermediaries } \\
\text { - Innovation solutions for the } \\
\text { individual adoption process. }\end{array}$ & $\begin{array}{l}\text { - Confirmed importance of some } \\
\text { RE policies (e.g. economic } \\
\text { incentives). }\end{array}$ & $\begin{array}{l}\text { - Strong } \\
\text { institutionalized } \\
\text { networks (e.g. federal } \\
\text { cooperative networks, } \\
\text { trade associations, } \\
\text { industry networks). } \\
\text { - Specific incentives or } \\
\text { regulatory instruments } \\
\text { targeted at actors of } \\
\text { parallel system. }\end{array}$ \\
\hline
\end{tabular}

Finally, strong networks in a parallel system may, through political leverage at the diffusion system level, lead to new regulations, which may facilitate the adoption process of an adopter. For instance, strong networks within the pulp and paper industry in Sweden have, thanks to important political leverage, influenced the design of the TGC system in a way that made investments in RE production very attractive for pulp and paper companies. As a result, most Swedish pulp and paper companies have pursued such investments. 


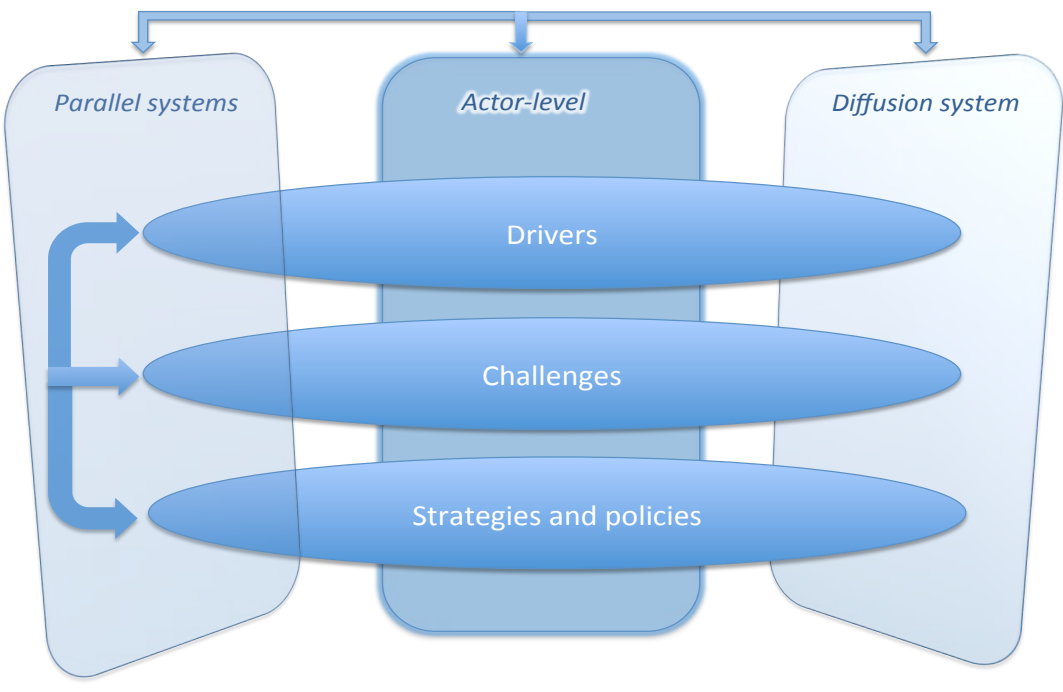

Figure 3. Dynamics of the large-scale diffusion process

When analyzing the large-scale diffusion process, it is important to understand that, among the dynamics of influences, levels, and systems, the central component is the adopter. Indeed, adopters link different systems and they are also, to a large extent, both determinant for the impact of drivers and challenges (i.e. through their perceptions) and determinant in developing strategies that lead the large-scale diffusion forward. This raises a number of implications with regard to policies and managerial strategies. 


\section{Conclusions and opportunities for further research}

\subsection{Conclusions}

The aim of this thesis was to explore the adoption dynamics shaping large-scale diffusion of innovation by taking an integrated actor- and system-level approach. More specifically, the thesis addressed three research questions: (1) what are the actor- and system-level drivers and challenges of adoption during the large-scale diffusion of innovation, (2) how do the actor- and system-level drivers and challenges affect adoption decisions and strategies during large-scale diffusion of innovation, and (3) how can large-scale diffusion of innovation be conceptualized, based on an improved understanding of the adoption dynamics shaping that process?

Through the development of an analytical framework gathering input from the diffusion of innovation literature, innovation systems literature, and energy policy literature, i.e. three theoretical strands that have previously tried to understand the process of innovation diffusion, the thesis highlighted that three main gaps needed to be addressed in order to completely understand the large-scale diffusion process: questionable assumptions about adopters and their behaviors, a lack of focus on the large-scale diffusion phase and its specificities, and a lack of integrated actor and system levels of analysis.

Through qualitative and quantitative methods, including interviews with 51 adopters in Sweden and France, five experts of RE cooperative projects in France, Germany, and Sweden, three project developers in Sweden, and a survey sent to the total population of RE technology adopters in Sweden, the thesis reached a number of results with implications for the understanding of the large-scale diffusion process of RE innovations.

With regard to the actor- and system-level drivers of adoption during large-scale diffusion, the thesis found that the previous assumptions about adopters' drivers and challenges were mostly incorrect. In particular, the results showed that adopters are heterogeneous with regard to their characteristics, as well as to the drivers, challenges, and strategies that affect their adoption processes.

Adopters come from different sectors or industries, are different sizes, and have different access to resources. Moreover, adopters perceive different system-level drivers and react differently to these institutional demands. Some are influenced to adopt by demands coming from their task environments, others by formal institutional demands, and others from informal demands, including collective demands from their social networks or cognitive demands from their cognitive frameworks. As a consequence, adopters also develop different motives for adopting. In addition to the economic instrumental motives assumed in the literature, adopters have non-economic 
instrumental motives, environmental motives and symbolic motives. Even the economic instrumental motives are more complex than earlier assumed, because some adopters are motivated by the opportunity to make money, while others are motived by the opportunity to save money or to exploit a resource that is available to them.

Adopters also differ with regard to the challenges that affect them. Some are particularly affected by both system-level challenges, such as policy instability or lack of financial or knowledge infrastructure, and actor-level challenges, such as lack of (and access to) resources. Unexpectedly, access to resources creates in some cases as many challenges as lack of resources. Finally, the results show that there are some specific types of adopters, such as RE cooperative organizations, and some specific institutional contexts, such as the adoption context for RE innovations in France, which are particularly affected by challenges.

With regard to how actor- and system-level drivers and challenges affect adoption decisions and strategies, the thesis found that the formal and informal pressures have either an inducing or imposing impact on the adoption decision; some adopters can perceive a institutional demand as an opportunity to adopt, while others may feel as if that demand was forcing them to adopt. Likewise, challenges affect the adoption process by either blocking or restraining it; some adopters may feel completely blocked by a challenge in their adoption process, while others may not perceive the same challenge at all, or they may manage to develop innovative solutions to pursue their adoption process.

Instead of the rational behavior assumed in the previous literature, the results show that adopters have different strategies for adopting innovation and implementing their adoption decisions. These strategies depend on adopters' motives and their perceptions of drivers and challenges. For instance, adopters with economic instrumental motives and who perceive economic policies as inducing seem to design the adoption in order to maximize the potential economic gain (or saving). Likewise, adopters with environmental or symbolic motives are likely to develop innovative solutions to challenges, even if these strategies prolong the implementation process and are very costly.

With regard to the implication of the improved understanding of adoption dynamics on the conceptualization of large-scale diffusion of innovation, the thesis found that there are some important distinctions to make between the phases of innovation development and early diffusion, and the phase of large-scale diffusion. While in the phases of early innovation systems growth, actors, networks, and institutions related to the technological innovation drive forward the innovation development and its early market diffusion, in the large-scale diffusion, the central drivers are the adopters of the innovation. Networks are also important drivers; but the important networks are the networks around adopters, not around the innovation. Likewise, the institutions driving 
this phase are aimed at facilitating the diffusion rather than the institutions encouraging the development of innovation.

New challenges also appear during the phase of large-scale diffusion. These challenges are primarily situated at the actor level of adoption. Among these challenges are lack of (and access to) resources and networks, as well as negative consequences of adopters' strategies. Rather than totally blocking the process, these challenges may be blocking but also restraining, in the sense that they can slow down the diffusion process but still be overcome by some adopters. Nevertheless, these challenges affect the large-scale diffusion because they may result in longer adoption processes and the inefficient use of resources.

Based on the findings on the drivers and challenges present at the stage of large-scale diffusion, the thesis raised the need to consider large-scale diffusion as part of a new system, different from the innovation system, that accounts for the specificities of this process. The thesis presented a tentative model accounting for the central role of adopters and for the interactions between adopters, parallel systems, and the diffusion system.

\subsection{Contributions and suggestions for further research}

The findings of this thesis contribute to the analytical understanding of adopters, and in particular, of adopters within RE production, as well as to the analytical understanding of large-scale diffusion of innovation, which lays a ground for further research.

The fact that adopters are heterogeneous in terms of characteristics, drivers, motives, perceptions, challenges, and strategies is largely new to the energy policy literature. This finding sheds a new light on the way to approach recommendations to policymakers about what policies may increase investments or adoption, as well as the way to conduct both qualitative and quantitative studies aimed at evaluating current policies. Indeed, the findings of the thesis show that when the large-scale diffusion of an innovation goes too slowly and needs to be speeded up, it is important to consider the complexity of the adopter group and to acknowledge its potential diversity, rather than assuming that the group is homogeneous and that all adopters behave in the same way. A way to consider adopters' heterogeneity is through the acquisition of detailed knowledge about the adopter group. For instance, a starting point may be to develop an understanding of the composition of the adopter group in terms of main industry, organizational form, or geographic area. Based on that information, policymakers may identify the potential pressures affecting the group, its different adoption motives, and its potential challenges. 
The findings of this thesis also contribute to the diffusion of innovation literature with regard to the understanding of the adopter group. Indeed, although this literature stream has previously emphasized that adopters have different characteristics, networks, and values depending on when they adopt, the dominant methods have not allowed any detailed understanding of these aspects. The qualitative and adoptercentered approach taken in this thesis provides new information about adopters, how they make their adoption decisions and why, how they react to external pressures, what challenges emerge during the adoption process that can lead to unsuccessful adoption, and what strategies they develop to go forward with adoption decisions. Such detailed information about adopters gives a much stronger foundation for future studies of diffusion, for instance, for marketing forecasts or for the development of corporate or industry strategies for speeding up the large-scale diffusion of innovation.

As shown in the theoretical framework of the thesis, previous literature on technological transition has paid particular attention to the dynamics of innovation development and early diffusion. This focus has resulted in a good understanding of the early diffusion process and provided an analytical basis for understanding the blocking and inducement mechanisms at this stage and adapting the policy design accordingly. Nevertheless, the findings of this thesis show that frameworks of innovation development and early diffusion cannot be used straight away on the largescale diffusion process. Indeed, actors, networks, and institutions are different at this stage, which results in new challenges, new influences, and, as a consequence, new inducement and blocking mechanisms. As a result, I propose that the early and later stages of diffusion should be approached as two different processes.

This thesis introduces a new model for the understanding of the large-scale diffusion process. As the main components of this model, drivers, motives, perceptions, challenges, strategies, and policies are considered because they clearly either induce or slow down large-scale diffusion. In the model, the adopter level is central and dynamics coming from the diffusion system and the parallel systems are also considered. This new model has the potential to be used for a better analytical understanding of large-scale diffusion and for the development of policies aimed as facilitating and speeding up large-scale diffusion. 


\section{Implications}

\subsection{Implications for policy design}

The results of this thesis have many implications for policy design. This section presents some of the policy implications in the appended papers and some new suggestions based on the synthesis of the overall findings.

\subsubsection{Implications of adopters' heterogeneity}

Paper 1 underlines that adopters own the majority of the current RE production capacity. Hence, they contribute to the transition both to cleaner technologies and to a sustainable energy system. These adopters are heterogeneous with regards to their main activity, organizational form, or size. It is therefore crucial that policies aimed at facilitating and speeding up the large-scale diffusion of innovations consider the heterogeneity of actors who currently adopt innovations as well as those who may be interested in adopting.

This heterogeneity is an opportunity for the sustainability of the large-scale diffusion process. Indeed, because adopters react to different drivers and have different adoption motives, the group of adopters as a whole is less dependent on one specific driver or another. For instance, even if a policy incentive triggering some of the adopters with economic instrumental motives disappears, many other adopters with other motives will remain. It is therefore important that policymakers ensure that there is a place for many adopters on the market. To reach that aim, policy frameworks need to protect the variety of actors. Such policies disappear easily, as illustrated in Paper 4 with the 2014 reform of the renewable energy act, which generalized tendering procedures that gave an advantage to incumbent actors to the detriment of cooperatives and other smaller actors.

Adopters' heterogeneity also means that policymakers should reconsider one-for-all policies. Instead of such standardized instruments, there is a need for policy segmentation targeting different types of adopters, for instance, based on their motives and on the origin of the pressure leading them to adopt. As Paper 6 describes, among adopters with economic instrumental motives, there are not only adopters looking for the opportunity to make money, but also adopters wanting to save costs by benefiting from lower taxes or reduced energy costs. Therefore, economic policies should not only take the form of subsidies or price premiums, but also the form of tax exemptions or regulations allowing net debit metering for RE prosumers. As a matter of fact, because economic instrumental motives drive only a portion of adopters, policymakers should also consider alternatives to economic incentive policies. For instance, although regulatory policies are often associated with a lack of proactiveness (e.g. Jaffe et al., 2002), creating problems is also a way to trigger adoption among adopters 
with symbolic motives. Likewise, because only some adopters react to formal institutional demands, policymakers may use alternative sources of pressures, for instance, pressures from adopters' networks, e.g. industry or social networks. Policymakers may do this, for instance, by encouraging specific industry standards or strategies, or by targeting specific communities (e.g. specific geographical regions) with information about the innovation and its implementation.

In addition to policies targeting the drivers of adoption, there is also a great potential for policies to facilitate the large-scale diffusion of innovation by minimizing challenges of adoption. Here again, different adopters face different challenges and therefore need different support. Therefore, it may be relevant for policymakers to prioritize the challenges to be targeted. Although policymakers should consider all challenges because they all slow down large-scale diffusion, one way to prioritize would be to target the challenges faced by the majority of adopters. In particular, the lack of knowledge, experience, and supporting networks often creates blocking or restraining challenges of adoption. This problem is not a surprise because, by definition, adopters are new at adopting, inexperienced at implementing the innovation, and rather unknown in the traditional system-level networks (e.g. in the technology supplier or user networks).

For the development of policies targeting adoption challenges, policymakers can take inspiration from adopters' own strategies. Papers 4 and 5 have shown that adopters handle challenges through a number of innovative solutions. Among these, they build coalitions with other adopters, for instance by forming RE cooperatives, which can benefit from other cooperative movements' networks and legitimacy. This approach has proven very efficient in both Germany and Sweden and policymakers may therefore recommend and encourage such an approach.

Another strategy numerous adopters use to hire intermediaries, such as consultants or project developers. These intermediaries are well established on the system level; they have contacts with suppliers and infrastructure actors and are very knowledgeable and experienced with implementing the technology. By hiring them, adopters get access to the networks and the expertise that they lack. Policies may therefore encourage the use of expert involvement during the implementation process, for instance through the creation of public intermediaries (as an alternative to private consultants) or, as has been done in the agricultural sector (e.g. Kilelu et al., 2014; Klerkx and Jansen, 2010), through the sponsoring of private intermediaries.

Overall, adopters' heterogeneity makes policy design very complicated, especially because what may facilitate for one adopter may instead represent a challenge for another adopter. It is therefore crucial for policymakers to develop a good understanding of the group that they target. This understanding can be cultivated by being open and democratic during the policy development process, e.g. by involving a 
variety of interest groups showing interest for the policy debate (instead of, for instance, involving only actors that have traditionally been present in the activity). Another way to gather such information is to collaborate with universities or research institutes, which may gather information about adopters to be used for policy design and suggest instruments for the analytical understanding of adopters of specific innovations.

\subsubsection{Implications of the new systems dynamics}

The fact that new systems dynamics appear when innovations have reached the phase of large-scale diffusion also has a number of policy implications. First, during largescale diffusion, there are new actors and networks to target. These adopters need specific support and incentives, which are different than those needed by technology developers or suppliers at the time of innovation development. Indeed, during innovation development and early diffusion, technology developers need support targeted at increasing the legitimacy of the technology or incentives to invest in innovation (e.g. Bergek et al., 2008c), but with regard to large-scale diffusion, adopters need incentives to buy the technology and support to get access to knowledge on how to choose the most adapted technology and to implement it.

Moreover, while at the time of innovation development and early diffusion, networks are active around the innovation (e.g. technology supporting networks, supplier networks, etc.), at the time of large-scale diffusion, new networks are focused around adopters, for instance within their task environments or their networks of family and friends. These new networks can create new drivers through collective pressure and can help adopters during the implementation process. Therefore, these networks represent new potential channels for policy signals and support, which may increase the number of innovations adopted. For example, trade associations may distribute material promoting investments in renewable electricity among farmers and information meetings may inform relevant communities about the development of wind power plants.

Adapted policies are also required to address the new challenges of large-scale diffusion, such as adopters' lack of knowledge, experience, political leverage, and legal status. In addition to the actor-level challenges, during the large-scale diffusion process, challenges coming from parallel systems must also be addressed. As a consequence, when policymakers design policies, they should consider not only the potential challenges related to the diffusion system but, if they want to attract or support specific adopters, also the potential challenges of parallel system. For instance, if policymakers see a potential for companies within the building industry to participate in the large-scale diffusion of RE innovations, they should understand the potential industry regulations restraining or blocking the participation of these actors, 
and, if needed, affect these regulations in order to make adoption possible. To facilitate the understanding of parallel systems' impact, there is a need for new tools of analysis, such as those developed for the analysis of technological innovation systems (e.g. Bergek et al., 2008b).

\subsection{Implications for managerial practice}

The thesis highlights some aspects that can serve as inspiration or lessons for managers planning to adopt a highly system-embedded innovation, and particularly for those planning to adopt a RE innovation.

\subsubsection{Implications of adopters' heterogeneity}

The studies conducted within the frame of this thesis highlighted a number of adoption processes and strategies. Of interest for managers is that many types of adopters, e.g. those with different characteristics, values, and motives, developed these processes and strategies. Therefore, this thesis should give managers a range of solutions or inspiration matching their specific contexts, e.g. their resources or their motives for adopting. For instance, managers interested in adopting in order to improve their images can be inspired by the profile of adopters with symbolic motives and the specific solutions that these adopters have found in order to enhance their adoption. Likewise, managers interested in adopting can learn that adopting is possible even if they lack the knowledge and experience to adopt. Such managers can follow some of the strategies described in the cases, such as getting support from intermediaries or from their social and business networks.

Different strategies have different advantages and drawbacks. Managers can thus consider the pros and cons of the different strategies and choose the one best matching their goals and expectations. Some strategies prolong the implementation process and are very costly. Also, some strategies lead to learning whereas others lead to dissatisfaction.

In particular, the results show that designing and implementing the adoption process alone is a problematic strategy, especially in contexts with many system challenges or if adopters themselves are exposed to challenges (e.g. due to their access of resources or their individual values or perceptions). As a consequence, adopters hesitating between several countries to invest should, for instance, consider that some countries are more subject to adoption challenges than others. Likewise, as Paper 3 illustrates, adopters should realize that doing everything alone during the adoption process might seem cheaper at first, but can become very costly at the end. Indeed, adopting an innovation often requires more than financial or intellectual resources; sometimes, access to specialized networks and legitimacy are needed. On the contrary, as Paper 5 illustrates, adopters tempted to delegate the whole adoption process should also 
understand that hiring an intermediary without any condition or without active involvement is not a perfect solution either, because it can lead to loss of control of the implementation, which may result in lack of satisfaction or an unsuccessful adoption. Instead, such strategy requires balanced power relations and a lot of involvement, in order to keep some control on the implementation (to ensure some satisfaction) and to learn something from the collaboration.

\subsubsection{Implications of the new systems dynamics}

The cases of adoption processes described in the studies have underlined a number of specificities related to the adoption of highly system-embedded innovations at the time of large-scale diffusion, which also have direct implications for managers. In particular, the results show that managers should be aware that there are a number of specific challenges to adopting a highly system-embedded innovation, such as a lack of infrastructure, market obstacles, or challenges related to soft and hard institutions. Moreover, there are different challenges whether the innovation is still in its early diffusion phase or whether it has reached the large-scale diffusion phase. Indeed, during the large-scale diffusion phase, adoption may be easier because at this point, the legitimacy of the innovation has had the time to increase, the price of the technology has reduced and become competitive in comparison to the incumbent technology, and specialized intermediaries are available to provide expertise during the implementation process.

Yet, some new challenges also appear at this stage. For instance, managers may themselves face specific challenges related to a lack of legitimacy, a lack of knowledge and experience, or a lack of institutional status. For these challenges, there are solutions to be found (or mistakes to avoid) on the level of adopters, as well as on the level of their task environments and on the system level. For instance, one strategy for managers may be to evaluate the concentration of challenges as well as the availability of potential supporting dynamics situated at different levels before adopting: Are there relevant resources, contacts, and institutions that can be used at the different levels? In that regard, the importance of the dynamics situated in parallel systems may be a great opportunity for managers, who may, for instance, decide to form coalitions with other managers within their industry networks. 


\section{References}

Abrahamson, E., 1991. Managerial Fads and Fashions: The Diffusion and Rejection of Innovations. The Academy of Management Review 16, 586-612.

Abrahamson, E., Fombrun, C., 1992. Forging the iron cage: interorganizational networks and the production of macro-culture. Journal of Management Studies 29, 175-194.

Acha, V., Davies, A., Hobday, M., Salter, A., 2004. Exploring the capital goods economy: complex product systems in the UK. Industrial and Corporate Change 13, 505-529.

Ackermann, T., Andersson, G., Söder, L., 2001. Overview of government and market driven programs for the promotion of renewable power generation. Renewable Energy 22, 197-204.

Agterbosch, S., Vermeulen, W., Glasbergen, P., 2004. Implementation of wind energy in the Netherlands: the importance of the social-institutional setting. Energy Policy 32, 2049-2066.

Aiman-Smith, L., Green, S.G., 2002. Implementing new manufacturing technology: The related effects of technology characteristics and user learning activities. Academy of management journal 45, 421-430.

Aldhaban, F., 2012. Exploring the adoption of Smartphone technology: Literature review. Presented at the Technology Management for Emerging Technologies (PICMET), 2012 Proceedings of PICMET'12:, IEEE, pp. 2758-2770.

Ambec, S., Cohen, M.A., Elgie, S., Lanoie, P., 2013. The Porter hypothesis at 20: can environmental regulation enhance innovation and competitiveness? Review of Environmental Economics and Policy 7, 2-22.

Andersson, B.A., Jacobsson, S., 2000. Monitoring and assessing technology choice: the case of solar cells. Energy Policy 28, 1037-1049.

Awerbuch, S., 2006. Portfolio-Based Electricity Generation Planning: Policy Implications For Renewables And Energy Security. Mitigation and Adaptation Strategies for Global Change 11, 693-710.

Awerbuch, S., 2003. Determining the real cost: Why renewable power is more costcompetitive than previously believed. Renewable Energy World 6.

Awerbuch, S., 2000. Investing in photovoltaics: risk, accounting and the value of new technology. Energy Policy 28, 1023-1035.

Barradale, M.J., 2010. Impact of public policy uncertainty on renewable energy investment: Wind power and the production tax credit. Energy Policy 38, 7698-7709.

Baruch, Y., Holtom, B.C., 2008. Survey response rate levels and trends in organizational research. Human Relations 61, 1139-1160.

Bass, F.M., 1969. A New Product Growth for Model Consumer Durables. Management Science 15, 215-227.

Batlle, C., Pérez-Arriaga, I.J., Zambrano-Barragán, P., 2012. Regulatory design for RES-E support mechanisms: Learning curves, market structure, and burden-sharing. Energy Policy 41, 212-220.

Beise, M., Rennings, K., 2005. Lead markets and regulation: a framework for analyzing the international diffusion of environmental innovations. Ecological economics 52, 5-17.

Bergek, A., Berggren, C., KITE Research Group, 2014. The impact of environmental policy instruments on innovation: A review of energy and automotive industry studies. Ecological Economics 106, 112-123.

Bergek, A., Hekkert, M., Jacobsson, S., 2008a. Functions in innovation systems: A framework for analysing energy system dynamics and identifying goals for systembuilding activities by entrepreneurs and policy makers, in: Foxon, T., Köhler, J., Oughton, C. (Eds.), Innovation for a Low Carbon Economy: Economic, Institutional 
and Management Approaches. Edward Elgar, Cheltenham.

Bergek, A., Hekkert, M., Jacobsson, S., Markard, J., Sandén, B., Truffer, B., 2015.

Technological innovation systems in contexts: Conceptualizing contextual structures and interaction dynamics. Environmental Innovation and Societal Transitions 16, 5164.

Bergek, A., Jacobsson, S., 2010. Are tradable green certificates a cost-efficient policy driving technical change or a rent-generating machine? Lessons from Sweden 2003-2008. Energy Policy 38, 1255-1271.

Bergek, A., Jacobsson, S., Carlsson, B., Lindmark, S., Rickne, A., 2008b. Analyzing the functional dynamics of technological innovation systems: A scheme of analysis. Research policy 37, 407-429.

Bergek, A., Jacobsson, S., Hekkert, M., Smith, K., 2010. Functionality of innovation systems as a rationale for and guide to innovation policy, in: Smits, R., Kuhlmann, S., Shapira, P. (Eds.), The Theory and Practice of Innovation Policy - An International Research Handbook, PRIME Series on Research and Innovation Policy in Europe. Edward Elgar Publishing, Cheltenham (UK) and Northampton, MA, p. 469.

Bergek, A., Jacobsson, S., Sandén, B.A., 2008c. "Legitimation" and "development of positive externalities": two key processes in the formation phase of technological innovation systems. Technology Analysis \& Strategic Management 20, 575-592.

Bergek, A., Mignon, I., 2016. Motives to adopt in renewable energy technologies: evidence from Sweden. Linköping University, Working paper, Linköping.

Bergek, A., Mignon, I., Sundberg, G., 2013. Who invests in renewable electricity production? Empirical evidence and suggestions for further research. Energy Policy 56, 568-581.

Berry, D., 2009. Innovation and the price of wind energy in the US. Energy Policy 37, 44934499.

Bhattacharya, A., Kojima, S., 2012. Power sector investment risk and renewable energy: A Japanese case study using portfolio risk optimization method. Energy Policy 40, 69 80.

Bloomberg New Energy Finance, 2015. Global Trends in Renewable Energy Investment 2015 (Global Trends Reports).

Boyd, R., Krutilla, K., Viscusi, W.K., 1995. Energy taxation as a policy instrument to reduce CO2 emissions: a net benefit analysis. Journal of Environmental Economics and Management 29, 1-24.

Brown, M.A., 2001. Market failures and barriers as a basis for clean energy policies. Energy policy 29, 1197-1207.

Brown, R.R., Farrelly, M.A., Loorbach, D.A., 2013. Actors working the institutions in sustainability transitions: The case of Melbourne's stormwater management. Global Environmental Change 23, 701-718.

Budde, B., Alkemade, F., Weber, K.M., 2012. Expectations as a key to understanding actor strategies in the field of fuel cell and hydrogen vehicles. Technological forecasting and social change 79, 1072-1083.

Burkhardt, M.E., Brass, D.J., 1990. Changing patterns or patterns of change: The effects of a change in technology on social network structure and power. Administrative science quarterly $35,104-127$.

Butler, L., Neuhoff, K., 2008. Comparison of feed-in tariff, quota and auction mechanisms to support wind power development. Renewable Energy 33, 1854-1867.

Caird, S., Roy, R., Herring, H., 2008. Improving the energy performance of UK households: Results from surveys of consumer adoption and use of low-and zero-carbon technologies. Energy Efficiency 1, 149-166.

Cansino, J.M., Pablo-Romero, M. del P., Román, R., Yñiguez, R., 2010. Tax incentives to 
promote green electricity: An overview of EU-27 countries. Energy Policy 38, 60006008.

Carlsson, B., Jacobsson, S., 1997. In search of useful public policies-key lessons and issues for policy makers, in: Technological Systems and Industrial Dynamics. Springer, pp. 299-315.

Carlsson, B., Stankiewicz, R., 1991. On the nature, function and composition of technological systems. J Evol Econ 1, 93-118.

Chesbrough, H.W., 2003. Open innovation: The new imperative for creating and profiting from technology. Harvard Business Press, Boston, MA.

Conley, T., Udry, C., 2001. Social learning through networks: The adoption of new agricultural technologies in Ghana. American Journal of Agricultural Economics 83, 668-673.

Creswell, J.W., 2013. Research design: Qualitative, quantitative, and mixed methods approaches, Thousand Oaks. ed. Sage publications, CA.

David, P.A., 1994. The reaper and the robot: the adoption of labor-saving machinery in the past and future, in: Essays in Honor of Sir John Habakkuk, Oxford University Press. Oxford.

David, P.A., 1991. Computer and dynamo: The modern productivity paradox in a not-too distant mirror, in: Technology and Productivity: The Challenge for Economic Policy, Organization for Economic Co-Operation and Development, Paris. Paris.

De Leeuw, E.D., Hox, J.J., Dillman, D.A., 2008. Cornerstones of survey tesearch, in: International Handbook of Survey Methodology. Taylor \& Francis, Hove, East Sussex.

del Río González, P., 2007. The interaction between emissions trading and renewable electricity support schemes. An overview of the literature. Mitigation and adaptation strategies for global change 12, 1363-1390.

Deutskens, E., de Jong, A., de Ruyter, K., Wetzels, M., 2006. Comparing the generalizability of online and mail surveys in cross-national service quality research. Marketing Letters 17, 119-136.

DiMaggio, P.J., Powell, W.W., 1983. The Iron Cage Revisited: Institutional Isomorphism and Collective Rationality in Organizational Fields. American Sociological Review 48, 147-160.

Dinica, V., 2011. Renewable electricity production costs - A framework to assist policymakers' decisions on price support. Energy Policy 39, 4153-4167.

Dinica, V., 2006. Support systems for the diffusion of renewable energy technologies - an investor perspective. Energy Policy 34, 461-480.

Dóci, G., Vasileiadou, E., Petersen, A.C., 2015. Exploring the transition potential of renewable energy communities. Futures 66, 85-95.

Eastin, M.S., 2002. Diffusion of e-commerce: an analysis of the adoption of four e-commerce activities. Telematics and informatics 19, 251-267.

Eisenhardt, K.M., 1989. Building theories from case study research. Academy of management review 14, 532-550.

Eisenhardt, K.M., Graebner, M.E., 2007. Theory building from cases: opportunities and challenges. Academy of management journal 50, 25-32.

Ellison, G., Fudenberg, D., 1993. Rules of thumb for social learning. Journal of political Economy 101, 612-643.

Enzensberger, N., Fichtner, W., Rentz, O., 2003. Evolution of local citizen participation schemes in the German wind market. International journal of global energy issues 20, 191-207.

Eugene Pereira, R., 2002. An adopter-centered approach to understanding adoption of 
innovations. European Journal of Innovation Management 5, 40-49.

European Commission, 2010. Energy 2020: A strategy for competitive, sustainable and secure energy, COM (2010).

European Parliament and Council, 2009. Directive 2009/28/EC of the European Parliament and of the Council of 23 April 2009 on the promotion of the use of energy from renwable sources and amending and subsequently repealing Directives 2001/77/EC and 2003/30/EC.

Faúndez, P., 2008. Renewable energy in a market-based economy: How to estimate its potential and choose the right incentives. Renewable Energy 33, 1768-1774.

Fleten, S.E., Maribu, K.M., Wangensteen, I., 2007. Optimal investment strategies in decentralized renewable power generation under uncertainty. Energy 32, 803-815.

Fouquet, D., 2013. Policy instruments for renewable energy-From a European perspective. Renewable Energy 49, 15-18.

Frambach, R.T., Schillewaert, N., 2002. Organizational innovation adoption: a multi-level framework of determinants and opportunities for future research. Journal of Business Research 55, 163-176.

Fullan, M.G., 1993. Why teachers must become change agents. Educational leadership 50, $12-12$.

Garcia, R., Calantone, R., 2002. A critical look at technological innovation typology and innovativeness terminology: a literature review. Journal of product innovation management 19, 110-132.

Gassmann, O., Daiber, M., Enkel, E., 2011. The role of intermediaries in cross-industry innovation processes. R\&D Management 41, 457-469.

Geels, F.W., 2002. Technological transitions as evolutionary reconfiguration processes: a multi-level perspective and a case-study. Research Policy 31, 1257-1274.

Greene, J.C., Caracelli, V.J., Graham, W.F., 1989. Toward a conceptual framework for mixed-method evaluation designs. Educational evaluation and policy analysis 11, 255-274.

Grübler, A., 1996. Time for a change: on the patterns of diffusion of innovation. Daedalus $125,19-42$.

Grübler, A., 1991. Diffusion: Long-term patterns and discontinuities. Technological Forecasting and Social Change 39, 159-180.

Hargadon, A.B., 1998. Firms As Knowledge Brokers: Lessons in pursuing continuous innovation. California Management Review 40, 209-227.

Hatch, J.A., 2002. Doing qualitative research in education settings. State University of New York Press, Albany, NY.

Havens, A.E., 1975. 'Diffusion of new seed varieties and its consequences: A Colombian case, in: Problems of Rural Development: Case Studies and Multidisciplinary Perspective. Brill, Leiden, pp. 94-111.

Hekkert, M.P., Suurs, R.A.A., Negro, S.O., Kuhlmann, S., Smits, R.E.H.M., 2007. Functions of innovation systems: A new approach for analysing technological change. Technological Forecasting and Social Change 74, 413-432.

Hellsmark, H., 2010. Unfolding the formative phase of gasified biomass in the European Union: The role of system builders in realising the potential of second-generation transportation fuels from biomass, PhD Dissertation. Chalmers University of Technology, Gothenburg.

Hobday, M., 1998. Product complexity, innovation and industrial organisation. Research policy $26,689-710$.

Howells, J., 2006. Intermediation and the role of intermediaries in innovation. Research Policy $35,715-728$. 
Hughes, T.P., 1987. The evolution of large technological systems, in: The Social Construction of Technological Systems: New Directions in the Sociology and History of Technology. Cambridge, Mass., pp. 51-82.

Hughes, T.P., 1982. Networks of power: electrification in Western society, 1880-1930. JHU Press, Baltimore.

International Renewable Energy Agency, 2014. REthinking Energy: Towards a new power system.

Jacobsson, S., Bergek, A., 2011. Innovation system analyses and sustainability transitions: Contributions and suggestions for research. Environmental Innovation and Societal Transitions 1, 41-57.

Jacobsson, S., Bergek, A., 2004. Transforming the energy sector: the evolution of technological systems in renewable energy technology. Industrial and corporate change 13, 815-849.

Jacobsson, S., Bergek, A., Finon, D., Lauber, V., Mitchell, C., Toke, D., Verbruggen, A., 2009. EU renewable energy support policy: Faith or facts? Energy Policy 37, $2143-$ 2146.

Jacobsson, S., Johnson, A., 2000. The diffusion of renewable energy technology: an analytical framework and key issues for research. Energy Policy 28, 625-640.

Jacobsson, S., Karltorp, K., 2013. Mechanisms blocking the dynamics of the European offshore wind energy innovation system-Challenges for policy intervention. Energy Policy 63, 1182-1195.

Jacobsson, S., Karltorp, K., 2012. Formation of competences to realize the potential of offshore wind power in the European Union. Energy Policy 44, 374-384.

Jaffe, Newell, R., Stavins, R., 2002. Environmental Policy and Technological Change. Environ Resource Econ 22, 41-70.

Jaffe, Stavins, R.N., 1995. Dynamic incentives of environmental regulations: The effects of alternative policy instruments on technology diffusion. Journal of environmental economics and management 29, 43-63.

Johnson, A., Jacobsson, S., 2001. Inducement and Blocking Mechanisms in the Development of a New Industry: The Case of Renewable Energy Technology in Sweden, in: Coombs, R., Green, K., Walsh, V., Richards, A. (Eds.), Technology and the Market: Demand, Users and Innovation, Edward Elgar, Cheltenham.

Kahn, E., 1996. The production tax credit for wind turbine powerplants is an ineffective incentive. Energy Policy 24, 427-435.

Kangas, H.-L., Lintunen, J., Pohjola, J., Hetemäki, L., Uusivuori, J., 2011. Investments into forest biorefineries under different price and policy structures. Energy Economics 33, $1165-1176$.

Kaplowitz, M.D., Hadlock, T.D., Levine, R., 2004. A comparison of web and mail survey response rates. Public opinion quarterly $68,94-101$.

Karltorp, K., 2014. Scaling up renewable energy technologies -The role of resource mobilisation in the growth of technological innovation systems. Ph.D. Dissertation. Chalmers University of Technology, Gothenburg

Katz, M.L., Shapiro, C., 1986. Technology adoption in the presence of network externalities. The journal of political economy 94, 822-841.

Kennedy, A.M., 1983. The adoption and diffusion of new industrial products: a literature review. European Journal of Marketing 17, 31-88.

Kilelu, C.W., Klerkx, L., Leeuwis, C., 2014. How dynamics of learning are linked to innovation support services: insights from a smallholder commercialization project in Kenya. The Journal of Agricultural Education and Extension 20, 213-232.

Klein, K.J., Knight, A.P., 2005. Innovation Implementation: Overcoming the Challenge. 
Current Directions in Psychological Science 14, 243-246.

Klein, K.J., Sorra, J.S., 1996. The Challenge of Innovation Implementation. The Academy of Management Review 21, 1055-1080.

Klein Woolthuis, R., Lankhuizen, M., Gilsing, V., 2005. A system failure framework for innovation policy design. Technovation $25,609-619$.

Klerkx, L., Jansen, J., 2010. Building knowledge systems for sustainable agriculture: supporting private advisors to adequately address sustainable farm management in regular service contacts. International Journal of Agricultural Sustainability 8, 148 163.

Kline, S.J., Rosenberg, N., 1986. An overview of innovation, in: Landau, R., Rosenberg, N. (Eds.), The Positive Sum Strategy. Washington DC, pp. 275-305.

Kluge, S., 2000. Empirically grounded construction of types and typologies in qualitative social research. Presented at the Forum Qualitative Sozialforschung/Forum: Qualitative Social Research.

Knowler, D., Bradshaw, B., 2007. Farmers' adoption of conservation agriculture: A review and synthesis of recent research. Food policy 32, 25-48.

Kwak, N., Radler, B., 2002. A comparison between mail and web surveys: Response pattern, respondent profile, and data quality. Journal of Official Statistics 18, 257-274.

Langley, A., Truax, J., 1994. A process study of new technology adoption in smaller manufacturing firms. Journal of Management Studies 31, 619-652.

Langniss, O., 1996. Instruments to foster renewable energy investments in Europe a survey under the financial point of view. Renewable Energy 9, 1112-1115.

Langniss, O., Wiser, R., 2003. The renewables portfolio standard in Texas: an early assessment. Energy Policy 31, 527-535.

Lee, E.-J., Kwon, K.-N., Schumann, D.W., 2005. Segmenting the non-adopter category in the diffusion of internet banking. International Journal of Bank Marketing 23, 414- 437.

Leeuwis, C., Aarts, N., 2011. Rethinking communication in innovation processes: creating space for change in complex systems. Journal of Agricultural Education and Extension $17,21-36$.

Lesnick, P.C., 2000. Technology transfer in the Dominican Republic: a case study of the diffusion of photovoltaics, Ph.D. Dissertation. Union Institute, Cincinnati, OH.

Linton, J.D., 2002. Implementation research: state of the art and future directions. Technovation 22, 65-79.

Lyytinen, K., Damsgaard, J., 2001. What's wrong with the diffusion of innovation theory?, in: Ardis, M.A., Marcolin, B.L. (Eds.), Diffusing Software Product and Process Innovations. Kluwer Academic Press, Boston, pp. 1-20.

MacVaugh, J., Schiavone, F., 2010. Limits to the diffusion of innovation: A literature review and integrative model. European Journal of Innovation Management 13, 197-221.

Malerba, F., 2002. Sectoral systems of innovation and production. Research policy 31, 247264.

Marcati, A., Guido, G., Peluso, A.M., 2008. The role of SME entrepreneurs' innovativeness and personality in the adoption of innovations. Research Policy 37, 1579-1590.

Masini, A., Frankl, P., 2003. Forecasting the diffusion of photovoltaic systems in southern Europe: A learning curve approach. Technological Forecasting and Social Change 70, $39-65$.

Masini, A., Menichetti, E., 2013. Investment decisions in the renewable energy sector: An analysis of non-financial drivers. Technological Forecasting and Social Change 80, 510-524.

Masini, A., Menichetti, E., 2012. The impact of behavioural factors in the renewable energy investment decision making process: Conceptual framework and empirical findings. 
Energy Policy 40, 28-38.

Meade, N., Islam, T., 2006. Modelling and forecasting the diffusion of innovation - A 25year review. International Journal of Forecasting 22, 519-545.

Menanteau, P., Finon, D., Lamy, M.-L., 2003. Prices versus quantities: choosing policies for promoting the development of renewable energy. Energy Policy 31, 799-812.

Meyer, N.I., 2007. Learning from wind energy policy in the EU: lessons from Denmark, Sweden and Spain. European Environment 17, 347-362.

Mignon, I., Bergek, A., 2016. System- and actor-level challenges for the diffusion of renewable electricity technologies: an international comparison. Journal of Cleaner Production 128, 105-115.

Mignon, I., Rüdinger, A., 2016. The impact of systemic factors on the deployment of cooperative projects within renewable electricity production - An international comparison. Renewable and Sustainable Energy Reviews 65, 478-488.

Morris, C., Pehnt, M., 2015. Energy transition - The German Energiewende. Heinrich Böll Stiftung, Berlin.

Muñoz, J.I., Sánchez de la Nieta, A.A., Contreras, J., Bernal-Agustín, J.L., 2009. Optimal investment portfolio in renewable energy: The Spanish case. Energy Policy 37, 5273 5284.

Munshi, K., 2004. Social learning in a heterogeneous population: technology diffusion in the Indian Green Revolution. Journal of development Economics 73, 185-213.

Musiolik, J., Markard, J., Hekkert, M., 2012. Networks and network resources in technological innovation systems: Towards a conceptual framework for system building. Technological Forecasting and Social Change 79, 1032-1048.

Negro, S.O., Alkemade, F., Hekkert, M.P., 2012. Why does renewable energy diffuse so slowly? A review of innovation system problems. Renewable and Sustainable Energy Reviews 16, 3836-3846.

Nelson, R.R., Nelson, K., 2002. Technology, institutions, and innovation systems. Research Policy 31, 265-272.

Nordhaus, W.D., 2007. To Tax or Not to Tax: Alternative Approaches to Slowing Global Warming. Review of Environmental Economics and Policy 1, 26-44.

Nord, W.R., Tucker, S., 1987. Implementing routine and radical innovations. Lexington Books, Lexington, MA.

Palm, J., Tengvard, M., 2011. Motives for and barriers to household adoption of small-scale production of electricity: examples from Sweden. Sustainability: Science, Practice, \& Policy 7, 6-15.

Pettersson, F., Söderholm, P., 2009. The diffusion of renewable electricity in the presence of climate policy and technology learning: The case of Sweden. Renewable and Sustainable Energy Reviews 13, 2031-2040.

Poize, N., Rüdinger, A., 2014. Projets citoyens pour la production d'énergie renouvelable : une comparaison France Allemagne, Working Papers. IDDRI, Paris, France.

Rao, K.U., Kishore, V.V.N., 2010. A review of technology diffusion models with special reference to renewable energy technologies. Renewable and Sustainable Energy Reviews 14, 1070-1078.

Rode, J., 2014. Renewable Energy Adoption in Germany-Drivers, Barriers and Implications, PhD Dissertation. Darmstadt University of Technology, Darmstadt.

Rogers, E.M., 2003. Diffusion of Innovations, 5th edition. ed. The Free Press, New York. Rogers, E.M., 1962. Diffusion of Innovations, 1st edition. ed. The Free Press, New York.

Scherer, C.W., Cho, H., 2003. A social network contagion theory of risk perception. Risk analysis $23,261-267$.

Schiavone, F., MacVaugh, J., 2009. A user-based perspective on limits to the adoption of new 
technology. International Journal of Technoentrepreneurship 2, 99-114.

Seligman, L., 2006. Sensemaking throughout adoption and the innovation-decision process. European Journal of Innovation Management 9, 108-120.

Selwyn, N., 2003. Apart from technology: understanding people's non-use of information and communication technologies in everyday life. Technology in society $25,99-116$.

Siggelkow, N., 2007. Persuasion with case studies. Academy of Management Journal 50, 20 24.

Smith, A., 2000. Policy networks and advocacy coalitions: explaining policy change and stability in UK industrial pollution policy? Environment and Planning C 18, 95-114.

Smith, K., 2000. Innovation as a systemic phenomenon: rethinking the role of policy. Enterprise and innovation management studies 1, 73-102.

Söderholm, P., Ek, K., Pettersson, M., 2007. Wind power development in Sweden: Global policies and local obstacles. Renewable and Sustainable Energy Reviews 11, 365-400.

Söderholm, P., Klaassen, G., 2007. Wind Power in Europe: A Simultaneous InnovationDiffusion Model. Environmental and Resource Economics 36, 163-190.

Stake, R., 2006. Multiple Case Study Analysis. The Guilford Press, New York.

Teo, H.-H., Wei, K.K., Benbasat, I., 2003. Predicting intention to adopt interorganizational linkages: An institutional perspective. MIS quarterly 19-49.

Tingling, P., Parent, M., 2002. Mimetic Isomorphism and Technology Evaluation: Does Imitation Transcend Judgment? Journal of the Association for Information Systems 3, $113-143$.

Tornatzky, L.G., Klein, K.J., 1982. Innovation Characteristics and Innovation AdoptionImplementation: A Meta-Analysis of Findings. IEEE Transactions on Engineering Management 29, 28-43.

United Nations Framework Convention on Climate Change, 2009. Report of the Conference of Parties on its fifteenth session, held in Copenhagen from 7 to 19 December 2009.

Utterback, J.M., Abernathy, W.J., 1975. A dynamic model of process and product innovation. Omega 3, 639-656.

Valente, T.W., Davis, R.L., 1999. Accelerating the diffusion of innovations using opinion leaders. The Annals of the American Academy of Political and Social Science 566, $55-67$.

van Lente, H., 1993. Promising technology: the dynamics of expectations in technological developments, Ph.D. Dissertation. Universiteit Twente, Enschede.

Voss, C.A., 1985. The need for a field of study of implementation of innovations. Journal of Product Innovation Management 2, 266-271.

Weick, K.E., 2007. The generative properties of richness. Academy of Management Journal $50,14-19$.

Wejnert, B., 2002. Integrating models of diffusion of innovations: A conceptual framework. Annual review of sociology 28, 297-326.

Wierenga, B., Ophuis, P.A.O., 1997. Marketing decision support systems: Adoption, use, and satisfaction. International journal of research in marketing 14, 275-290.

Woiceshyn, J., Daellenbach, U., 2005. Integrative capability and technology adoption: evidence from oil firms. Industrial and Corporate Change 14, 307-342.

Wüstenhagen, R., Menichetti, E., 2012. Strategic choices for renewable energy investment: Conceptual framework and opportunities for further research. Energy Policy 40, 1-10.

Yildiz, Ö., 2014. Financing renewable energy infrastructures via financial citizen participation-The case of Germany. Renewable Energy 68, 677-685.

Yin, R.K., 1981. The case study crisis: Some answers. Administrative science quarterly 26, $58-65$.

Zimmerman, M.A., Zeitz, G.J., 2002. Beyound survival: Achieving new venture growth by 
building legitimacy. Academy of Management Review 27, 414-431. 



\section{Appended Papers}

The articles associated with this thesis have been removed for copyright reasons. For more details about these see:

http://urn.kb.se/resolve?urn=urn:nbn:se:liu:diva-131029 